\title{
Long-term care after stroke : development and evaluation of a long-term intervention in primary care
}

Citation for published version (APA):

Quint-Fens, M. H. (2014). Long-term care after stroke : development and evaluation of a long-term intervention in primary care. [Doctoral Thesis, Maastricht University]. Maastricht University. https://doi.org/10.26481/dis.20140416mq

Document status and date:

Published: 01/01/2014

DOI:

10.26481/dis.20140416mq

Document Version:

Publisher's PDF, also known as Version of record

\section{Please check the document version of this publication:}

- A submitted manuscript is the version of the article upon submission and before peer-review. There can be important differences between the submitted version and the official published version of record.

People interested in the research are advised to contact the author for the final version of the publication, or visit the DOI to the publisher's website.

- The final author version and the galley proof are versions of the publication after peer review.

- The final published version features the final layout of the paper including the volume, issue and page numbers.

Link to publication

\footnotetext{
General rights rights.

- You may freely distribute the URL identifying the publication in the public portal. please follow below link for the End User Agreement:

www.umlib.nl/taverne-license

Take down policy

If you believe that this document breaches copyright please contact us at:

repository@maastrichtuniversity.nl

providing details and we will investigate your claim.
}

Copyright and moral rights for the publications made accessible in the public portal are retained by the authors and/or other copyright owners and it is a condition of accessing publications that users recognise and abide by the legal requirements associated with these

- Users may download and print one copy of any publication from the public portal for the purpose of private study or research.

- You may not further distribute the material or use it for any profit-making activity or commercial gain

If the publication is distributed under the terms of Article $25 \mathrm{fa}$ of the Dutch Copyright Act, indicated by the "Taverne" license above, 


\section{Long-term care after stroke}

\section{Development and evaluation of a long-term intervention in primary care}


The research presented in this thesis was conducted at the Maastricht University Medical Centre+ (MUMC+), Department of Patient and Care, in collaboration with the School of Public Health and Primary Care (CAPHRI) and the School for Mental Health and Neuroscience (MHeNS).

CAPHRI participates in the Netherlands School of Primary Care Research CaRe, which has been acknowledged since 1995 by the Royal Netherlands Academy of Arts and Sciences (KNAW).

MHeNS participates in the European Graduate School of Neuroscience EURON which has recently been re-accredited by the Royal Netherlands Academy of Arts and Sciences (KNAW).

Both schools were classified as "excellent" by external evaluation committees in recent years.

The research was funded by Foundation Elisabeth Strouven, Annadal Foundation Maastricht, health insurance companies CZ and VGZ.

Financial support for the publication of this thesis was kindly provided by MUMC+

(C) Manon Quint-Fens, Maastricht 2014

ISBN: 9789081795876

Picture cover: Karin Fens-van Stigt

Printing and cover design: Grafische Dienstverlening F.B. MUMC+ 


\title{
Long-term care after stroke
}

\section{Development and evaluation of a long-term intervention in primary care}

\author{
Proefschrift \\ ter verkrijging van de graad van doctor aan de Universiteit Maastricht \\ op gezag van de Rector Magnificus, Prof. dr. L.L.G. Soete, \\ volgens het besluit van het College van Decanen, \\ in het openbaar te verdedigen \\ op woensdag 16 april 2014 om 16.00 uur. \\ door \\ Maria Hendrika Quint-Fens
}


Promotores

Prof. dr. J.F.M. Metsemakers

Prof. dr. C.M. van Heugten

Prof. dr. M. Limburg (Flevoziekenhuis, Almere)

Copromotor

Dr. G.H.M.I. Beusmans

Beoordelingscommissie

Prof. dr. R.J. van Oostenbrugge (voorzitter)

Prof. Dr. Th. van Achterberg (Katholieke Universiteit, Leuven)

Dr. K.T. Konings

Prof. dr. G.M. Ribbers (Rijndam revalidatiecentrum en Erasmus MC, Rotterdam)

Prof. dr. J.M.G.M. Schols 




\section{Contents}

Chapter 1 General introduction 7

Chapter 2 Multidisciplinary care for stroke patients living in the community; a systematic review

Chapter 3 Development and preliminary testing of an Assessment tool for long-term Consequences After Stroke (ACAS), a developmental and feasibility study

Chapter 4 Effect of a stroke-specific follow-up care model on the quality of life of stroke patients and caregivers; a controlled trial

Chapter 5 A process evaluation of a stroke-specific follow-up care model for stroke patients and caregivers; a longitudinal study

Chapter $6 \quad$ Not as transient: patients with transient ischaemic attack or minor stroke experience cognitive and communication problems; an exploratory study

Chapter 7 General discussion

Chapter 8 Summary

Chapter 9 Samenvatting

Chapter 10 Dankwoord

Chapter 11 Curriculum Vitae

Chapter 12 List of publications and presentations 



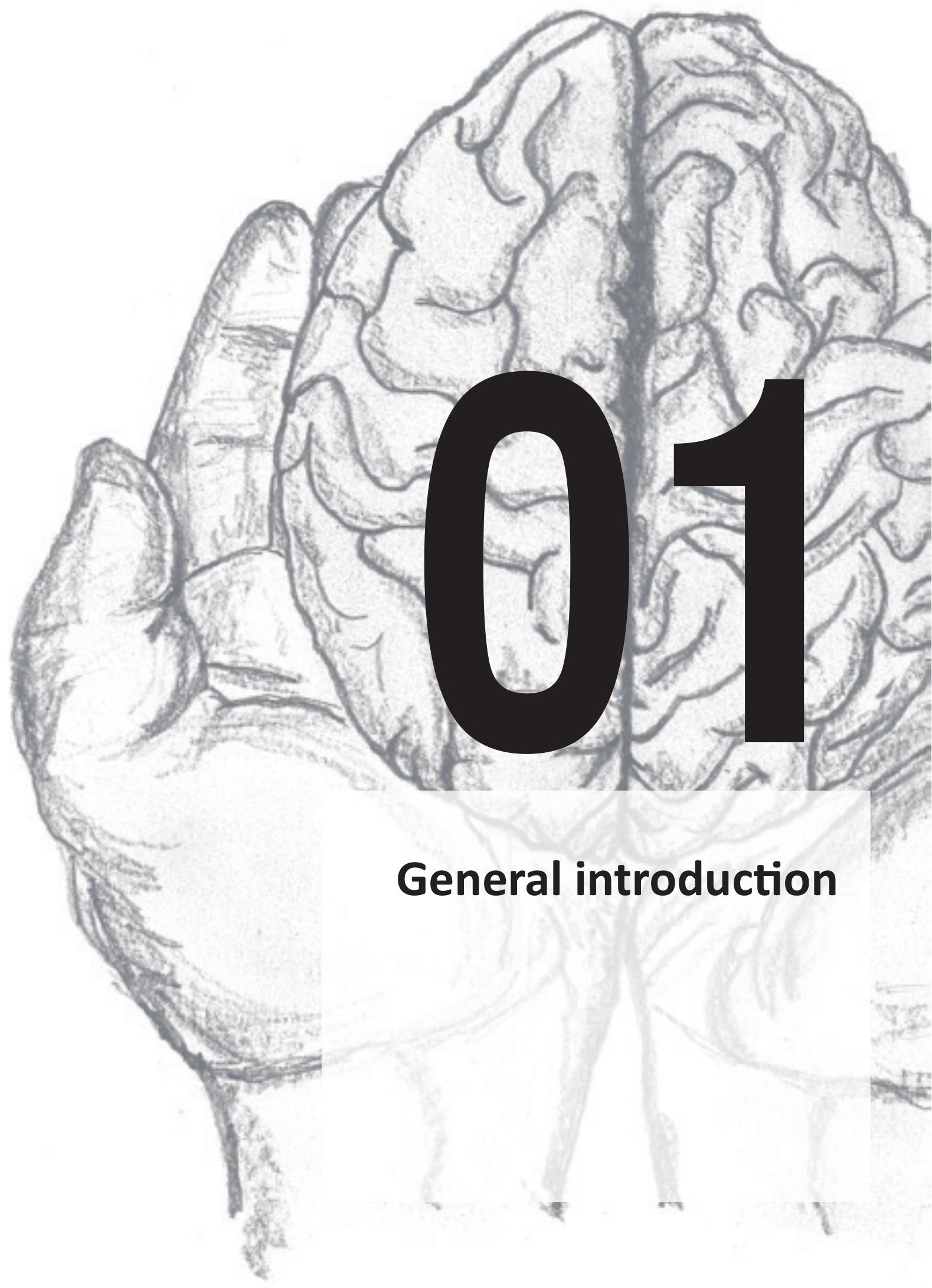


8 | Chapter 1: General Introduction 


\section{The long-term consequences after stroke}

Each year about 40.000 people suffer from their first stroke in the Netherlands. ${ }^{1}$ Most people have a stroke above the age of 65 years, but also younger people are at risk of having a stroke. Stroke survivors often experience somatic and mental consequences, as well as physical and psychological problems. The lives of their caregivers are also affected by the consequences of the stroke, because they often take partial or full responsibility for the care of the stroke patient once discharged home.

Stroke patients can experience physical limitations, such as paralysis, loss of muscle strength or being physically fatigued..$^{2,3,4,5}$ These physical limitations can improve during the first six months after the event. A large group of patients however do not fully recover and have persistent limitations. ${ }^{2,6}$ Moreover, new problems can emerge several months after the event, such as psychological and cognitive problems when patients and caregivers try to return to the life as before the stroke. Many researchers have evaluated the psychological problems of stroke patients and they showed that many stroke patients become depressed shortly after the event. ${ }^{7,8,9}$ Research has also indicated that $45 \%$ of the stroke patients have depressive feelings after 9 months ${ }^{10}$, which continues to persist even up to three years after the stroke. ${ }^{11}$ Another major long-term problem of stroke patients is cognitive limitations, which are present in half of the stroke patients one year after the event. ${ }^{10,12}$ The most common problems are difficulties with memory, a limited capacity to mentally process information and a diminished attention $\operatorname{span}^{10,12,13}$, which remain stable after 2 years. ${ }^{14}$ In some cases, the cognitive problems can progress to vascular dementia. ${ }^{14}$ One out of five patients is limited in communication after one year as a result of the stroke, such as recognizing and expressing affection. ${ }^{15}$ The most common communicative limitation is aphasia. ${ }^{16}$ The psychological, cognitive and communication problems can also alter the social life of stroke patients. ${ }^{17}$ Stroke patients are limited to be socially active and social relationships can be affected after one year. ${ }^{7}$ Research has indicated that one out of three patients feels socially isolated after 18 months. ${ }^{18}$ All these life changes can have an emotional impact on 
both stroke patients and their caregivers. ${ }^{10}$ They have to learn to accept their limitations and learn how to deal with them in daily life.

Caregivers of stroke patients are also confronted with the consequences of the event. In addition, the lives of caregivers are affected because of the limitations and problems of the stroke patients. First of all, the event can be a traumatic experience for the caregivers, accompanied by the fear of losing their partner or relative. Research has shown that $55 \%$ of caregivers feel emotional distress after six months ${ }^{19}$, $33 \%$ after two to five years. ${ }^{20,21}$ Furthermore, many caregivers feel responsible to take partial of full care for the patient, which can cause strain. Half of the caregivers experience strain after one year, which decreases during the following years. ${ }^{22}$ The provision of care can also limit the level of social activities of caregivers after two years. ${ }^{23,24}$ Moreover, the burden of providing care to stroke patients can cause psychological problems, such as feelings of depression for $51 \%$ of the caregivers after three $_{\text {years. }}^{8,22}$ Characteristics of caregivers and the psychical and cognitive limitations of the stroke patients have an influence on the level of caregivers' strain. $^{24}$

\section{What is the problem?}

As shown above, stroke patients and their caregivers experience many negative consequences due to the stroke. Most recovery after stroke occurs in the first six months ${ }^{25}$ and follow-up care is usually organized during this period, but new and different problems can emerge after six months. A study of Hare and colleagues has shown that many patients still have a need for care after five years, because strokerelated problems were still present on the long-term. ${ }^{26}$ Often no suitable care is available $^{27,28}$ and patients no longer have regular contact with stroke care professionals, not even with their own general practitioner. ${ }^{29}$ Due to the persistent limitations of the event, stroke should, however, be considered as a chronic disease that requires long-term care for stroke patients and their caregivers. ${ }^{28,30}$ In this thesis we will regard structured care for less than six months as follow-up care and structured care for longer than six months as long-term care. Long-term care can be 
very complex, because many functions can be affected and many different health care professionals can be involved. Therefore it is important that the broad spectrum of stoke-related problems are structurally assessed to offer the best options for referral and further long-term care. Adequate assessment tools are however lacking. ${ }^{27,31,32,33}$ In addition, due to the persistent long-term problems after stroke it is also desirable that all patients receive long-term care, which is often not the case. This was the state of art of the care for stroke patients in the Netherlands anno 2007. Several of these gaps were also present in the region of Maastricht: the care for stroke patients was most intensive in the first six months; there was no structured assessment procedure; and no structured care after six months. In addition, after that period there was limited contact between the general practitioners, other health care professionals and stroke patients. Furthermore, patients who were sent home after a visit to the emergency room, patients who were not admitted to the stroke unit of the hospital and stroke patients who were discharged home after hospitalization received no structured long-term care. The care for stroke patients in the region Maastricht thus needed improvements. During the last few years, there have been many innovations in stroke care in the hospital and rehabilitation units, but the way the long-term care should be organized for patients living in the community did not receive much attention. Therefore, there was still a great need to improve the way long-term care should be organized for stroke patients and their caregivers.

\section{The organization of follow-up and long-term care for stroke patients in the}

\section{Netherlands}

In 2009 , we have performed an inventory search about the way in which the followup and long-term care was organized in different regions in the Netherlands. ${ }^{34}$ Based on the gathered information, it became clear that, on the one hand, the care in these regions contains the following care elements; nurses specialized in stroke, home visits and outpatient clinics. On the other hand, the way the care was organized also 
differed greatly in terms of type of care, type of health care professional, frequency and duration of care.

There are several regions in the Netherlands which offer the follow-up and long-term care by means of an outpatient clinic. For instance, stroke patients in the region of Midden-Brabant and Nijmegen are invited for a consult at the outpatient clinic of the hospital six to eight weeks after being discharged home. A nurse specialized in stroke assesses problems with which patients are confronted being at home after the stroke. After the visit of the patient to the outpatient clinic the nurse consults a multidisciplinary team to discuss what kind of care is adequate for the stroke patient. In Amsterdam, an experimental regional center of expertise (Beroerte Advies Centrum, BAC) was developed for stroke patients who need help after one year. The nurses specialized in stroke of the BAC offer information, advice and support to stroke patients, caregivers and health care professionals. Patients can contact or visit the BAC and ask questions or ask for information about stroke. In addition, when patients have more severe problems, the nurse visits patients and caregivers at home or invites them for a consult at the BAC. Based on the home visit or the consult, patients can be referred to health care professionals for more care.

Another example of long-term care that is offered to stroke patients is a telephone helpdesk at the outpatient clinic (Almere) for information and advice even years after the event. The specialized stroke nurse, however, indicated that there are only a few stroke patients who make use of this type of care.

In some regions, there are different health care organisations that provide the follow-up and long-term care to stroke patients. In the regions of Rotterdam and Dordrecht, for instance, the hospital, the nursing home, the rehabilitation centre and home care services agree that the health care organisation, which provides the care before the patient is being discharged home, also organises the follow-up and longterm care for that patient.

These different ways in which long-term care are organised pose several considerations: 
- Is long-term care offered in a clinical setting the optimal setting to make the proper assessment of the stroke-related problems in the home situation of the stroke patient?

- Is a structured assessment procedure required concerning the stroke-related problems?

- Is the provision of long-term care by means of providing a telephone number for information and advice the best option for stroke patients, because stroke patients can have communicational problems or show a lack of initiative to contact the health care professional? Therefore, is a face to face contact between stroke patients and stroke specialized nurses a better way to have regular checkups of stroke-related problems and might it be more accessible for stroke patients?

- The coordination of long-term care by different health care organisations poses the risk that some patients receive care from two or more health care organisations. It seems therefore preferable that the long-term care is organised by a central coordinator who is specialized in stroke, assesses stroke-related problems, coordinates the long-term care and works together with a multidisciplinary team. Is a central coordinator the most suitable person to provide and organise the long-term care?

\section{Follow-up and long-term care in the region of Maastricht}

The way the follow-up and long-term care was organized in the region Maastricht was implemented in $2006 .{ }^{35}$ About half of the patients who were admitted to the stroke unit of the hospital, were being discharged home directly after hospitalization. These patients received a check-up at the outpatient clinic of the hospital, six to eight weeks after being discharged home. The outpatient clinic was coordinated by a nurse practitioner, who was specialized in stroke. During the visit to the outpatient clinic, the nurse practitioner checked the medical condition and possible problems experienced by the stroke patient. As needed, the patient was referred to a specialist, such as a neurologist, cardiologist or neuropsychologist. Stroke patients, 
who received a visit of the rehabilitation physician during hospitalization, received the check-up by the rehabilitation physician at the outpatient clinic of the rehabilitation unit of the hospital.

Patients, who were not being discharged home from hospitalization, were transferred to the nursing home which provided a special program to stroke patients in the stroke service of Maastricht. ${ }^{35}$ Each patient transferred received a three-day assessment to determine the care for the patient. There were four possible routes:

- patients were being discharged home after the assessment;

- patients with a slow rate of recovery received inpatient rehabilitation in the nursing home, after which they were discharged home;

- patients who had a fast rate of recovery, were referred to inpatient rehabilitation in the rehabilitation clinic. Patients being discharged home after rehabilitation received a check-up at the outpatient clinic of the rehabilitation clinic. These patients were offered a session three to six months after discharge for information and advice and to discuss their stroke-related problems with other stroke patients. The rehabilitation clinic also focused on the social integration and interaction for stroke patients.

- patients were permanently admitted to the nursing home;

Patients who were discharged home from the hospital or nursing home were transferred to home care services for long-term care provided by a stroke care coordinator. This stroke care coordinator offered a maximum of four home visits during the first year to the stroke patients. The first home visit was planned within two weeks after discharge home, followed by a second home visit four weeks after the first visit. Although patients could receive four home visits of the stroke care coordinator, most patients received less visits and care for only six months. As needed, the stroke care coordinator referred patients to specific health care professionals and specialists for subsequent care. 


\section{Optimizing the long-term care in the region of Maastricht}

The long-term care provided in the region Maastricht needed several improvements as mentioned above. Considering the long-term care provided in other regions and our considerations with these care models, we have developed a long-term care model which was organized within the capacities of the health care services in this region, containing several important elements:

(1) All stroke patients in the region of Maastricht have to be referred to a stroke care coordinator (SCC) of the home care services for long-term care after being discharged home from the hospital or inpatient rehabilitation. (2) Each patient receives five home visits by the SCC, who is specialized in stroke and coordinates the long-term care. (3) The first home visit is planned within 1-2 weeks after being discharged home. Subsequently, the SCC visits stroke patients at home after 3, 6, 12 and 18 months. (4) During each home visits the SCC uses a structured assessment tool that is developed in this study to assess a broad spectrum of stroke related problems. Based on a full assessment, suitable long-term care can be initiated, such as supportive listening, providing information or referring patients to other health care professionals. (5) Therefore the SCC can consult a multidisciplinary team for advice as needed.

The aim of this long-term care model is to improve and optimize long-term care for stroke patients and their caregivers who are being discharged home after hospitalization or inpatient rehabilitation. An important element of this long-term care model is the development of a structured assessment procedure as a help and guidance for health care professionals assess stroke-related problems and health care needs and to provide long-term care.

\section{Aim and research questions:}

The aim of the research in this thesis was to evaluate the new long-term care model in terms of effectiveness and process. The main research questions were:

- What are effective long-term care interventions for stroke patients living at home after hospitalization and inpatient rehabilitation? 
- To what extent is the structured assessment tool feasible for use in health care?

- To what extent does the long-term care model improve the quality of life of stroke patients and their caregivers?

- To what extent is the intervention performed according to protocol and what are the results of the structured assessment procedure in terms of problems identified and initiated subsequent long-term care?

- What is the opinion of patients, their caregivers and the SCCs about the long-term care they received or provided after being discharged home after hospitalization of inpatient rehabilitation?

- To what extent do patients with a TIA or minor stroke experience persistent stroke-related problems after being discharged home from the TIA outpatient clinic or emergency room?

\section{Outline of this thesis}

In chapter 2, we review the effectiveness of different multidisciplinary interventions for stroke patients living in the community in an international review to identify important elements of long-term care for stroke patients. The development of an assessment tool and the validity and feasibility of this assessment tool are reported in Chapter 3. Chapter 4 describes a non-randomized controlled trial, evaluating the long-term care model in terms of effectiveness on the quality of life of stroke patients and their caregivers, in which the region of Maastricht is compared to a control region (Eindhoven). To gain insight into process-related factors that can affect the effectiveness of the long-term care model, a process evaluation is performed and illustrated in chapter 5. In addition, we investigated whether the long-term care for stroke patients should be provided for other stroke-related populations. Therefore we have used the assessment tool in a small population of patients with a transient ischemic attack (TIA) or minor stroke to evaluate whether these patients have persistent problems after the event (chapter 6). In chapter 7, we discuss the methods and the findings of the different studies that were performed. 
Moreover, implications and recommendations for clinical health care and future research are highlighted. 


\section{References}

1. Jager-Geurts MH, Peters RJG, van Dis SJ, Bots ML. Hart- en vaatziekten in nederland 2006, cijfers over ziekte en sterfte. Den Haag: Nederlandse Hartstichting; 2006.

2. Cramer SC. Changes in motor system function and recovery after stroke. Restor Neurol Neurosci. 2004;22:231-238.

3. Hesse S. Recovery of gait and other motor functions after stroke: Novel physical and pharmacological treatment strategies. Restor Neurol Neurosci. 2004;22:359369.

4. Jager-Geurts MH, Bots ML. Epidemiologie van beroerte. In: Franke CL, M.Limburg, eds. Handboek cerebrovasculaire aandoeningen. Utrecht: De Tijdstroom; 2006:13-22.

5. van Bennekom CAM, van Heugten $\mathrm{CM}$. Revalidatie na een beroerte 1: Langetermijngevolgen. In: Franke $\mathrm{CL}$, Limburg $\mathrm{M}$, eds. Handboek cerebrovasculaire aandoeningen. Utrecht: De Tijdstroom; 2006:317-330.

6. Patel MD, Tilling K, Lawrence E, Rudd AG, Wolfe CD, McKevitt C. Relationships between long-term stroke disability, handicap and health-related quality of life. Age Ageing. 2006;35:273-279.

7. Kwok, T., Lo, R. S., Wong, E., Wai-Kwong, T., Mok, V., \& Kai-Sing, W. Quality of life of stroke survivors: a 1-year follow-up study. Arch Phys Med Rehabil. 2006;87(9), 1177-1182, quiz 1287.

8. Kotila, M., Numminen, H., Waltimo, O., \& Kaste, M. Depression after stroke: results of the FINNSTROKE Study. Stroke. 1998; 29(2), 368-372.

9. Lightbody CE, Baldwin R, Connolly M, Gibbon B, Jawaid N, Leathley M, et al. Can nurses help identify patients with depression following stroke? A pilot study using two methods of detection. J Adv Nurs. 2007;57(5):505-512.

10. Hochstenbach, J., Prigatano, G., \& Mulder, T. Patients' and relatives' reports of disturbances 9 months after stroke: subjective changes in physical functioning, cognition, emotion, and behavior. Arch Phys Med Rehabil. 2005;86(8), 15871593.

11. Morrison V, Pollard B, Johnston M, MacWalter R. Anxiety and depression 3 years following stroke: Demographic, clinical, and psychological predictors. J Psychosom Res. 2005;59:209-213.

12. Rasquin SM, Lodder J, Ponds RW, Winkens I, Jolles J, Verhey FR. Cognitive functioning after stroke: A one-year follow-up study. Dement Geriatr Cogn Disord. 2004;18:138-144

13. Reitz C, Luchsinger JA, Tang MX, Manly J, Mayeux R. Stroke and memory performance in elderly persons without dementia. Arch Neurol. 2006;63:571-576.

14. Rasquin, S. M., Verhey, F. R., Lousberg, R., \& Lodder, J. Cognitive performance after first ever stroke related to progression of vascular brain damage: a 2 year follow up CT scan study. J Neurol Neurosurg Psychiatry. 2005;76(8), 1075-1079.

15. Borgaro, S. R., Prigatano, G. P., Kwasnica, C., Alcott, S., \& Cutter, N. Disturbances in affective communication following brain injury. Brain Inj. 2004;18(1), 33-39. 
16. Salter, K., Jutai, J., Foley, N., Hellings, C., \& Teasell, R. Identification of aphasia post stroke: a review of screening assessment tools. Brain Inj. 2006;20(6), 559568.

17. Murray, J., Young, J., Forster, A., \& Ashworth, R. Developing a primary care-based stroke model: the prevalence of longer-term problems experienced by patients and carers. Br J Gen Pract. 2003;53(495), 803-807.

18. Greveson GC, Gray CS, French JM, James OF. Long-term outcome for patients and carers following hospital admission for stroke. Age Ageing. 1991;20(5):337-344.

19. Dennis M, O'Rourke S, Lewis S, Sharpe M, Warlow C. A quantitative study of the emotional outcome of people caring for stroke survivors. Stroke. 1998;29:18671872.

20. Wade DT, Legh-Smith J, Hewer RL. Effects of living with and looking after survivors of a stroke. Br Med J (Clin Res Ed). 1986;293:418-420.

21. Wilkinson PR, Wolfe CD, Warburton FG, Rudd AG, Howard RS, Ross-Russell RW, Beech RR. A long-term follow-up of stroke patients. Stroke. 1997;28(3):507-512.

22. Visser-Meily A, Post M, van de Port I, van Heugten C, van den Bos T. Psychosocial functioning of spouses in the chronic phase after stroke: improvement or deterioration between 1 and 3 years after stroke? Patient Educ Couns. 2008;73(1):153-158.

23. Grafstrom M, Fratiglioni L, Sandman PO, Winblad B. Health and social consequences for relatives of demented and non-demented elderly. A population-based study. J Clin Epidemiol. 1992;45:861-870.

24. Bond MJ, Clark MS, Davies S. The quality of life of spouse dementia caregivers: Changes associated with yielding to formal care and widowhood. Soc Sci Med. 2003;57(12):2385-2395.

25. Tilling K, Sterne JA, Rudd AG, Glass TA, Wityk RJ, Wolfe CD. A new method for predicting recovery after stroke. Stroke. 2001;32:2867-2873.

26. Hare R, Rogers $H$, Lester $H$, McManus $R$, Mant J. What do stroke patients and their carers want from community services? Fam Pract. 2006;23(1):131-6.

27. Murray J, Young J, Forster A, Herbert G, Ashworth R. Feasibility study of a primary care-based model for stroke aftercare. Br J Gen Pract. 2006;56(531):775-780.

28. Visser-Meily JM, van den Bos GA, Kappelle LJ. Better acute treatment induces more investments in chronic care for stroke patients. Int J Stroke. 2009;4:352353.

29. Brotheridge, S., Young, J., Dowswell, G., Lawler, J. \& Forster, A. A preliminary investigation of patient and carer expectations of their general practitioner in longer-term stroke care. Journal of Evaluation in Clinical Practice. 1998;4(3), 237 241.

30. van den Bos GA, Triemstra AH. Quality of life as an instrument for need assessment and outcome assessment of health care in chronic patients. Qual Health Care. 1999;8:247-252.

31. Reynolds T, Thornicroft G, Abas M, Woods B, Hoe J, Leese M, et al. Camberwell Assessment of Need for the Elderly (CANE). Development, validity and reliability. Br J Psychiatry. 2000;176:444-452. 
32. Edwards DF, Hahn MG, Baum CM, Perlmutter MS, Sheedy C, Dromerick AW. Screening patients with stroke for rehabilitation needs: validation of the poststroke rehabilitation guidelines. Neurorehabil Neural Repair. 2006;20(1):42-48.

33. van Heugten C, Rasquin S, Winkens I, Beusmans G, Verhey F. Checklist for cognitive and emotional consequences following stroke (CLCE-24): development, usability and quality of the self-report version. Clin Neurol Neurosurg. 2007;109(3):257-262.

34. Workgroup Care in the Chronic Phase. [Uitbehandeld! Hoezo? Een leidraad in het doolhof aan zorg in de chronische fase na een CVA]. Maastricht, Knowledgenetwork Stroke Netherlands; 2011.

35. Heijnen R, Limburg M, Evers S, Beusmans G, van der Weijden T, Schols J. Towards a better integrated stroke care: the development of integrated stroke care in the southern part of the Netherlands during the last 15 years (Special 10th Anniversary Edition paper). International Journal of Integrated Care. 2012;12:e123. 


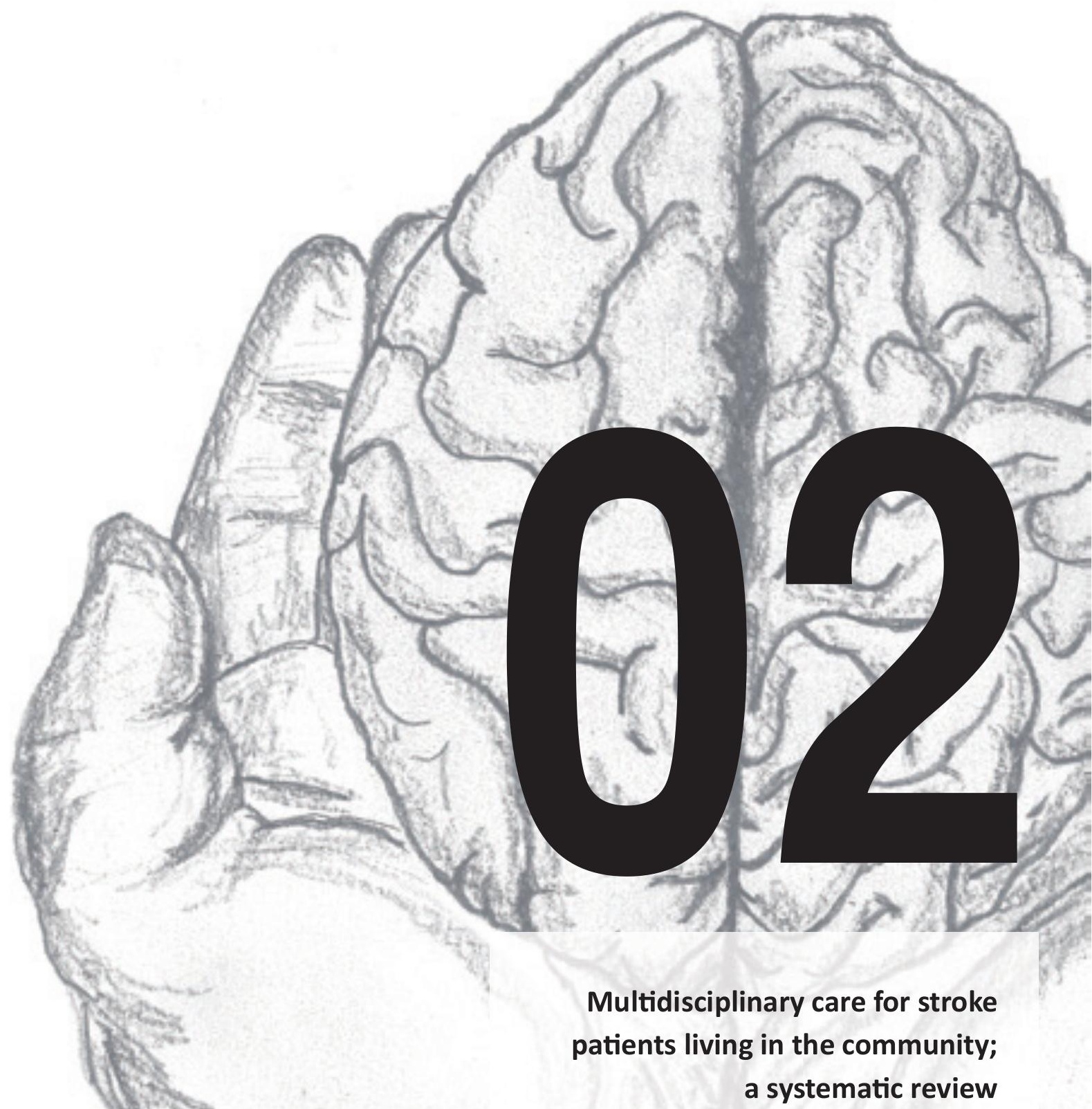

Fens, M., Vluggen, T., van Haastregt, J.C., Verbunt, J.A., Beusmans, G.H. \& van Heugten, C.M. (2013). Journal of Rehabilitation Medicine, 45(4), 321-330.

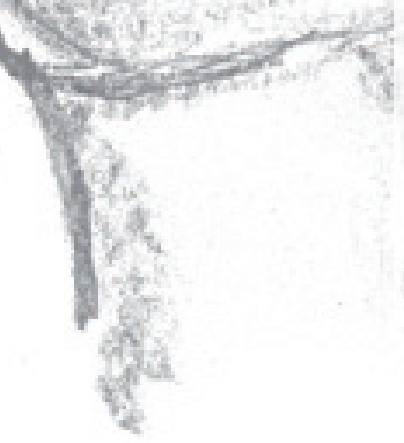




\begin{abstract}
Objective: A systematic review of randomized controlled trials was performed to evaluate the effectiveness of multidisciplinary care for stroke patients living in the community. Data sources: We used the databases Pubmed, Embase, Cinahl and Cochrane from January 1980 until July 2012. Study selection: Randomized controlled trials focused on multidisciplinary interventions for stroke patients living at home after hospitalization or inpatient rehabilitation were selected. The outcome domains were activities of daily living, social participation and quality of life. A total of 14 studies were included. Data extraction: Two authors independently extracted the data and independently assessed the quality of reporting of the included studies using the Consolidated Standards of Reporting Trials (CONSORT) statement 2010. Data synthesis: None of the studies showed a favorable effects of the intervention on activities of daily life and none assessed social participation. Furthermore, two studies reported favorable effects of the intervention in terms of quality of life. These concerned an intervention combining assessment with follow-up care and a rehabilitation intervention. Conclusions: There is little evidence for the effectiveness of multidisciplinary care for stroke patients being discharged home. Additional research should provide more insight into potentially effective multidisciplinary care for community-living stroke patients.
\end{abstract}

Keywords: review, stroke, ambulatory care, long-term care, quality of life, randomized controlled trial 


\section{Introduction}

Stroke is one of the major causes of mortality, loss of independence, and decreased quality of life. ${ }^{1,2}$ Care for stroke patients is concentrated largely in the acute and clinical phase, probably because most recovery occurs within this first period. ${ }^{3}$ However, there is a considerable group of patients with persistent disabilities, even many years after stroke. ${ }^{4-6}$ These disabilities can be physical limitations, such as paralysis or fatigue $e^{7-9}$, but also psychological and cognitive problems, such as depression and memory deficits. ${ }^{10-12}$ Many stroke survivors return to their former living environment, where they can be confronted with various difficulties in managing their daily activities and resuming their former social roles. ${ }^{13,} 14$ Patients have to learn how to deal with these difficulties for the rest of their lives and also learn how to socially reintegrate in the community. Although there seems to be a clear need for long-term care after being discharged home, adequate care is often lacking in this period. ${ }^{15}$

Previous research has indicated that organized inpatient care (stroke unit) is the health care model of choice within a hospital. ${ }^{16}$ However, nowadays there is still a lack of insight into how other components of stroke care should be provided. ${ }^{17}$ In particular, it is unclear how care should be organized after discharge from hospital or inpatient rehabilitation. ${ }^{18-22}$ In the last 10 years there have been several reviews of the effects of stroke care after discharge to the home situation, but these are dated $^{18,21}$, included cross-sectional studies and (non)-randomized trials ${ }^{20}$, focused on a single discipline ${ }^{22}$ or focused on more than a year post stroke. ${ }^{19} \mathrm{~A}$ recent review by Hillier and Inglis-Jassiem ${ }^{23}$, examined the effectiveness of stroke rehabilitation delivered at home or in an outpatient clinic for community-dwelling patients. This review showed that outpatient rehabilitation is more effective when it is provided in the patient's home. This study however concerned a specific comparison (i.e. home based versus clinic based care) and therefore there is still a need for additional insight into the effectiveness of other care programs for stroke patients after discharge. 
The present review aims to assess the effectiveness of different forms of multidisciplinary care delivered to stroke patients living in the community after discharge from hospital or inpatient rehabilitation. We reviewed the effectiveness of the interventions in terms of activities of daily living, social participation and quality of life, which we consider to be highly relevant outcome measures for stroke patients living in the community after discharge home.

Appendix 2.1: Search terms

\begin{tabular}{ll}
\hline Category & Search terms \\
\hline Stroke & stroke, cerebral infarction, cerebrovascular accident, brain \\
& infarction, cerebrovascular diseases \\
Type of intervention & follow-up care / follow-up service, ambulatory care / ambulatory \\
& care nursing, outpatient service, aftercare, long-term care, home \\
& care services / home care / home health care, community-based \\
& rehabilitation / community services / community care, home \\
& health care / community health care, home rehabilitation \\
Outcome & quality of life, activities of daily living / daily life activities / ADL, \\
Setting & social participation \\
& after discharge, living in the community / community living / \\
& community dwelling, patient discharge, hospital discharge, \\
& community residing / home residing \\
\hline
\end{tabular}

\section{Methods}

A systematic literature review was performed using the following databases: Pubmed, Embase, Cinahl and the Cochrane library from January 1980 until July 2012. The search strategy, developed to identify the appropriate studies, comprised four categories: diagnosis; type of intervention; outcome; and setting (see Appendix 2.1). The following inclusion criteria were used for the identified studies: randomized controlled trial; patients with a diagnosis of stroke; 18 years or older; community living after hospitalization or inpatient rehabilitation; multidisciplinary intervention; and outcome measures in the domains of activities of daily living, social participation and/or quality of life. We considered care to be multidisciplinary when care was provided by two or more different care professionals, working together as, or 
supported by, a team. Studies were excluded if the language was not English, Dutch or German. Furthermore, studies were excluded if the primary aim of the intervention was to reduce length of stay in hospital (i.e. early supported discharge). Studies were independently selected by two reviewers (MF and TV) based on title and abstract and the selected articles were subsequently reviewed based on full text. Additional articles were tracked by hand search from the references of selected articles. In case of disagreement during the selection process, a third author (CvH) made the final decision. After the final selection, the two reviewers (MF and TV) extracted data independently and assessed the quality of reporting of the studies, using the CONSORT statement $2010 .{ }^{24}$ The quality of the studies was indicated by the percentage of items of the CONSORT statement reported in the articles. Given the considerable heterogeneity of the interventions we decided not to statistically pool the data of the studies.

\section{Results}

Figure 2.1 shows the results of the selection process. Out of 1498 articles that were screened based on title and abstract, the two reviewers agreed on 1425 articles and 73 articles were presented to the third reviewer. A total of 95 articles and five additional articles found by hand search of references were read in full. The two reviewers reached consensus on 89 articles, nine articles were presented to the third reviewer and two articles were untraceable. Fourteen articles were selected for the review25-38 and 84 articles did not meet the inclusion criteria; no RCT (N=54), no stroke patients or community living patients $(\mathrm{N}=12)$, no multidisciplinary intervention $(\mathrm{N}=14)$, other outcome domains $(\mathrm{N}=3)$ and no English, Dutch or German $(\mathrm{N}=1)$. The selected 14 articles were published in English. Table 2.1 presents the characteristics of the included studies and table 2.2 presents the characteristic of the interventions assessed in these studies. 
Figure 2.1 Selection process of the systematic review. From: Moher D, Liberati A, Tetzlaff J, Altman DG, The PRISMA Group (2009). Preferred Reporting Items for Systematic Reviews and Meta-Analyses: The PRISMA Statement. PLoS Med 6(6): e1000097. doi:10.1371/ journal.pmed1000097. Fore more information, visit www.prisma-statement.org
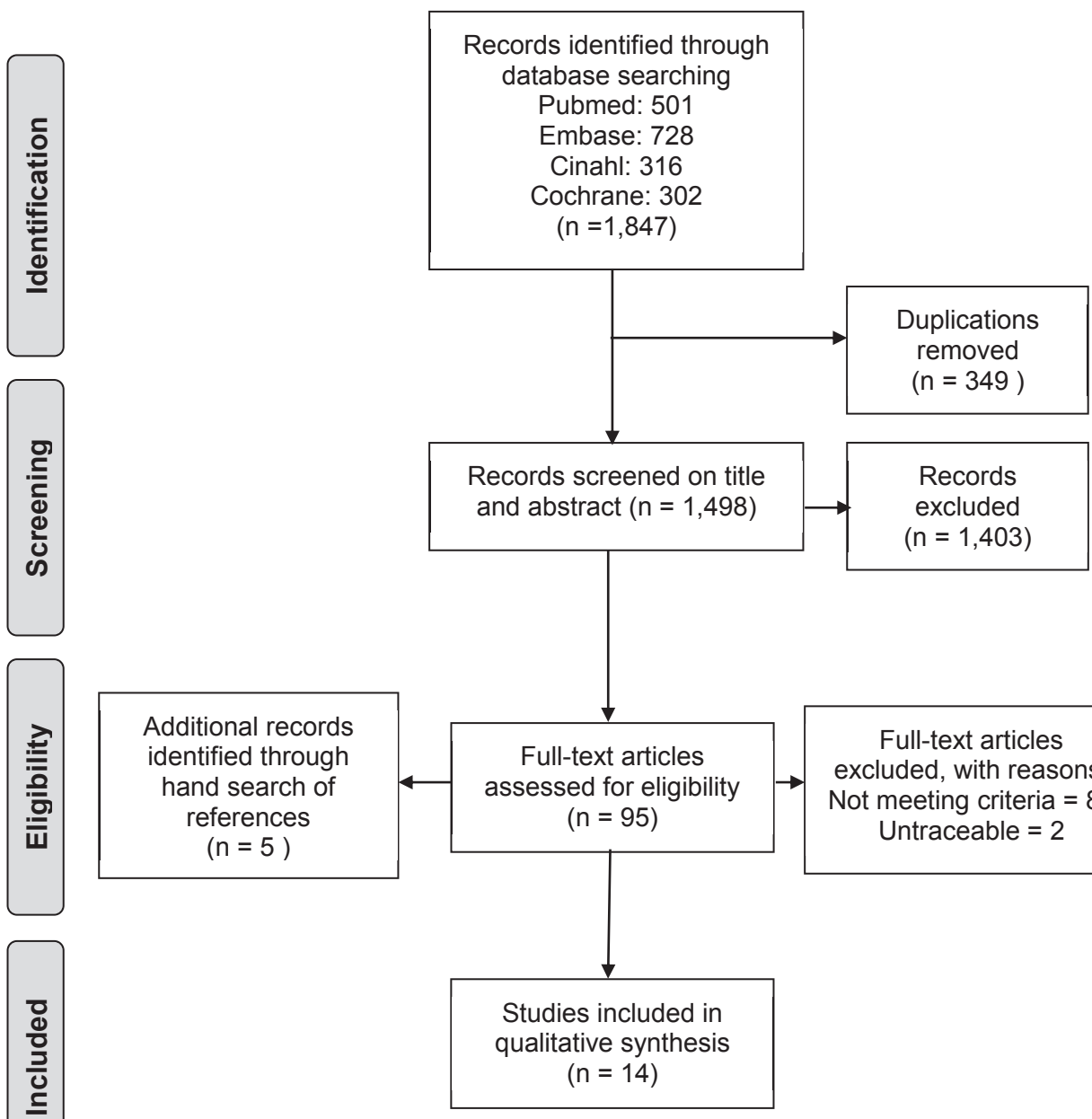

Full-text articles excluded, with reasons: Not meeting criteria $=84$ Untraceable $=2$

Studies included in $(n=14)$ 


\section{Study design}

Table 2.1 shows that 13 studies compared an intervention with usual care and one study compared intensive with non-intensive home-based rehabilitation. ${ }^{37}$ The content of the interventions will be discussed in more detail below. The definition of usual care differed considerably between studies, such as outpatient rehabilitation at a day clinic, inpatient case management, care from a general practitioner, home care services with non-professional support or a service information pack. In 12 studies patients were included immediately after discharge home from hospital, in one trial patients were included $\geq 18$ months post stroke ${ }^{33}$ and in another trial patients were included after discharge from a rehabilitation center. ${ }^{35}$ The period between stroke occurrence and discharge was described by only three out of 14 studies $^{29,35,37}$, varying from an average of 45 days $^{37}$ to 2.5 years. $^{33}$

\section{Patient characteristics}

The number of stroke patients in the intervention groups varied from $30^{27}$ to $190 .^{26}$ The mean age of patients was under 70 years in three studies ${ }^{26,27,35}$ and over 70 years in 11 studies. In general, men and women were equally represented in each of the studies; however in 1 study there were considerably more men (75\%) in the study group. ${ }^{27}$ 


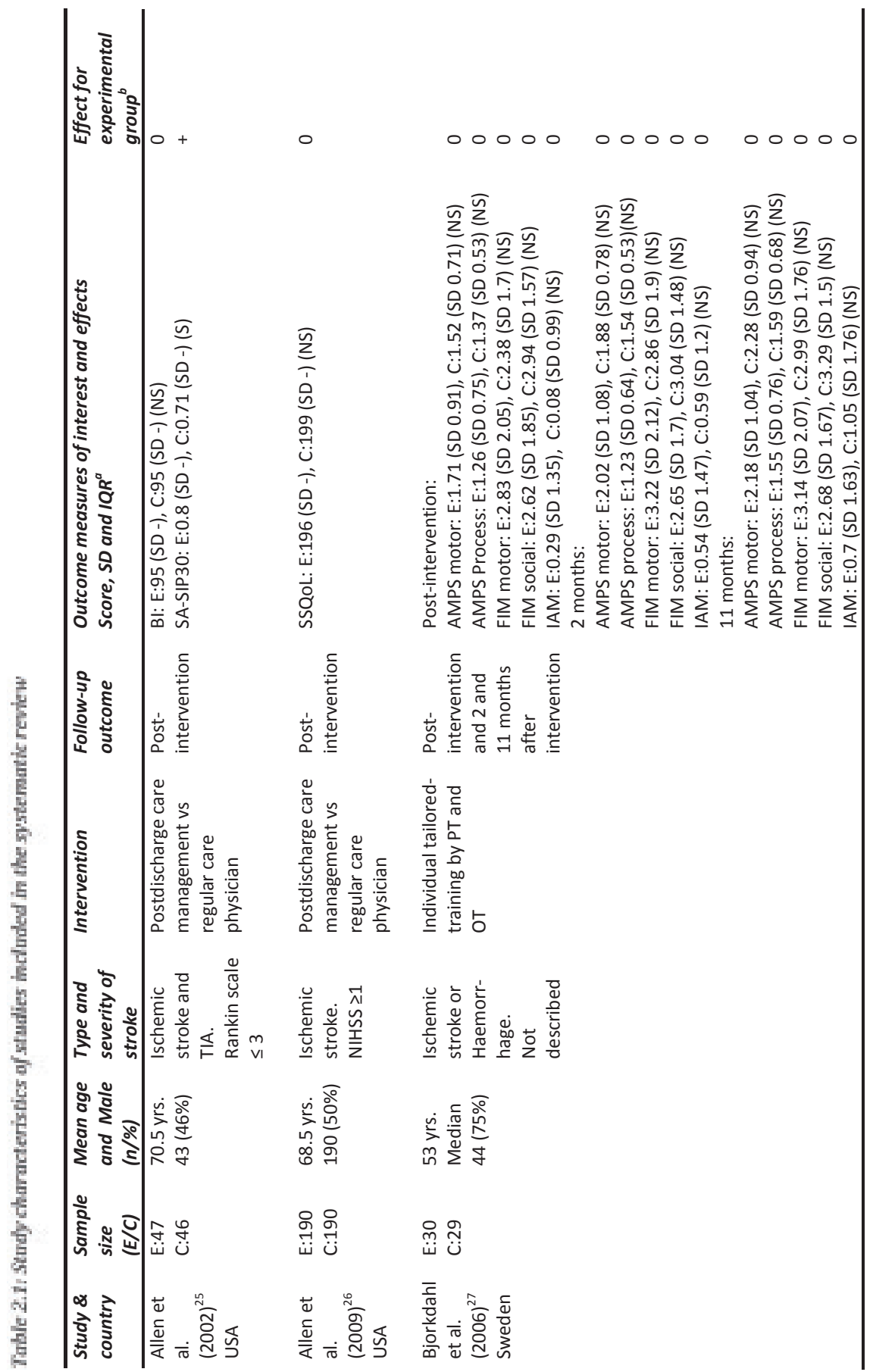




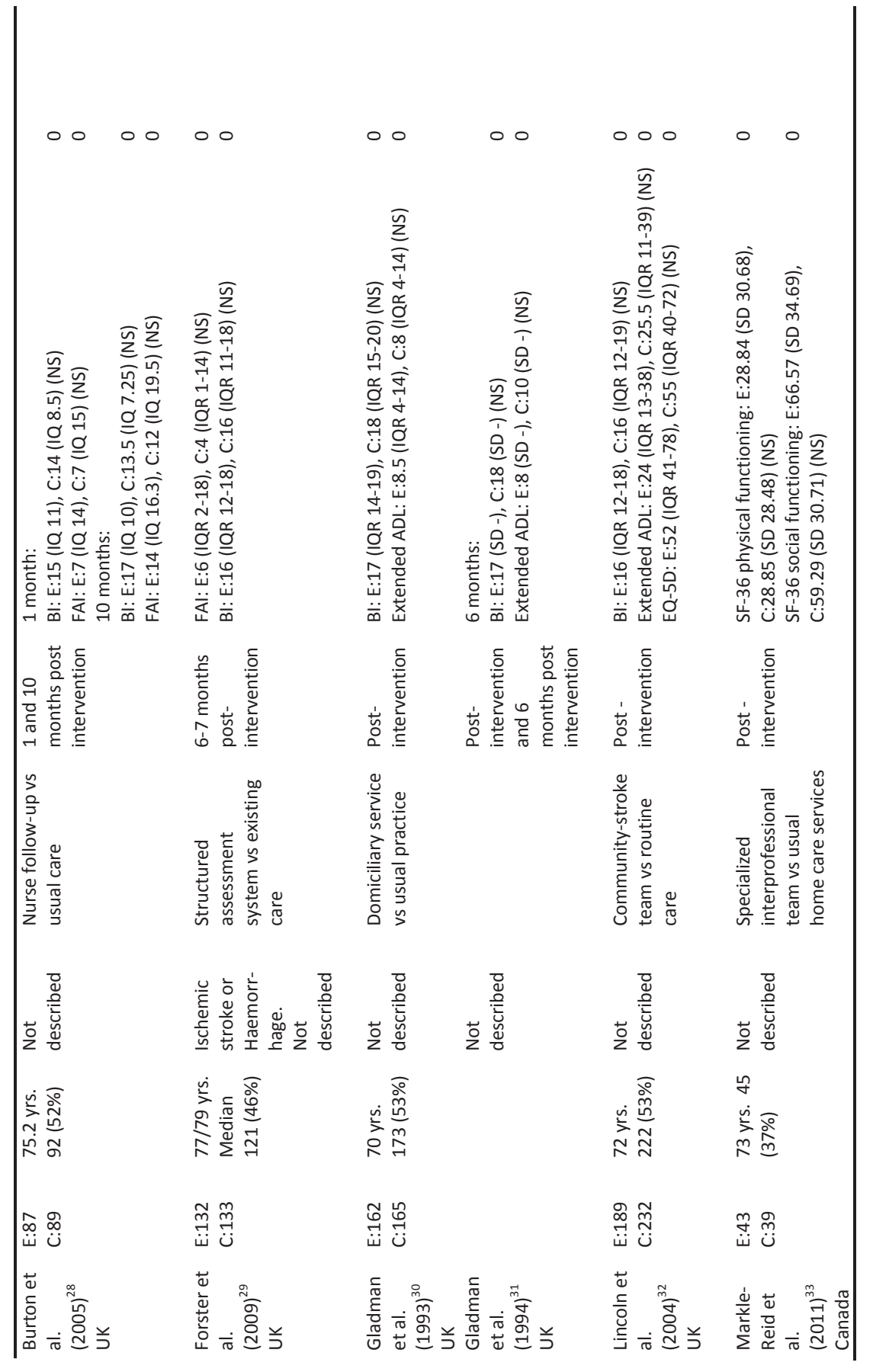




\begin{tabular}{|c|c|c|c|c|}
\hline 00000000 & $\circ$ & 0000 & $0+0$ & $\circ$ \\
\hline 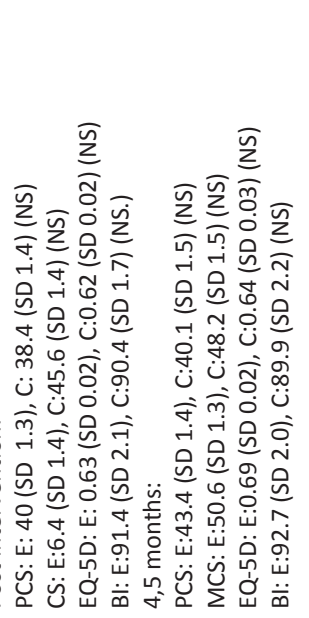 & 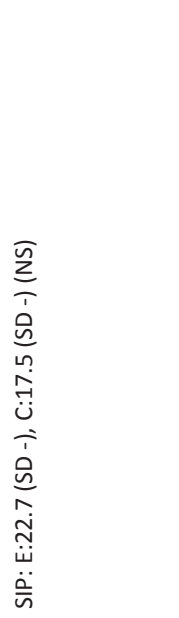 & 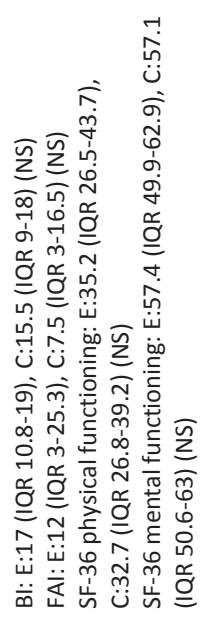 & 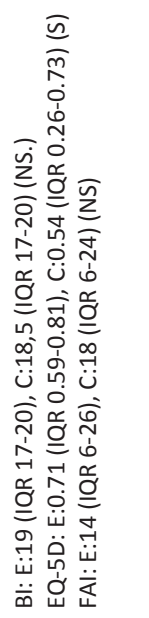 & 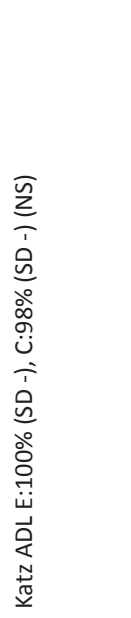 \\
\hline 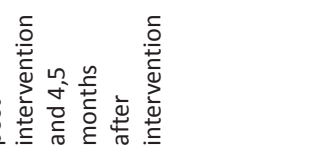 & 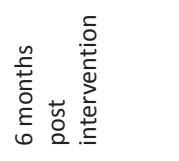 & 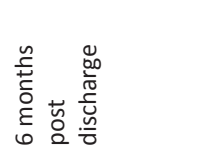 & 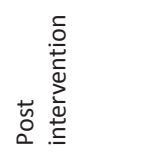 & 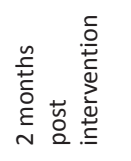 \\
\hline 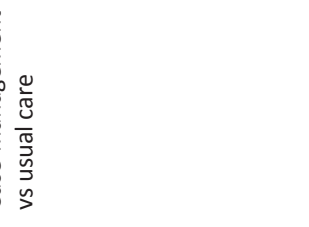 & 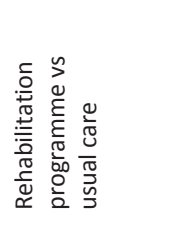 & 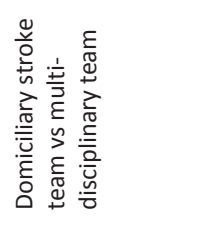 & 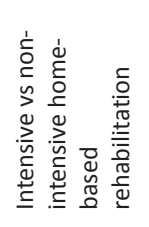 & 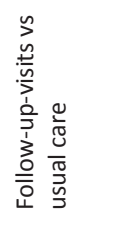 \\
\hline 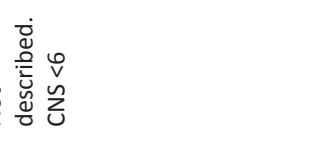 & 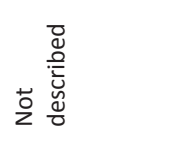 & 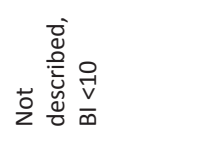 & 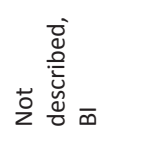 & 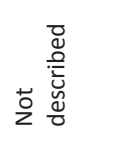 \\
\hline & 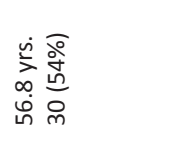 & 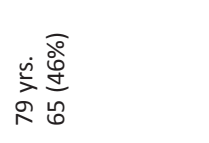 & 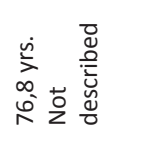 & 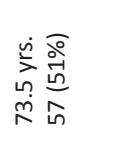 \\
\hline & $\stackrel{\infty}{\ddot{ن}} \stackrel{\infty}{\sim}$ & نُ & 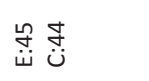 & 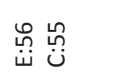 \\
\hline 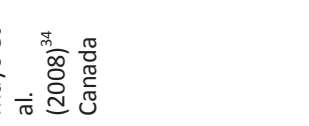 & 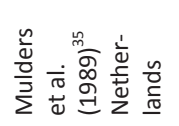 & 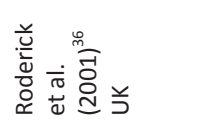 & 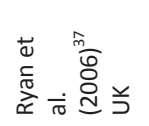 & 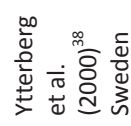 \\
\hline
\end{tabular}




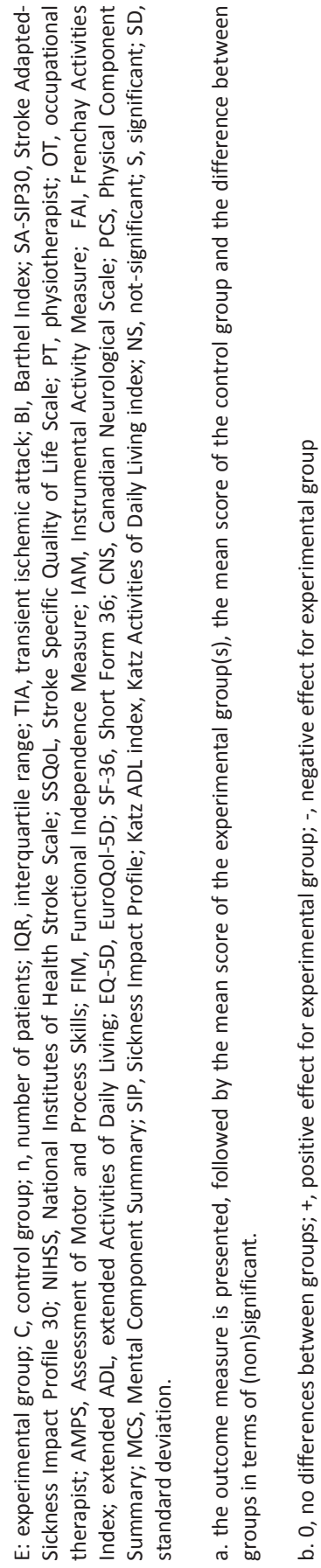




\section{Description of intervention}

Table 2.2 shows that the 14 interventions differed in terms of organization, disciplines involved, duration and intensity. Four main types of interventions could be identified: assessment $(\mathrm{N}=2)$; assessment combined with follow-up care $(\mathrm{N}=8)$; rehabilitation $(\mathrm{N}=3)$; and education $(\mathrm{N}=1)$.

The first type of intervention (assessment) consisted of a single visit at home or at a clinic, which aimed to prevent a negative course of events. ${ }^{29,}{ }^{38}$ The assessments were performed by a multidisciplinary team ${ }^{38}$, consisting of a physiotherapist, occupational therapist, counsellor and doctor, or a nurse with a consultant multidisciplinary team or with links to social services. ${ }^{29}$ The assessments were performed at one month ${ }^{38}$ or five to six months after discharge home. ${ }^{29}$

The second type of intervention (assessment combined with follow-up care) could be subdivided into assessment with either subsequent follow-up visits $(N=5)^{25,26,28,33,34}$ or assessment with subsequent rehabilitation $(\mathrm{N}=3) .{ }^{30-32}$ The five assessments with follow-up visits were aimed at coping with the consequences of stroke ${ }^{28}$ and improving the quality of life. ${ }^{33,34}$ Nurses performed the assessment and follow-up visits and consulted with the patient's physician ${ }^{34}$ or a multidisciplinary team. ${ }^{25,26,28,33}$ There was considerable variation in the duration of assessment and follow-up visits, varying from six weeks ${ }^{34}$ to 12 months. ${ }^{26,33}$ The three assessments performed with subsequent rehabilitation were focused on improving functional abilities of stroke patients. $^{30-32}$ The interventions were provided by a physiotherapist and an occupational therapist ${ }^{30,31}$, who could work together with a speech therapist and a nurse. $^{32}$ They provided therapy for a period of six months ${ }^{30,31}$ or as long as needed. ${ }^{32}$

The third type of intervention (rehabilitation) aimed to improve functional outcome and skills and involved disciplines such as physiotherapists, occupational therapists, physicians and speech therapists. ${ }^{27,35,36}$ The duration of the program varied between three weeks ${ }^{27}$ to as long as needed ${ }^{35}$, and varied in intensity as well. All interventions were performed at the patient's home. 


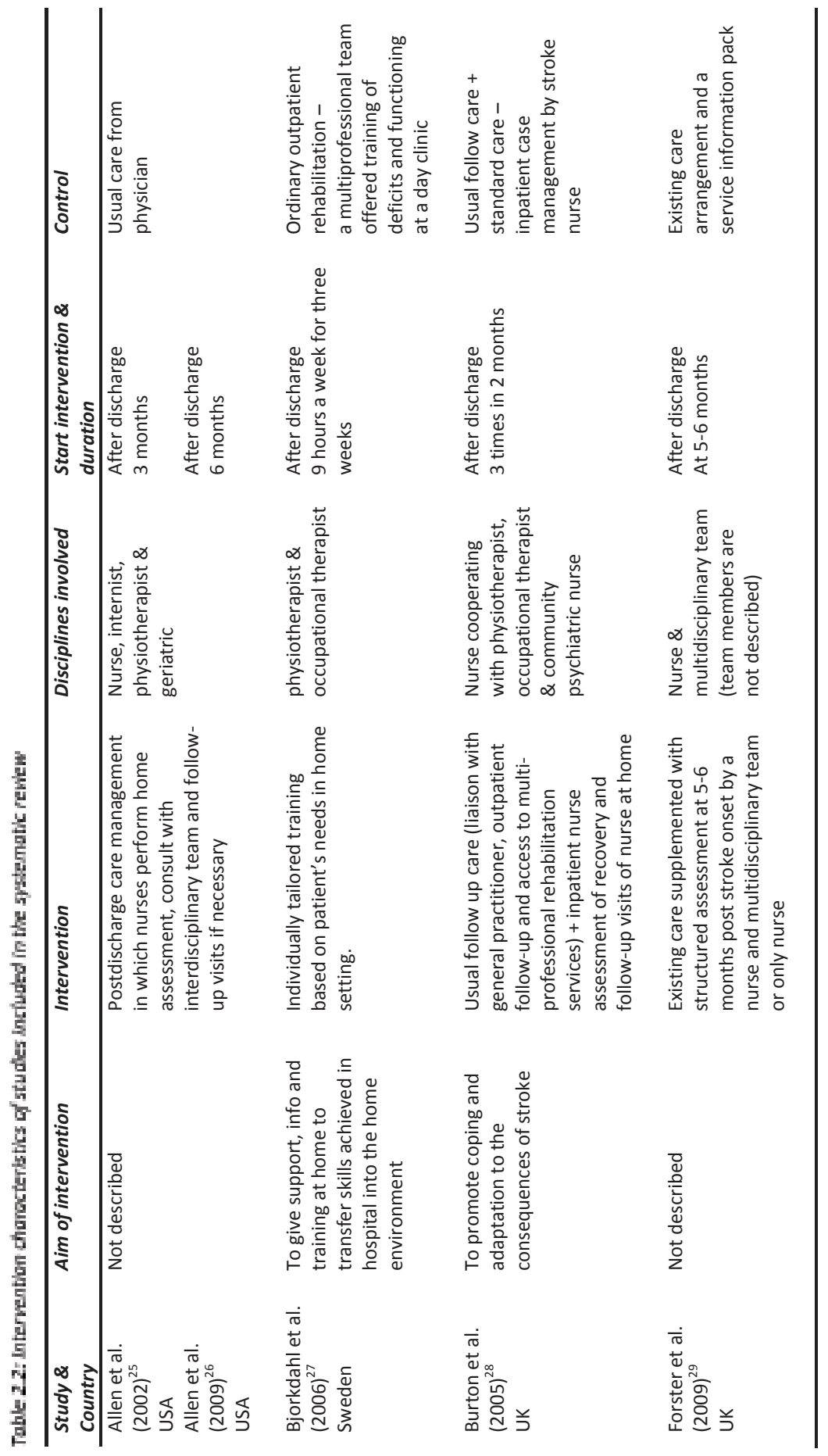




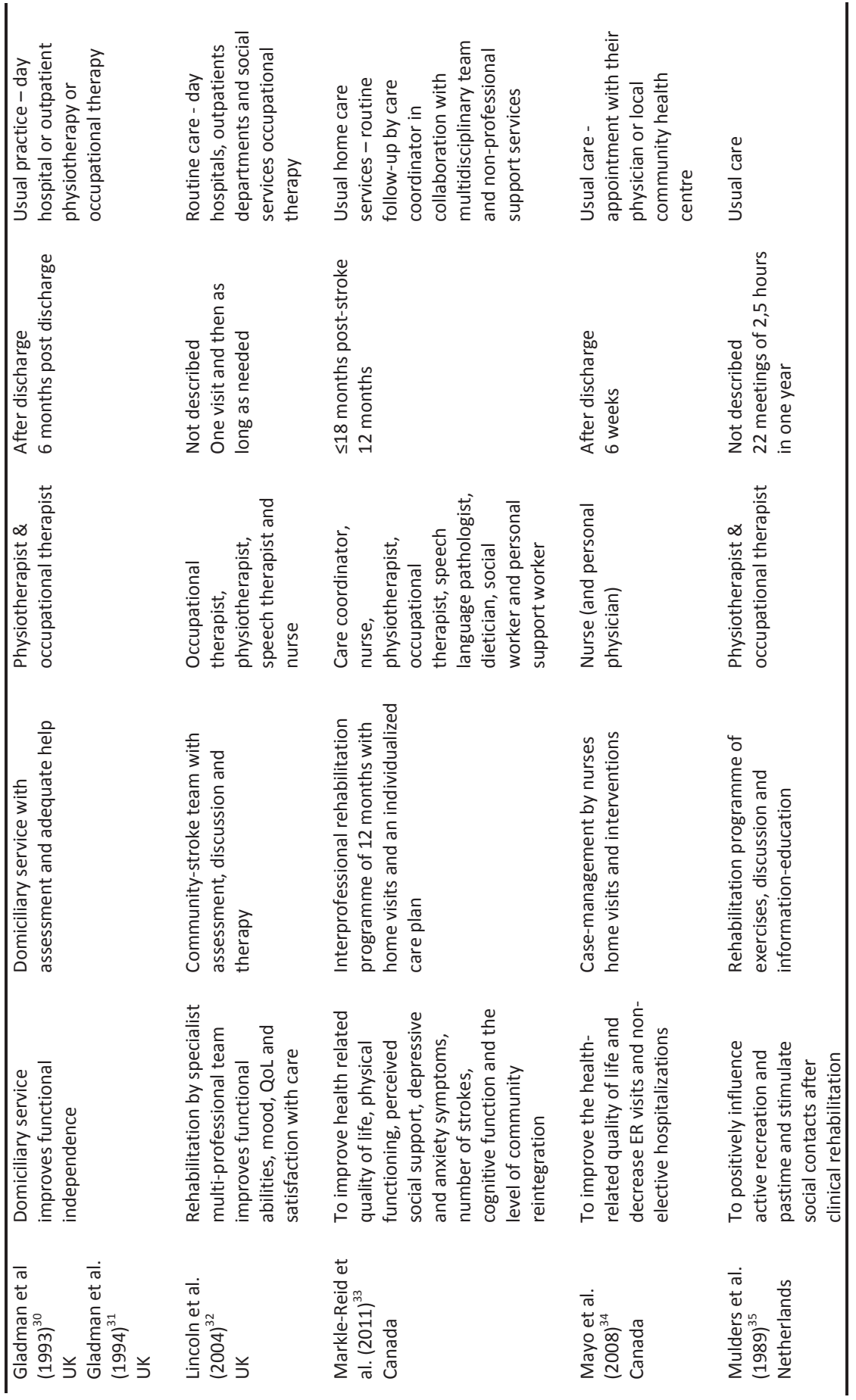




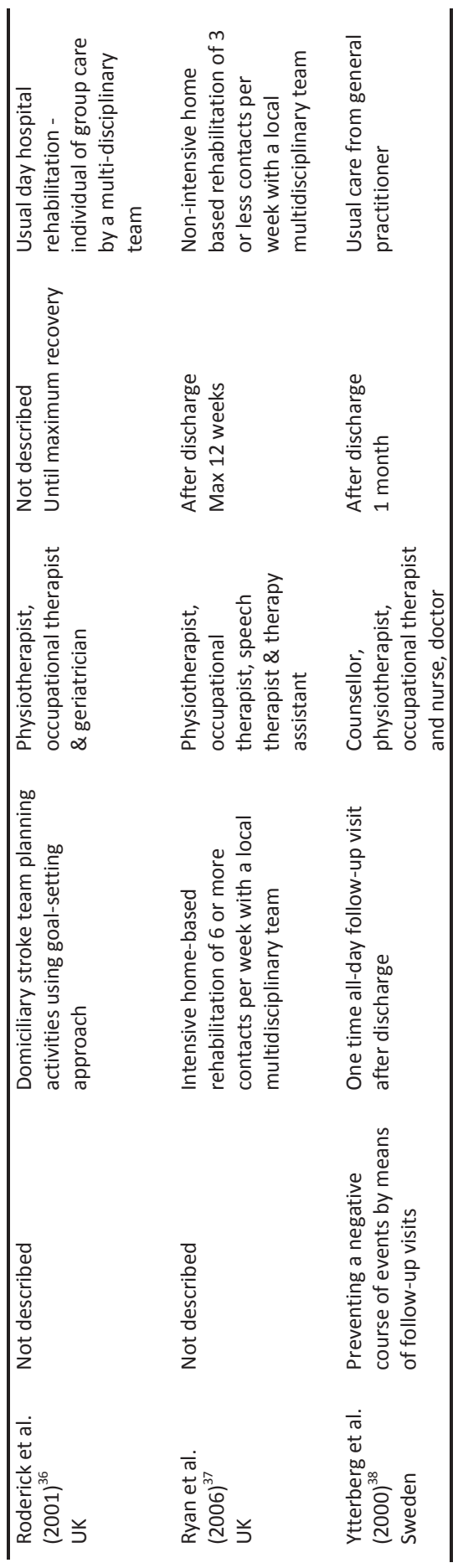


The fourth type of intervention (education) aimed to stimulate social contacts and active recreation. ${ }^{34}$ Patients participated in group discussions about current events and in outdoor activities such as dining and going to the theatre. The intervention was performed by physiotherapists and occupational therapists, providing education and information 22 times in one year.

Ten interventions started directly after discharge home from hospital and one intervention started within 18 months post-stroke. ${ }^{33}$ For the other three interventions it was unclear when the interventions started. ${ }^{32,35,36}$

\section{Outcome measures and effects}

Eleven studies assessed activities of daily living using the Barthel Index ( $N=9$ ), Frenchay Activities Index $(N=4)$, extended Activities of Daily Activities $(N=3)$, Functional Independence Measure $(N=1)$, Instrumental Activity Measure $(N=1)$, Assessment of Motor and Process Skills $(\mathrm{N}=1)$, Mental Component Summary/Physical Component Summary $(\mathrm{N}=1)$, and Katz Index $(\mathrm{N}=1) .^{25,27-32,34,36-38}$ None of these studies found an effect of the intervention on daily activities. Social participation was assessed in none of the studies. Eight studies assessed quality of life, using the Euroqol-5D (N=3), Stroke Adapted-Sickness Impact Profile $30(\mathrm{~N}=1)$, Short Form 36 $(\mathrm{N}=2)$, Stroke Specific Quality of Life Scale $(\mathrm{N}=1)$ and/or Sickness Impact Profile $(\mathrm{N}=1) .{ }^{25,26,32-37}$ Out of these eight studies, the studies of Allen et al. ${ }^{25}$ and Ryan et al. ${ }^{37}$ reported favorable effects of the intervention on quality of life.

In the study of Allen et al. ${ }^{25}$ (assessment with follow-up care), an advanced practice nurse care manager performed a telephone assessment three to seven days after discharge home and provided some education. A month later the advanced nurse visited patients at home for a standardized biopsychosocial assessment for strokespecific problems. The findings of this assessment were discussed by the post-stroke consultation team to develop an individual care plan. Three months after discharge home, patients receiving the intervention reported an increased quality of life, using a stroke adapted outcome measure (SA-SIP30). In the study of Ryan et al. ${ }^{37}$, (rehabilitation) a multidisciplinary team provided six or more face-to-face contacts a 
week. During these contacts, patients received therapy for a maximum period of 12 weeks, which was compared with a control group receiving 3 or less face-to-face contacts a week. None of the patients needed 12 weeks of therapy. The patients receiving six or more face-to-face contacts a week reported a better quality of life than patients who received 3 or less face-to-face contacts a week.

\section{Quality of reporting of the study}

The percentage of the CONSORT items reported in the included studies ranged from $35 \%$ to $73 \%$, with an average of $55 \%$ (table 2.3). The study of Markle-Reid ${ }^{33}$ had the highest quality $(73 \%)$, while the study of Ytterberg $^{38}$ had the lowest quality (35\%). The CONSORT statement can be divided into seven categories: 'title/abstract'; 'introduction'; 'methods-trial'; 'methods-randomization'; 'results'; 'discussion'; and 'other information'. In 4 of these categories ('methods-trial', 'methodsrandomization', 'results' and 'other information') $\leq 50 \%$ of the items was reported on average.

\section{Discussion}

This systematic review, evaluating the effectiveness of multidisciplinary care for stroke patients living in the community after being discharged home, showed that none of the 11 studies that assessed daily activities reported a favorable effect of the intervention on this outcome. In addition, the review showed that none of the included studies assessed the effects of the intervention on social participation. Furthermore, with regard to quality of life, our review showed that, of the 8 studies that assessed the effects of the intervention on quality of life, only two showed a favorable effect on this outcome domain. These two interventions were an assessment combined with follow-up visits ${ }^{25}$ and a rehabilitation intervention. ${ }^{37}$ These interventions differed considerably in organization, disciplines involved, duration and intensity, which makes the comparison and identification of essential care elements of effective multidisciplinary care impossible. 


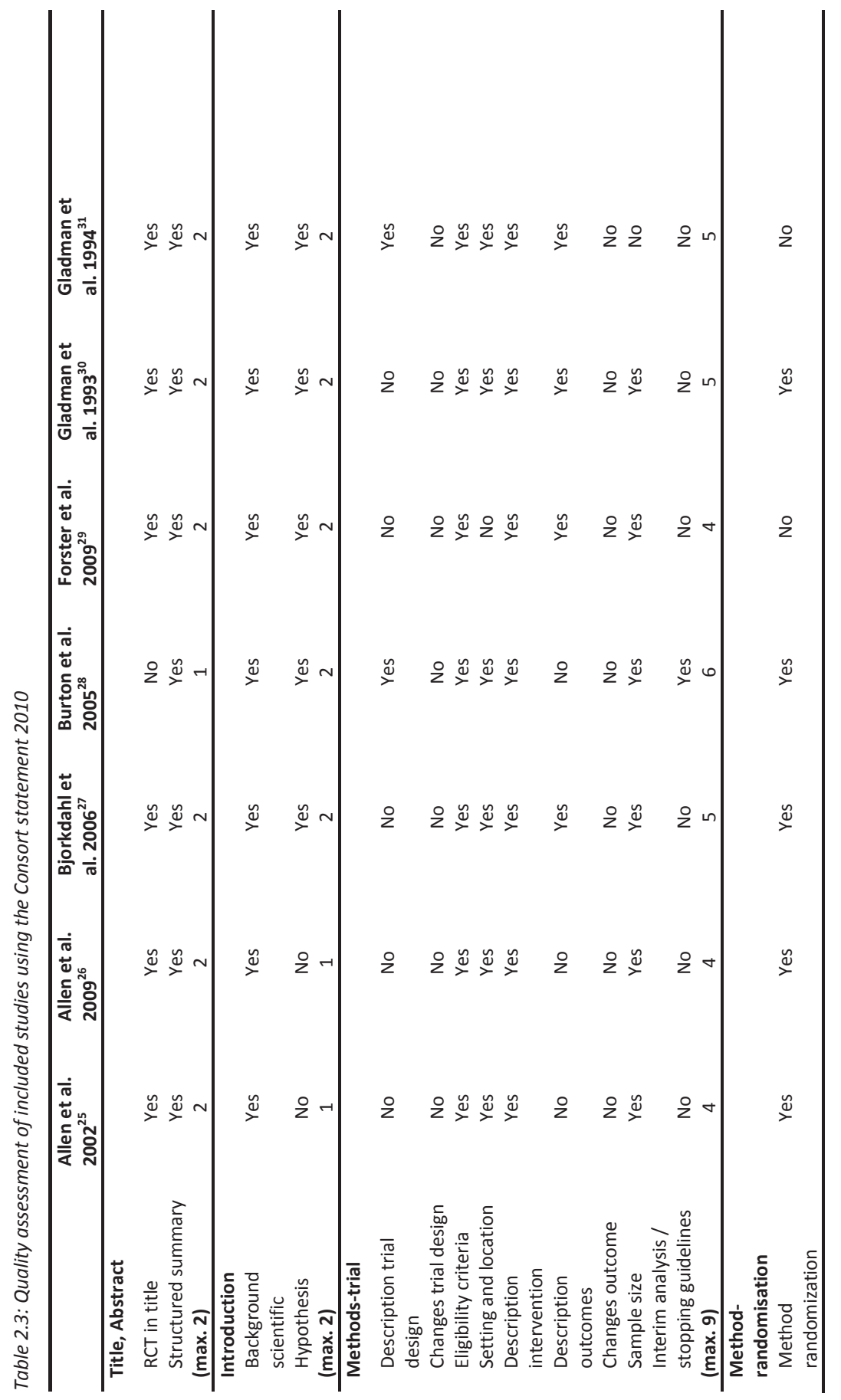




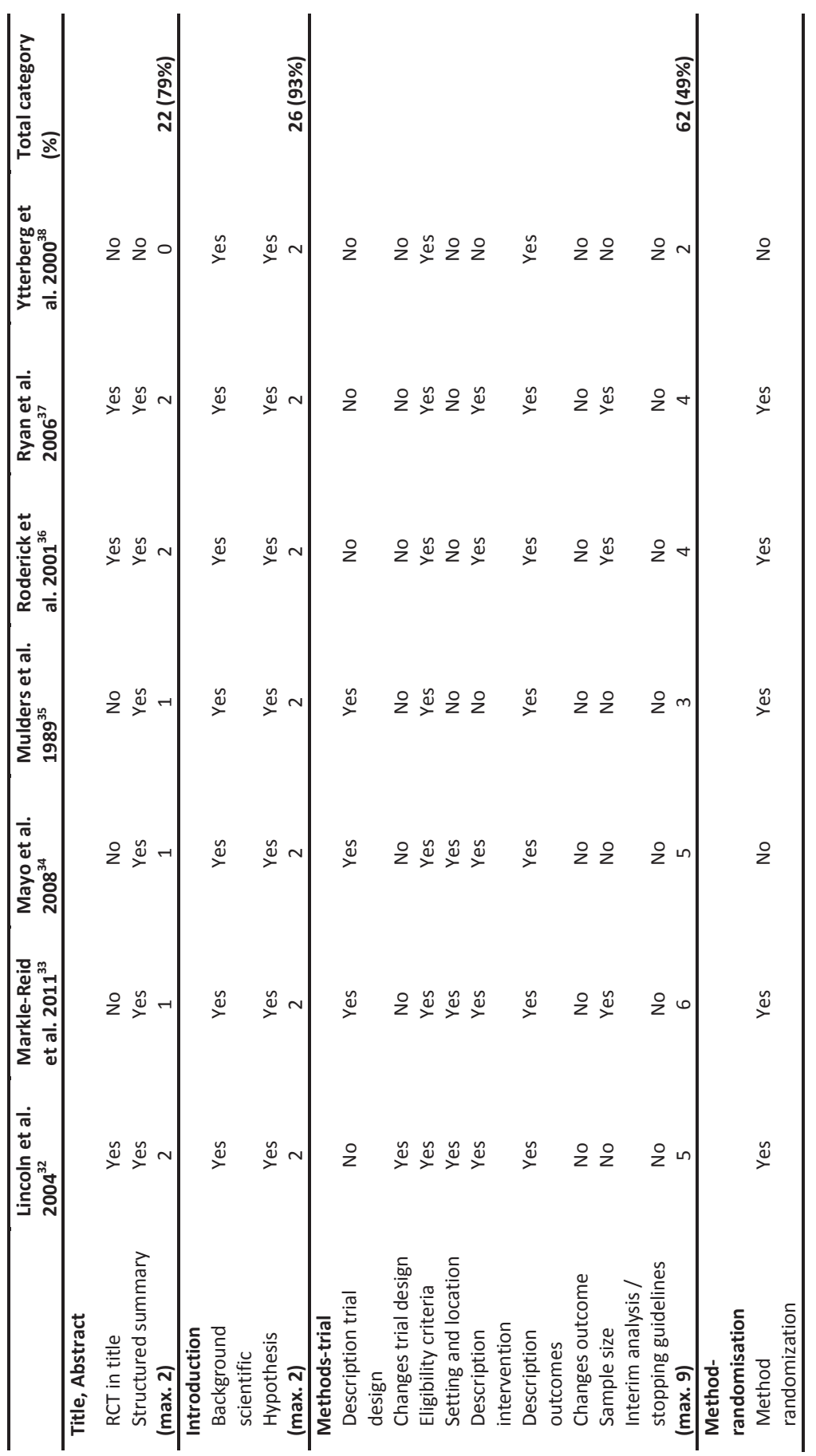




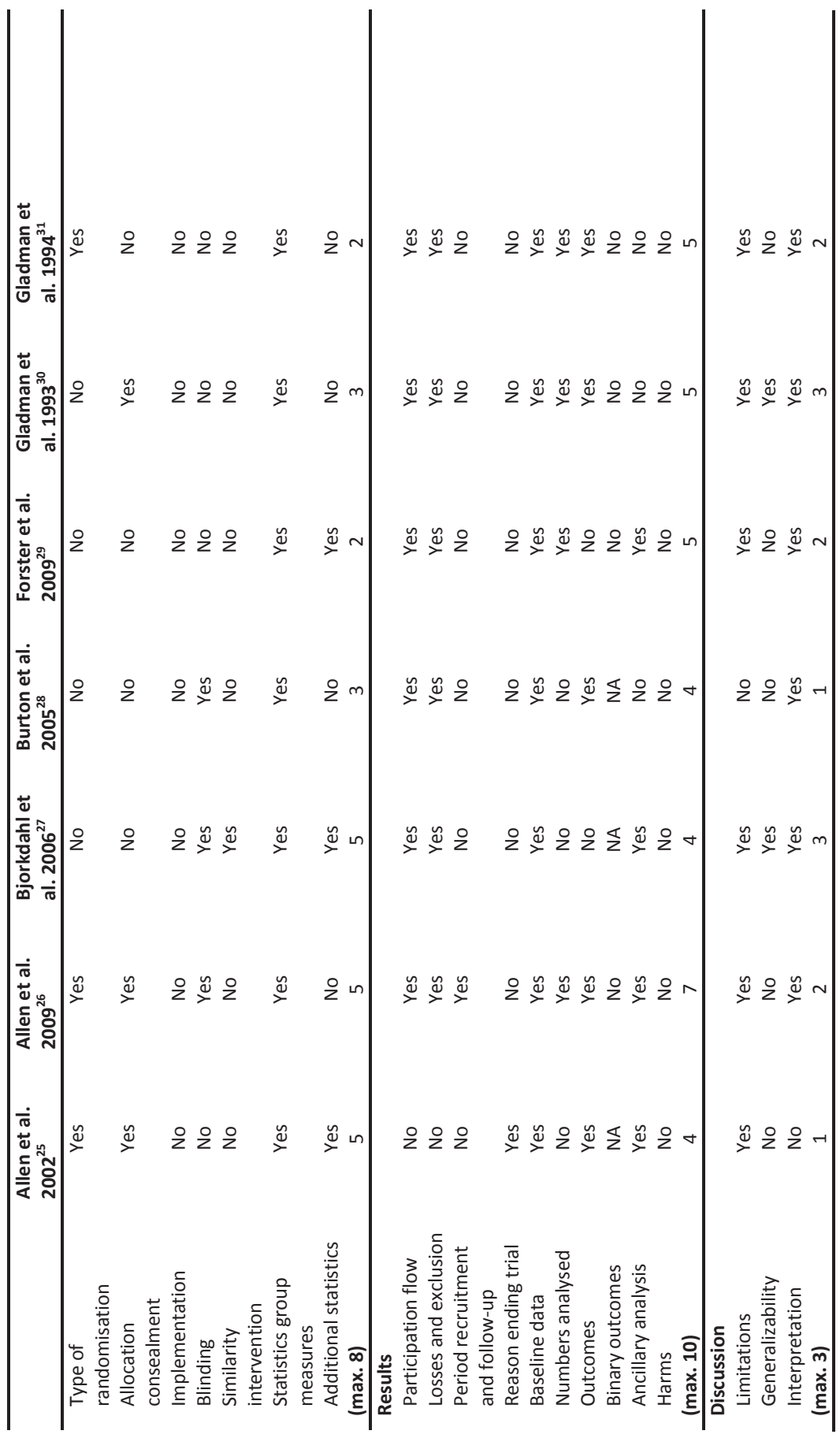




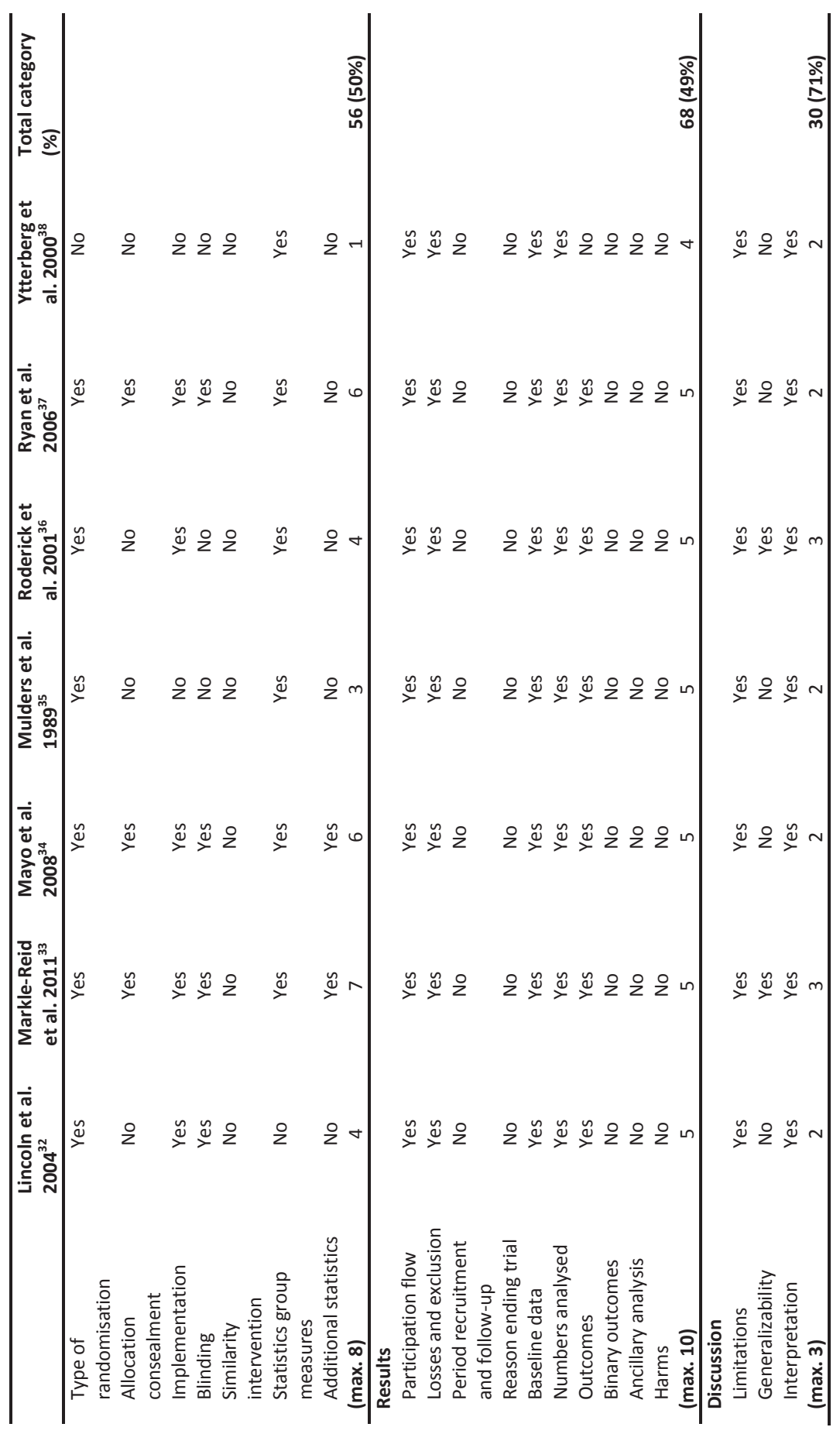




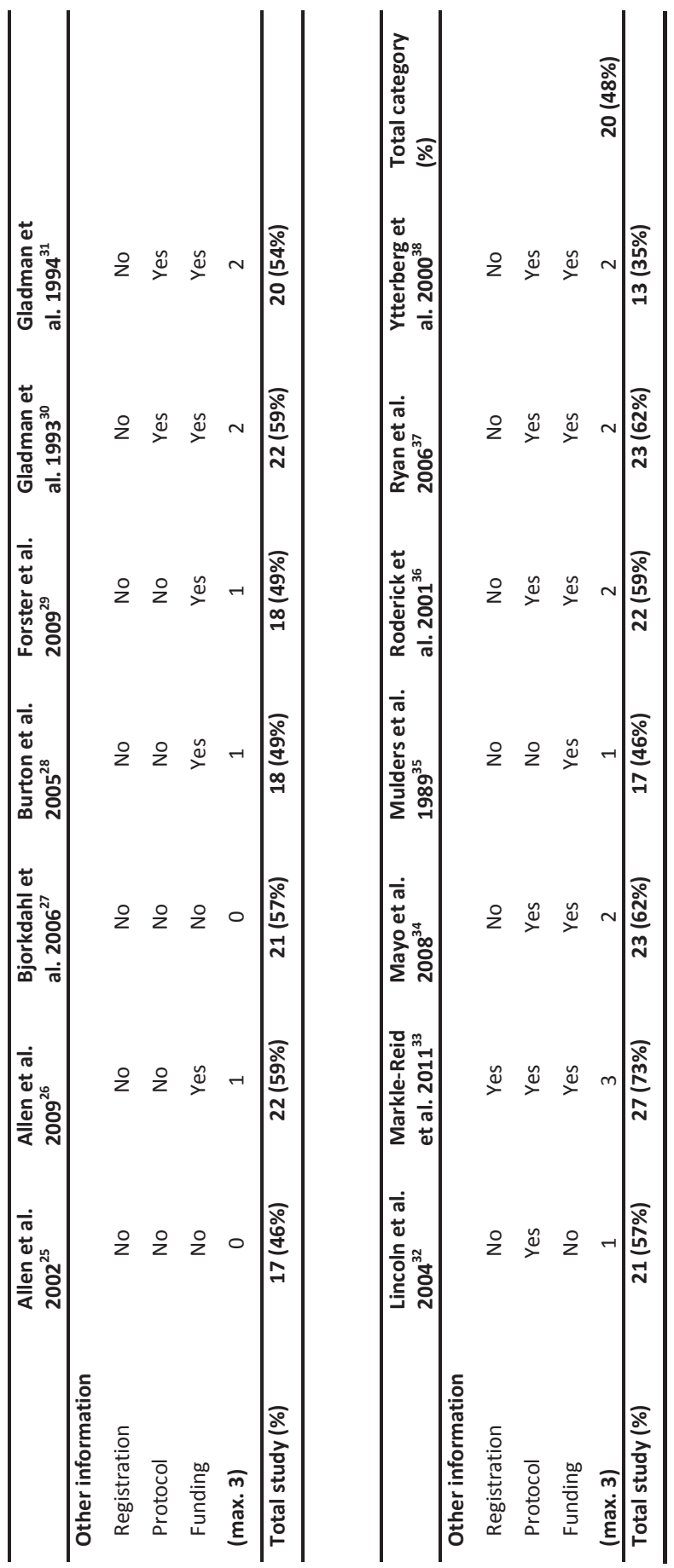


Previous reviews, which assessed the effects of home-based interventions provided by multidisciplinary teams, physiotherapists or occupational therapists, showed a statistically significant favorable effect of these interventions on daily activities. ${ }^{18,21}$ This appears to be in contrast with the findings of the present review. However, our review focused only on multidisciplinary interventions and reported only significant results. The results of the multidisciplinary studies included in previous reviews are in favor of the treatment on daily activities, but their results are non-significant ${ }^{18,21}$, which is in line with our findings. In addition, a previous review, which focused on the effects of therapy-based rehabilitation 1 year or more after stroke, found inconclusive evidence for the effectiveness of therapy-based interventions and reported that interventions were different in design, type of intervention and outcome, which is consistent with the findings of this review. ${ }^{19}$

The methodological quality of the 14 studies differed considerably and ranged between $35 \%$ and $73 \%$, indicating that substantial quality improvements can be made in future research. For instance, description of trial design, implementation procedure and period of recruitment could be reported more accurately. Furthermore, the generalization of the results should be reported because it can provide valuable information for clinical use. However, we have to consider that some items (such as blinding, serious harms and interim analysis) are less applicable for studies evaluating non-pharmacological interventions, which also decrease the percentage of reported items and thus the quality. Furthermore with regard to research in the field of stroke, we consider it very important to report the time between stroke and start of the intervention to facilitate a proper comparison of the effects of the different types of interventions and to gain insight into the phase in which these patients were at time of the intervention (rehabilitation or long-term care).

We conclude there is only limited evidence for the effectiveness of multidisciplinary care programs for community living stroke patients after being discharged home. There may be several explanations for the lack of effectiveness of these interventions. First, it is possible that the time between stroke and the start of the 
intervention was, in general, too long, which may make it more difficult to achieve significant favorable effects. ${ }^{39}$ This assumption is supported by the fact that two recent studies that evaluated interventions, that started in the acute phase and continued in the home setting (early supported discharge), showed favorable effects on functional outcome, even after 5 years. ${ }^{40,41} \mathrm{~A}$ second explanation might be found in the design of the studies. The experimental intervention was, in almost all included studies, compared to care as usual, which is, in general, poorly described in the studies. It is therefore unclear whether the contrast between the experimental care and care as usual was big enough to raise a substantial effect. A third explanation might be found in the fact that, for most interventions, it was not described whether the intervention was based on a specific theoretical framework and/or evidence of previous research. Furthermore, most studies did not present a clear description of the intensity and contents of the program. It is therefore possible that the quality of the interventions was simply too low, because the interventions were insufficiently based on theoretical frameworks and/or evidence from previous research.

A major strength of our review is the inclusion of eight studies that had not been evaluated by previous reviews. A limitation of this review may be the selection of appropriate search terms for the interventions, because multidisciplinary care can be described by many different terms. Therefore, it is possible that we have missed relevant studies. Another limitation may be the fact that we focused in our review on three outcome measures: daily activity, quality of life and social participation. Although we have only found two effective interventions regarding quality of life, the included interventions may have had favorable effects on other outcomes such as depression, cost reduction or care satisfaction, which we did not consider in this review.

Our systematic review showed that only two of the eight multidisciplinary interventions that assessed quality of life reported favorable effects on quality of life in stroke patients discharged home after hospitalization or inpatient rehabilitation. Furthermore, none of the studies showed favorable effects on daily activity. 
Therefore, there is still a great need for additional high-quality studies assessing the effectiveness of different types of multidisciplinary care for stroke patients after being discharged home. It seems important that future intervention programs are based on theoretical frameworks and/or results of previous research, in order to increase the (potential) quality of the programs. In addition, future research into the effects of multidisciplinary care among stroke patients discharged home should also evaluate the effects on social participation, as this important outcome has not been included in previous research. 


\section{References}

1. Weimar C, Kurth T, Kraywinkel K, Wagner M, Busse O, Haberl RL et al. Assessment of functioning and disability after ischemic stroke. Stroke. 2002;33:2053-2059

2. Mackay J, Mensah G. Atlas of heart disease and stroke. World Health Organization. Geneva. 2004

3. Tilling K, Sterne JA, Rudd AG, Glass TA, Wityk RJ, Wolfe CD. A new method for predicting recovery after stroke. Stroke. 2001;32:2867-2873

4. Lincoln NB, Gladman JR, Berman P, Noad RF, Challen K. Functional recovery of community stroke patients. Disability rehabilitation 2000;22:135-139

5. Wade DT, Collen FM, Robb GF, Warlow CP. Physiotherapy intervention late after stroke and mobility. Bmj. 1992;304:609-613

6. Patel MD, Tilling K, Lawrence E, Rudd AG, Wolfe CD, McKevitt C. Relationships between long-term stroke disability, handicap and health-related quality of life. Age Ageing. 2006;35:273-279

7. Cramer SC. Changes in motor system function and recovery after stroke. Restor Neurol Neurosci. 2004;22:231-238

8. D'Alisa S, Baudo S, Mauro A, Miscio G. How does stroke restrict participation in long-term post-stroke survivors? Acta Neurol Scand. 2005;112:157-162

9. Clarke PJ, Black SE, Badley EM, Lawrence JM, Williams Jl. Handicap in stroke survivors. Disabil Rehabil. 1999;21:116-123

10. Lightbody CE, Baldwin R, Connolly M, Gibbon B, Jawaid N, Leathley M, et al. Can nurses help identify patients with depression following stroke? A pilot study using two methods of detection. J Adv Nurs. 2007;57:505-512

11. Morrison V, Pollard B, Johnston M, MacWalter R. Anxiety and depression 3 years following stroke: Demographic, clinical, and psychological predictors. J Psychosom Res. 2005;59:209-213

12. Rasquin SM, Lodder J, Ponds RW, Winkens I, Jolles J, Verhey FR. Cognitive functioning after stroke: A one-year follow-up study. Dement Geriatr Cogn Disord. 2004;18:138-144

13. Desrosiers J, Noreau L, Rochette A, Bravo G, Boutin C. Predictors of handicap situations following post-stroke rehabilitation. Disabil Rehabil. 2002;24:774-785

14. Dijkerman HC, Wood VA, Hewer RL. Long-term outcome after discharge from a stroke rehabilitation unit. J R Coll Physicians Lond. 1996;30:538-546

15. Murray J, Ashworth R, Forster A, Young J. Developing a primary care-based stroke service: A review of the qualitative literature. Br J Gen Pract. 2003;53:137-142

16. Stroke Unit Trialists' Collaboration. Organised inpatient (stroke unit) care for stroke. Cochrane Database Syst Rev. 2002:CD000197

17. Langhorne P. Developing comprehensive stroke services: An evidence-based approach. Postgrad Med J. 1995;71:733-737

18. Outpatient Service Trialists. Therapy-based rehabilitation services for stroke patients at home. Cochrane Database Syst Rev. 2003;1:DOI: 10.1002/14651858.CD002925. 
19. Aziz NA, Leonardi-Bee J, Phillips M, Gladman JR, Legg L, Walker MF. Therapybased rehabilitation services for patients living at home more than one year after stroke. Cochrane Database Syst Rev. 2008:CD005952

20. Boter $\mathrm{H}$, de Haan RJ, Rinkel GJ. Regional differences in the use of out-patient services by stroke patients after hospitalisation. Eur Neurol. 2005;53:10-14

21. Legg L, Langhorne P. Rehabilitation therapy services for stroke patients living at home: Systematic review of randomised trials. Lancet. 2004;363:352-356

22. Legg LA, Drummond AE, Langhorne P. Occupational therapy for patients with problems in activities of daily living after stroke. Cochrane Database Syst Rev. 2006:CD003585

23. Hillier S, Inglis-Jassiem G. Rehabilitation for community-dwelling people with stroke: Home or centre based? A systematic review. Int J Stroke. 2010;5:178-186

24. Schulz KF, Altman DG, Moher D. Consort 2010 statement: Updated guidelines for reporting parallel group randomized trials. Annals of internal medicine. 2010; 152(1):1-7.

25. Allen KR, Hazelett S, Jarjoura D, Wickstrom GC, Hua K, Weinhardt J, et al. Effectiveness of a postdischarge care management model for stroke and transient ischemic attack: A randomized trial. J Stroke Cerebrovasc Dis. 2002;11:88-98

26. Allen K, Hazelett S, Jarjoura D, Hua K, Wright K, Weinhardt J, et al. A randomized trial testing the superiority of a postdischarge care management model for stroke survivors. J Stroke Cerebrovasc Dis. 2009;18:443-452

27. Bjorkdahl A, Nilsson AL, Grimby G, Sunnerhagen KS. Does a short period of rehabilitation in the home setting facilitate functioning after stroke? A randomized controlled trial. Clin Rehabil. 2006;20:1038-1049

28. Burton C, Gibbon B. Expanding the role of the stroke nurse: A pragmatic clinical trial. J Adv Nurs. 2005;52:640-650

29. Forster A, Young J, Green J, Patterson C, Wanklyn P, Smith J, et al. Structured reassessment system at 6 months after a disabling stroke: A randomised controlled trial with resource use and cost study. Age and Ageing. 2009;38:576-583

30. Gladman JR, Lincoln NB, Barer DH. A randomised controlled trial of domiciliary and hospital-based rehabilitation for stroke patients after discharge from hospital. J Neurol Neurosurg Psychiatry. 1993;56:960-966

31. Gladman JR, Lincoln NB. Follow-up of a controlled trial of domiciliary stroke rehabilitation (domino study). Age Ageing. 1994;23:9-13

32. Lincoln N, Walker M, Dixon A, Knights $P$. Evaluation of a multiprofessional community stroke team: A randomized controlled trial. Clinical Rehabilitation. 2004;18:40-47

33. Markle-Reid M, Orridge C, Weir R, Browne G, Gafni A, Lewis M, et al. Interprofessional stroke rehabilitation for stroke survivors using home care. The Canadian journal of neurological sciences. Le journal canadien des sciences neurologiques. 2011;38:317-334

34. Mayo NE, Nadeau L, Ahmed S, White C, Grad R, Huang A, et al. Bridging the gap: The effectiveness of teaming a stroke coordinator with patient's personal physician on the outcome of stroke. Age Ageing. 2008;37:32-38 
35. Mulders A, De Witte L, Diederiks J. Evaluation of a rehabilitation after-care programme for stroke patients. Journal of Rehabilitation Sciences. 1989;2:97-103

36. Roderick P, Low J, Day R, Peasgood T, Mullee MA, Turnbull JC, et al. Stroke rehabilitation after hospital discharge: $\mathrm{A}$ randomized trial comparing domiciliary and day-hospital care. Age Ageing. 2001;30:303-310

37. Ryan T, Enderby P, Rigby AS. A randomized controlled trial to evaluate intensity of community-based rehabilitation provision following stroke or hip fracture in old age. Clin Rehabil. 2006;20:123-131

38. Ytterberg C, Anderson Malm S, Britton M. How do stroke patients fare when discharged straight to their homes? A controlled study on the significance of hospital follow-up after one month. Scand J Rehabil Med. 2000;32:93-96

39. Langhorne P, Bernhardt J, Kwakkel G. Stroke rehabilitation. Lancet.377:1693-1702

40. Thorsen AM, Holmqvist LW, de Pedro-Cuesta J, von Koch L. A randomized controlled trial of early supported discharge and continued rehabilitation at home after stroke: Five-year follow-up of patient outcome. Stroke. 2005;36:297-302

41. Fjaertoft $H$, Rohweder G, Indredavik B. Stroke unit care combined with early supported discharge improves 5-year outcome: A randomized controlled trial. Stroke 2011;42:1707-1711 


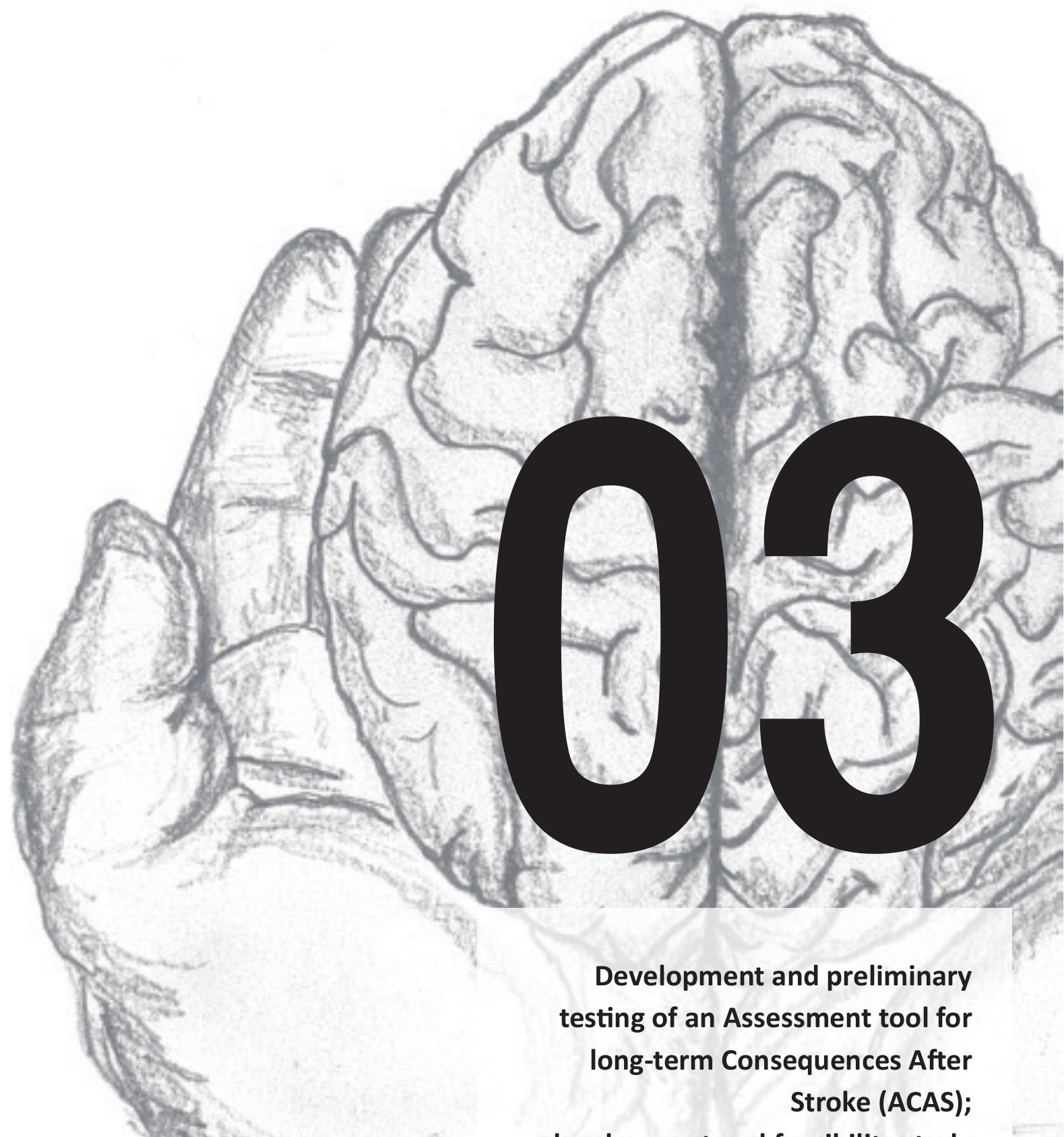
a development and feasibility study

Manon Fens, George Beusmans, Martien Limburg, Job Metsemakers, Liesbeth van Hoef, Caroliene van Heugten. Submitted 


\begin{abstract}
Objective: The objective was to develop an assessment tool to detect long-term stroke-related problems and test the feasibility and content and criterion validity. Method: Stroke patients $(\mathrm{N}=14)$ at home and their caregivers $(\mathrm{N}=12)$ received an assessment. Patients, caregivers and fifteen health care professionals received several questionnaires to evaluate the feasibility. The content validity ratio (CVR) was used to measure the content validity. Criterion validity was expressed in terms of sensitivity and specificity. Finally, an adjusted version was used to assess 62 stroke patients. Results: All participants regarded the assessment tool as feasible in health care. The CVR ranged from 0.36 to 1.00 . The sensitivity ranged from $0 \%$ to $100 \%$ and the specificity ranged from $72.7 \%$ to $100 \%$. Use of the adjusted version in 62 stroke patients yielded comparable results. Conclusion: Overall, the assessment tool showed moderate to good content and criterion validity. All respondents considered the assessment tool to be feasible in clinical practice.
\end{abstract}

Keywords: feasibility studies, long-term care, needs assessment, nursing assessment, stroke 


\section{Introduction}

Stroke patients and their caregiver, living at home after hospitalization or inpatient rehabilitation, often experience problems due to persistent deficits resulting from their stroke, such as physical, cognitive and psychological complaints. ${ }^{1-5}$ Furthermore, professional care is usually limited to the first six months and there is often no longterm care available. $^{6}$ Long-term care for stroke patients is complicated, because there are many functions that may be affected, resulting in the involvement of many disciplines. An effective approach for long-term care is to monitor chronic stroke patients regularly ${ }^{6,7}$, by means of a comprehensive structured assessment, to detect the problems and care needs of stroke patients and caregivers. This assessment should cover the full spectrum of stroke-related problems. Any health care professional performing this assessment should preferably be knowledgeable about stroke and be able to provide care over a wide range of health related issues. Although general practitioners (GPs) meet these requirements, a full assessment is often time-consuming, making it difficult to perform for GPs. ${ }^{8}$ Other care professionals who might be suitable are stroke care coordinators and social liaison workers, who can provide multifaceted care. ${ }^{9,10}$ Several assessment tools have been developed to assess health problems, but none of these instruments is adequate for use in long-term stroke care, e.g. are not stroke specific ${ }^{11}$, measure only specific stroke problem areas ${ }^{12,13}$ or are not yet ready for clinical use. ${ }^{14}$ There is thus a need for an assessment tool meeting the above requirements. The purpose of this study was therefore to develop and test (feasibility, content and criterion validity) a new assessment tool that covers a broad spectrum of stroke-related problems and should be useful in chronic care for patients living at home after hospitalization or inpatient rehabilitation.

\section{Instrument Development}

\section{Development}

Draft versions were developed, based on a literature search on relevant problems and existing and validated measurements. These versions were repeatedly discussed 
with two stroke care coordinators (SCCS). The SCCs were health care professionals from home care services specialized in stroke, who visit patients at home. The third draft version was used in the study to measure the feasibility, content and criterion validity.

\section{Third draft version}

The third draft version of the Assessment tool for long-term Consequences After Stroke (ACAS) had a stepwise structure and consisted of 12 domains with a total of 17 items. The broad spectrum of stroke-related problems required a stepwise procedure, in which each domain contained a brief initial questions to identify whether there was a problem relating to that domain. If no problems were identified (the answer is NO), no further specifications were required and the next domain was addressed. If a problem was present (the answer is YES), the domain could be explored by additional questions (e.g. did the patient still require aids or home adjustments; did the patient still require physiotherapy or occupational therapy) or by validated measurement instruments.

The additional questions were standardized and had been formulated to further specify the patient's needs for long-term care, without the need of validated measurement instruments. The validated measurement instruments were the Barthel Index $(\mathrm{BI})^{15}$; the Frenchay Activities Index (FAI) ${ }^{16,17}$; the Checklist for Cognitive and Emotional consequences following stroke $(\mathrm{CLCE}-24)^{12}$; the Hospital Anxiety and Depression Scale (HADS) $)^{18}$; the Fatigue Severity Scale (FSS) $)^{19}$ and the Caregiver Strain Index (CSI). ${ }^{20}$ These instruments are reliable and valid for stroke patients. The medical consumption domain was not regarded as a problem domain, but was included to consistently monitor the use of medication and therapy.

A full assessment was intended to identify the complete spectrum of stroke-related problems, allowing effective care to be provided. This assessment tool was primarily developed to assess the presence of stroke-related problems and not intended as a diagnostic instrument or to assess the severity of stroke-related problems. 
Therefore, the assessment tool had no score or score range. The third draft version of the ACAS was translated into English and back-translated to Dutch.

\section{Methods}

\section{Design}

This study is a developmental and feasibility study.

\section{Study participants}

In September 2007, we searched the database of a home care organization for patients living in the community in the region of Maastricht, the Netherlands. We selected stroke patients who would receive long-term care from an SCC within the next two months and were 50 years or older. Caregivers of patients were also asked to participate and both gave informed consent.

\section{Procedure}

The SCCs visited the patients and caregivers at home (called 'the study group') and administered the ACAS according to protocol. The patients, the caregivers and the SCCs received a questionnaire after each home visit to determine the feasibility of the ACAS. The researcher contacted patients and caregivers one week after the home visit, to administer those validated measurement instruments which the SCC had not administered during assessment because they had identified no problems in these domains. This way, all validated measurement instrument were administered to the patients and caregivers, either by the SCC or by the researcher, in order to determine the criterion validity. In addition, fifteen health care professionals (nurses, rehabilitation physician, physiotherapist, speech therapist, general practitioner, member of a patients' association) were asked to evaluate the feasibility and content validity of the ACAS by means of a questionnaire. 


\section{Feasibility}

The questionnaire for patients and caregivers contained items about their general opinion about the assessment, the stepwise assessment approach, duration, relevant or missing items and whether items were too emotional or too personal. The SCCS received questions about problems perceived during administration of the assessment, practical use of the assessment tool, the duration and relevant or missing items. All health care professionals received questions about their general opinion, the protocol and suitability of the assessment. In addition to the questionnaires, the duration of assessment and the problems identified during each assessment were recorded.

\section{Content validity}

Health care professionals received a questionnaire to measure the content validity. They were asked to indicate whether the problem areas were essential to stroke patients and should be included in the assessment. The content validity ratio (CVR) was used to measure the content validity, indicating the agreement between experts' judgments that is unlikely due to chance. The value ranges from -1 to +1 (a positive value means that at least half of the experts rate the problem area as essential). The critical value of the CVR is dependent on the number of experts. ${ }^{21}$

\section{Criterion validity}

To measure the criterion validity, the scores of the brief initial questions and the presence or absence of a problem as indicated by the validated measurement instrument, using predefined cut-off points, were used (BI <15; FAI <30; CLCE-24 = any item scoring 1+; HADS-anxiety >7; HADS-depression >7; FSS >4; CSI >6). The cutoff points were based on the associated norm of the measurement instrument if available, scores of a reference groups or whether the score indicated that the problem was a strain for the patient. These scores were used to calculate the sensitivity and specificity of the assessment tool. 


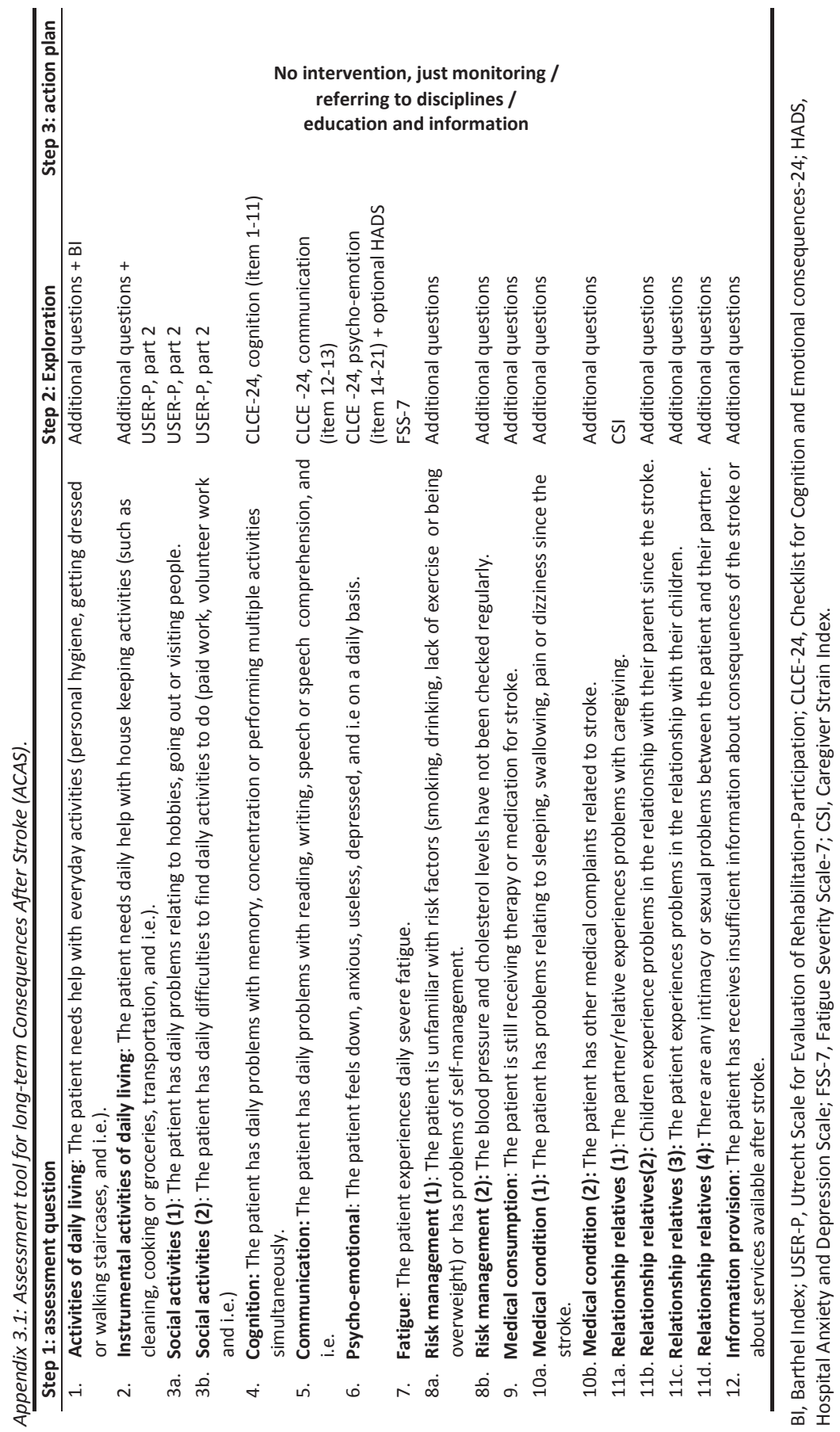




\section{Adjusting the third version and testing it's feasibility in health care}

Based on the outcomes of the study group, some adjustments were made and a fourth draft version was further tested for feasibility in regular health care as part of an intervention study for long-term care for stroke patients (2008-2010). A total of 62 patients participated in the intervention study, who were recently discharged home after hospitalization or inpatient rehabilitation (called the 'health care group'). The SCCs visited the patients at home and administered the assessment tool of which the results were recorded and led to a final version (Appendix 3.1).

\section{Analyses}

Frequencies, means, standard deviations and percentages were used to describe patients' characteristics, the results of the assessment of the study group and the health care group and feasibility of the assessment tool. SPSS (version 18) was used for all statistical analyses.

\section{Ethical considerations}

Both studies were approved by the medical ethics committee of the Maastricht University Medical Centre+.

\section{Results}

\section{Participants}

In the study group, 19 patients and 13 caregivers were asked to participate, and 14 patients and 12 caregivers consented. In the health care group, 62 patients and 41 caregivers participated in the intervention. Table 3.1 shows the characteristics of both groups.

\section{Feasibility}

All included participants of the study group received the assessment, and a total of 87 problems were identified. As shown in table 3.2, the main problem areas were secondary prevention $(\mathrm{N}=12)$, fatigue $(\mathrm{N}=11)$, cognitive problems $(\mathrm{N}=8)$ and lack of 
Table 3.1: Participants' characteristics and outcome of study group and health care group

\begin{tabular}{lll}
\hline Patient characteristics & Study group & Health care group \\
\hline Number & 14 & 62 \\
Gender (male / \%) & $6(43 \%)$ & $32(52 \%)$ \\
Age, mean (SD) & $69.7 \mathrm{y} \cdot(9.1)$ & $72.6 \mathrm{y} .(10.0)$ \\
Discharge from hospital (N/\%) & $7(50 \%)$ & $44(71 \%)$ \\
$\quad$ inpatient rehabilitation (N/\%) & $7(50 \%)$ & $18(29 \%)$ \\
& & \\
Caregiver characteristics & & 41 \\
\hline Number & 12 & $10(24 \%)$ \\
Gender (male /\%) & $5(42 \%)$ & $63.7 \mathrm{y} .(14.5)$ \\
Age mean (SD) & $61.8 \mathrm{y} .(11.2)$ & \\
\hline
\end{tabular}

$\mathrm{N}$, number; SD, standard deviation; $y$, years.

Table 3.2: Results of the assessment of the study group ( $N=14)$ and health care group $(N=62)$

\begin{tabular}{|c|c|c|c|c|}
\hline Assessment characteristics & \multicolumn{2}{|c|}{ Study group } & \multicolumn{2}{|c|}{ Health care group } \\
\hline Assessment since stroke (mean in months + SD) & \multicolumn{2}{|c|}{$5.7(4.8)$} & \multicolumn{2}{|c|}{$1.8(1.5)$} \\
\hline Assessment since discharge home (mean in months $+\mathrm{SD}$ ) & \multicolumn{2}{|c|}{$4.4(4.0)$} & \multicolumn{2}{|c|}{$0.9(1.0)$} \\
\hline about 1 month & \multicolumn{2}{|l|}{5} & \multicolumn{2}{|l|}{54} \\
\hline about 3 months & \multicolumn{2}{|l|}{4} & \multicolumn{2}{|l|}{7} \\
\hline about 6 months & \multicolumn{2}{|l|}{2} & \multicolumn{2}{|l|}{1} \\
\hline about 12 months & \multicolumn{2}{|l|}{3} & \multicolumn{2}{|l|}{ - } \\
\hline Duration of assessment (mean, in minutes + SD) & \multicolumn{2}{|c|}{$85.7(27.5)$} & \multicolumn{2}{|l|}{-} \\
\hline Problems identified & $\mathrm{N}$ & $\%$ & $\mathrm{~N}$ & $\%$ \\
\hline Activities of daily life & 4 & 29 & 16 & 26 \\
\hline Instrumental ADL & 7 & 50 & 39 & 63 \\
\hline Social activities - hobbies & 6 & 43 & 29 & 47 \\
\hline Social activities - daily schedule & 1 & 7 & 11 & 18 \\
\hline Cognition & 8 & 57 & 30 & 48 \\
\hline Psycho-emotional & 3 & 21 & 19 & 31 \\
\hline Communication & 6 & 43 & 24 & 39 \\
\hline Fatigue & 11 & 79 & 49 & 79 \\
\hline Risk management - smoking/drinking & 12 & 86 & 12 & 19 \\
\hline Risk management - blood pressure/cholesterol & 7 & 50 & 24 & 39 \\
\hline Medical condition - sleep/swallow/pain/dizziness & 5 & 36 & 31 & 50 \\
\hline Medical condition - other & 5 & 36 & 14 & 23 \\
\hline Relationship with relatives & 1 & 7 & 7 & 11 \\
\hline Relationship with children & 3 & 21 & 6 & 10 \\
\hline Intimacy with partner & - & - & 3 & 5 \\
\hline Information provision & 8 & 57 & 25 & 40 \\
\hline
\end{tabular}

$\mathrm{N}$, number; SD, standard deviation; $\mathrm{ADL}$, activities of daily life.

information $(\mathrm{N}=8)$. The duration of the assessment ranged from 25 minutes to 130 minutes, with an average of 86 minutes (SD $=27.5$ ). 
Patients and caregivers expressed a favorable opinion of the assessment, considered all problem areas to be relevant and wide-ranging, and indicated that sufficient attention was paid to them during the home visit. One patient reported that the assessment took too long.

The SCCs reported that the assessment tool provided guidance during the home visit and the assessment became easier after some practice. They also commented that they identified problems more easily in a single consult because of the use of the assessment tool. A minor problem was that the SCCS sometimes doubted the presence/absence of a problem.

All health care professionals considered the assessment tool feasible and suitable for use in health care.

\section{Content validity}

Thirteen health care professionals filled in the items about the content validity, which required a minimal CVR value of 0.54 based on the number of experts in our study. ${ }^{21}$ The CVR values ranged between 0.38 and 1.00 (table 3.3). The problem

Table 3.3: The content validity ratio (CVR) of each problem area ( $N=13)$.

\begin{tabular}{lll}
\hline Problem area & Rated as essential (N) & CVR $^{\text {a }}$ \\
\hline Activities of daily life & 13 & 1.0 \\
Instrumental ADL & 11 & 0.69 \\
Social activities & 10 & 0.54 \\
Cognition & 10 & 0.54 \\
Psycho-emotional & 11 & 0.69 \\
Communication & 10 & 0.54 \\
Fatigue & 9 & 0.38 \\
Risk management - smoking/drinking & 10 & 0.54 \\
Risk management - blood pressure/cholesterol & 10 & 0.54 \\
Medical condition & 10 & 0.54 \\
Relationship with relatives & 11 & 0.69 \\
Information provision & 9 & 0.38 \\
\hline
\end{tabular}

$\mathrm{N}$, number; $A D L$, activities of daily life.

a. Critical value is 0.54

domains of fatigue and information provision were below the critical CVR value. Some health care professionals commented that they missed items about falls prevention, problems with children, driving and dizziness. In addition, one 
respondent claimed that the scores of the FAI provided a distorted view of current social activities, because pre-stroke activities were neglected.

\section{Criterion validity}

Table 3.4 shows the scores of the sensitivity and specificity. The sensitivity ranged from $0 \%$ to $100 \%$ and the specificity from $72.7 \%$ to $100 \%$. The sensitivity of the HADS was low, therefore the domain psycho-emotion remained primarily linked with the CLCE-24. The specificity of the FSS and the sensitivity of the CSI could not be calculated, because there were no patients who scored NO on the brief initial question about fatigue and there were no caregivers who scored YES on the brief initial question about caregiver strain. The results of the FAI were disregarded, due to the distorted view.

Table 3.4: The sensitivity and specificity of the assessment tool questions and the corresponding validated measurement instrument

\begin{tabular}{llll}
\hline Assessment questions & Validated measurement instrument & Sensitivity & Specificity \\
\hline Activities of daily life & $\mathrm{BI}$ & $100 \%$ & $100 \%$ \\
Cognition & CLCE-24-cognition & $100 \%$ & $100 \%$ \\
Psycho-emotional & CLCE-24-psycho-emotional & $100 \%$ & $100 \%$ \\
& HADS-anxiety & $33.3 \%$ & $80 \%$ \\
& HADS-depression & $0 \%$ & $72.7 \%$ \\
Communication & CLCE-24-communication & $100 \%$ & $100 \%$ \\
Fatigue & CLCE-24-fatigue & $100 \%$ & $100 \%$ \\
Caregiver Strain & FSS & $87.5 \%$ & $\mathrm{NC}$ \\
\hline
\end{tabular}

$\mathrm{BI}$, Barthel Index; CLCE-24, Checklist for Cognitive and Emotional consequences following stroke-24; HADS, Hospital Anxiety and Depression Scale; FSS, Fatigue Severity Scale, CSI, Caregiver Strain Index; NC, not calculated.

\section{Adjustment of the third version}

Based on these results, the FAI was replaced by the delta FAI, which scores prestroke activities as well as current activities. The experience of dizziness was added to the problem domain of medical condition. The problem domain of fatigue and information provision remained included in the assessment tool, despite their low CVR value, because these problems were the main problem areas of the study group. 


\section{Feasibility in health care}

A total of 339 problems were identified in the health care group (table 3.2). The main problems identified were fatigue $(\mathrm{N}=49)$, instrumental $A D L(N=39)$, medical condition $(\mathrm{N}=31)$ and cognition $(\mathrm{N}=30)$. Based on these assessments, the SCCs offered information $(\mathrm{N}=36)$, home care and social services $(\mathrm{N}=21)$, physical aids and home adjustments $(\mathrm{N}=16)$ and referral to physiotherapist, occupational therapists or speech therapists $(\mathrm{N}=12)$.

\section{Final version (Appendix 3.1)}

Based on the outcome of the health care group, a time factor ('daily') was added to items 2 to 7, after which the questions were better in indicating the presence/absence of a problem. Based on consensus of an expert panel, the deltaFAI was replaced by the USER-P, because it had good reproducibility and accounts for the experience of patients. ${ }^{22}$ In addition, the FSS was replaced by the FSS-7, because it is more valid in stroke patients. ${ }^{23}$

\section{Discussion}

The results of the study showed that the ACAS was considered feasible by patients, caregivers and health care professionals, and seemed to have good content validity and moderate to good criterion validity. The assessment of the study group of 14 patients and of the health care group of 62 patients showed comparable results, except for secondary prevention focused on risk factors. Possibly, the attention for risk factors was more intensive in the health care group, because the time between stroke and assessment was shorter in this group.

The problems identified in this study are different from those reported in the study by Murray and colleagues ${ }^{14}$, as two major problem domains in this present study, fatigue and information provision, were not included in their assessment tool. It is also possible that these differences are related to national differences in health care organisation. ${ }^{24}$ However, both studies indicate the need for a systematic approach to identify a broad spectrum of care demands by stroke patients. Furthermore, the 
evaluations showed that the health care professionals disagreed about the inclusion of the problem domain of fatigue. A large number of patients in the study group as well as the health care group, however, experienced problems of fatigue, which conflict with the experts' judgments. A possible explanation for this conflicting result is that health care professionals are often unaware of the prevalence of fatigue after stroke. $^{25}$

The study poses several limitations and strengths. A limitation of our assessment tool is that we did not measure convergent validity, because of a lack of comparable instruments, nor did we measure the instrument's inter-rater reliability. However, we did evaluate the assessment tool for feasibility in health care, and found that the results were comparable to those in the exploratory study group. Next, we have to consider that although the ACAS was translated using a forward-backward translation procedure, this does not guarantee that the same results will be obtained in an English speaking population. A major strength of the assessment tool is that it is stroke-specific. Another strength is that health care professionals were involved in the development of the first draft of the assessment tool as well as the final version, improving its clinical value. Moreover, tailor-made care to stroke patients can be offered using the stepwise assessment procedure.

Our assessment tool is feasible for use in health care for stroke patients being discharged home. Care professionals who have to perform the assessments should preferably have specialized in stroke care, take a broad view of stroke-related problems and have a good social and medical network. In the current health care system, specialized nurses and nurse practitioners play an important role in the care for chronic patients in primary care and general practice. It might well be that they can also provide the long-term care for stroke patients. Regular monitoring of stroke patients and caregivers will help to detect problems at an early stage and will guide nurses in providing adequate care and preventing more long-term problems. Future research should focus on the effectiveness of regularly monitoring stroke patients by means of a structured assessment, to support the important position of nurses in providing long-term care. 


\section{References}

1. Cramer SC. Changes in motor system function and recovery after stroke. Restor Neurol Neurosci. 2004;22(3-5):231-238.

2. Lightbody CE, Baldwin R, Connolly M, Gibbon B, Jawaid N, Leathley M, et al. Can nurses help identify patients with depression following stroke? A pilot study using two methods of detection. J Adv Nurs. 2007;57(5):505-512. PubMed PMID: 17284278.

3. Morrison V, Pollard B, Johnston M, MacWalter R. Anxiety and depression 3 years following stroke: demographic, clinical, and psychological predictors. J Psychosom Res. 2005 Oct;59(4):209-213. PubMed PMID: 16223623.

4. Patel MD, Tilling K, Lawrence E, Rudd AG, Wolfe CD, McKevitt C. Relationships between long-term stroke disability, handicap and health-related quality of life. Age Ageing. 2006 May;35(3):273-279. PubMed PMID: 16638767.

5. Scholte op Reimer WJ, de Haan RJ, Rijnders PT, Limburg M, van den Bos GA. The burden of caregiving in partners of long-term stroke survivors. Stroke. 1998 Aug;29(8):1605-1611. PubMed PMID: 9707201.

6. Visser-Meily JM, van den Bos GA, Kappelle LJ. Better acute treatment induces more investments in chronic care for stroke patients. Int J Stroke. 2009 Oct;4(5):352-353. PubMed PMID: 19765123.

7. van den Bos GA, Triemstra AH. Quality of life as an instrument for need assessment and outcome assessment of health care in chronic patients. Qual Health Care. 1999 Dec;8(4):247-252. PubMed PMID: 10847887.

8. Whitford DL, Hickey A, Horgan F, O'Sullivan B, McGee H, O'Neill D. Is primary care a neglected piece of the jigsaw in ensuring optimal stroke care? Results of a national study. BMC family practice. 2009;10:27. PubMed PMID: 19402908. eng.

9. Ellis G, Mant J, Langhorne P, Dennis M, Winner S. Stroke liaison workers for stroke patients and carers: an individual patient data meta-analysis. Cochrane Database Syst Rev. 2010 (5):CD005066. PubMed PMID: 20464736.

10. Murray J, Forster A, Young J. Survey to investigate the role of the community stroke care coordinator. Br J Community Nurs. 2008 Jan;13(1):31-36. PubMed PMID: 18399369.

11. Reynolds T, Thornicroft G, Abas M, Woods B, Hoe J, Leese M, et al. Camberwell Assessment of Need for the Elderly (CANE). Development, validity and reliability. Br J Psychiatry. 2000 May;176:444-452. PubMed PMID: 10912220.

12. van Heugten C, Rasquin S, Winkens I, Beusmans G, Verhey F. Checklist for cognitive and emotional consequences following stroke (CLCE-24): development, usability and quality of the self-report version. Clin Neurol Neurosurg. 2007 Apr;109(3):257-262. PubMed PMID: 17126480.

13. Edwards DF, Hahn MG, Baum CM, Perlmutter MS, Sheedy C, Dromerick AW. Screening patients with stroke for rehabilitation needs: validation of the poststroke rehabilitation guidelines. Neurorehabil Neural Repair. 2006 Mar;20(1):4248. PubMed PMID: 16467277. 
14. Murray J, Young J, Forster A, Herbert G, Ashworth R. Feasibility study of a primary care-based model for stroke aftercare. Br J Gen Pract. 2006 Oct;56(531):775-780. PubMed PMID: 17007708.

15. de Haan R, Limburg M, Schuling J, Broeshart J, Jonkers L, van Zuylen P. [Clinimetric evaluation of the Barthel Index, a measure of limitations in dailly activities]. Ned Tijdschr Geneeskd. 1993 May 1;137(18):917-921. PubMed PMID: 8492836. Klinimetrische evaluatie van de Barthel-index, een maat voor beperkingen in het dagelijks functioneren.

16. Post MW, de Witte LP. Good inter-rater reliability of the Frenchay Activities Index in stroke patients. Clin Rehabil. 2003 Aug;17(5):548-552. PubMed PMID: 12952162.

17. Schuling J, de Haan R, Limburg M, Groenier KH. The Frenchay Activities Index. Assessment of functional status in stroke patients. Stroke. 1993 Aug;24(8):11731177. PubMed PMID: 8342192.

18. Mondolo F, Jahanshahi M, Grana A, Biasutti E, Cacciatori E, Di Benedetto P. The validity of the hospital anxiety and depression scale and the geriatric depression scale in Parkinson's disease. Behav Neurol. 2006;17(2):109-115. PubMed PMID: 16873922.

19. Kleinman L, Zodet MW, Hakim Z, Aledort J, Barker C, Chan K, et al. Psychometric evaluation of the fatigue severity scale for use in chronic hepatitis C. Qual Life Res. 2000;9(5):499-508. PubMed PMID: 11190005.

20. van Exel NJ, Scholte op Reimer WJ, Brouwer WB, van den Berg B, Koopmanschap $M A$, van den Bos GA. Instruments for assessing the burden of informal caregiving for stroke patients in clinical practice: a comparison of CSI, CRA, SCQ and selfrated burden. Clin Rehabil. 2004 Mar;18(2):203-214. PubMed PMID: 15053130.

21. Lawshe $\mathrm{CH}$. A quantitative approach to content validity. Personnel Psychology. 1975;28(4):563-575.

22. van der Zee $\mathrm{CH}$, Priesterbach AR, van der Dussen L, Kap A, Schepers VP, VisserMeily JM, et al. Reproducibility of three self-report participation measures: The ICF Measure of Participation and Activities Screener, the Participation Scale, and the Utrecht Scale for Evaluation of Rehabilitation-Participation. Journal of rehabilitation medicine : official journal of the UEMS European Board of Physical and Rehabilitation Medicine. 2010 Sep;42(8):752-757. PubMed PMID: 20809057.

23. Lerdal A, Kottorp A. Psychometric properties of the Fatigue Severity Scale-Rasch analyses of individual responses in a Norwegian stroke cohort. International journal of nursing studies. 2011 Oct;48(10):1258-1265. PubMed PMID: 21414620.

24. Boter H, de Haan RJ, Rinkel GJ. Regional differences in the use of out-patient services by stroke patients after hospitalisation. Eur Neurol. 2005;53(1):10-14. PubMed PMID: 15627774.

25. Crosby GA, Munshi S, Karat AS, Worthington E, Lincoln NB. Fatigue after stroke: frequency and effect on daily life. Disability and rehabilitation. 2012;34(8):633637. PubMed PMID: 21978259. Epub 2011/10/08. eng. 
64 | Chapter 3: Development and preliminary testing of ACAS 


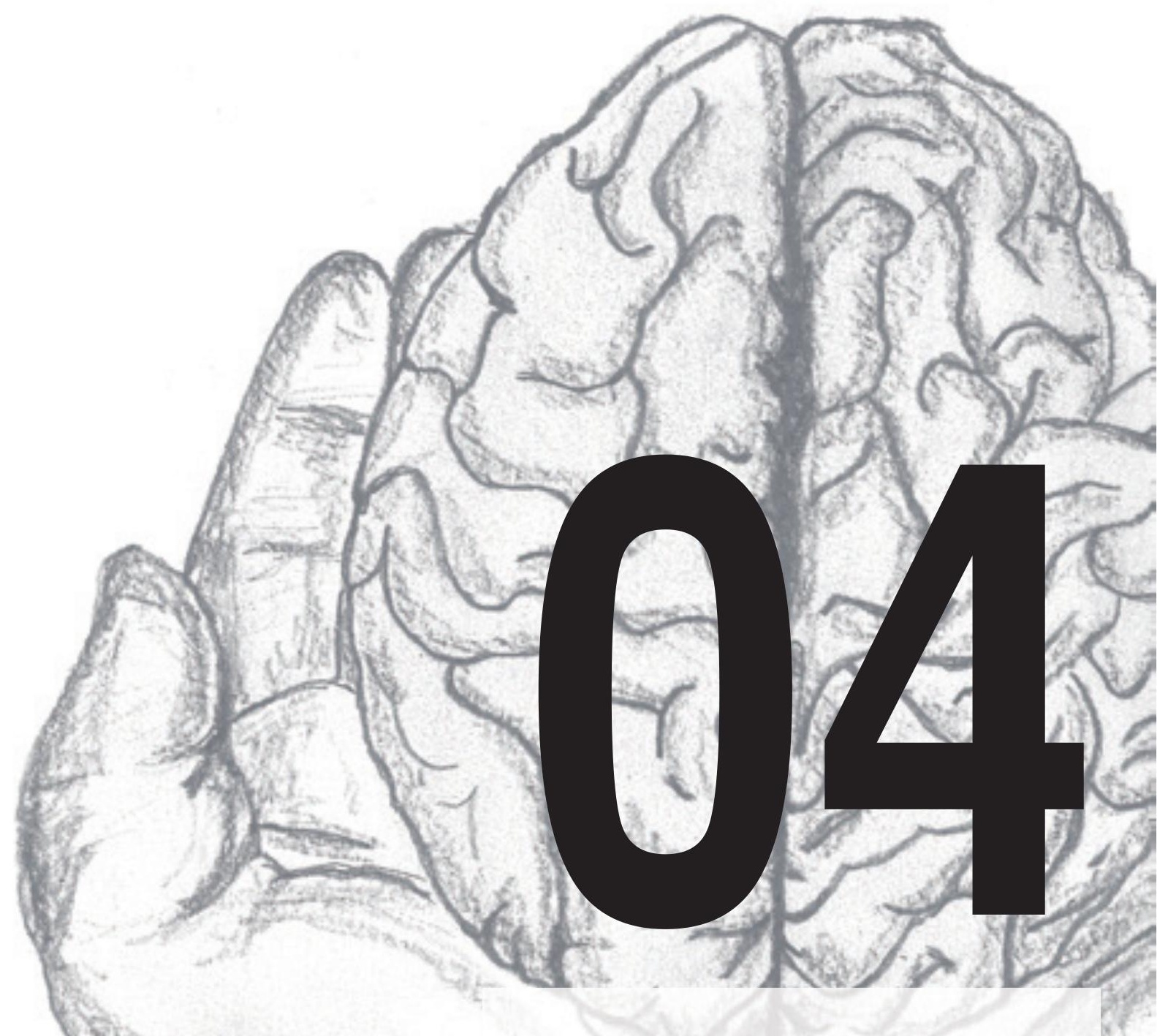

Effect of a stroke-specific follow-up care model on the quality of life of stroke patients and caregivers; a controlled trial

Manon Fens, Caroline van Heugten, George Beusmans, Job Metsenmakers, Arnold Kester \& Martien Limburg (2014), Journal of Rehabillitation medicine, 26(1),

7-15. doi: 12.2340/16501977-1239 


\begin{abstract}
Objective: To evaluate the effectiveness of a stroke-specific follow-up care model on quality of life for stroke patients, being discharged home, and their caregivers. Design: A non-randomized, controlled trial, comparing an intervention group with a control group (usual care). Subjects: Stroke patients and their caregivers. Methods: Intervention involved 5 home visits by a stroke care coordinator over a period of 18 months, using a structured assessment tool. Outcome measures were conducted at baseline (T0) and every 6 months thereafter (T6, T12 and T18) in the domains of quality of life (primary), activities of daily living, social activities, depression, anxiety and caregiver strain. Results: The intervention group $(\mathrm{N}=62)$ had significantly increased its social activities after 18 months, whereas the control group $(N=55)$ showed significantly decreased levels of social activities. In the first 6 months, levels of depression decreased significantly in caregivers of the intervention group. No differences were found for quality of life and the other outcome measures. Conclusion: The intervention was not effective in improving quality of life, but was effective in improving levels of social activities. The intervention may have been focused too much on screening for stroke-related problems and not as much on adequate follow-up care and referral.
\end{abstract}

Keywords: stroke, follow-up studies, long-term care, needs assessment, quality of life 


\section{Introduction}

Stroke survivors often experience problems in many different areas of functioning after being discharged home after hospitalization or inpatient rehabilitation. Stroke patients can have physical limitations ${ }^{1}$, but cognitive and emotional problems can also occur ${ }^{2,3}$, which can lead to limitations in daily life and social activities. ${ }^{4}$ The lives of their caregivers can also be affected by the consequences of the stroke, as they often take partial or full responsibility for care provision, which can lead to caregiver burden or depression. ${ }^{5}$ These stroke-related problems are mostly long-lasting, requiring the provision of chronic care to patients and their caregivers. ${ }^{6}$ However, suitable long-term care is often lacking. New problems can emerge over time when patients no longer have contact with stroke care professionals.

Chronic care for stroke patients is complex because of the many domains of functioning affected, the occurrence of new problems over time, and the involvement of many different stroke care professionals. There does not currently seem to be consensus about the organization of chronic care services. In addition, patients are often unaware that certain problems may be stroke-related and therefore do not seek specific help. ${ }^{7}$ We believe that all stroke patients should be monitored regularly for more than 1 year after being discharged home and that those with needs should receive suitable follow-up care.

With regard to type of care, several researchers have highlighted the importance of regularly monitoring stroke patients for issues other than somatic complaints, such as cognitive, psychological and social functioning. ${ }^{6,7}$ This may be achieved by using a comprehensive assessment tool covering all stroke-related problems to detect the needs of stroke patients and their caregivers. Such an assessment was developed by Murray and colleagues ${ }^{8}$, but this tool cannot yet be recommended for clinical use. The person carrying out the assessment, should preferably have sufficient knowledge of stroke, and the care professional should be able to provide multifaceted stroke care and be able to work with a multidisciplinary team. The preferred care professionals for this type of care might be general practitioners (GPs), but stroke 
care coordinators and social liaison workers can also provide equal or even better care than GPs on a wide range of chronic health problems. ${ }^{9}$

The provision of this multifaceted care, considering the many affected functions, should be organized in a multidisciplinary system. This aspect had been studied more during the last 10 years. There are many studies investigating the effectiveness of multidisciplinary care for stroke patients at home. Only a few interventions however, were effective ${ }^{10,11}$, and these were very heterogeneous in terms of care provider, type of care provided and duration of care provision, and no specific factors can be identified that contributed to their effectiveness.

\section{Aims and hypothesis}

To our knowledge, there have been no studies evaluating a model of chronic care for stroke patients and their caregivers that included all the important long-term care aspects as described above; regular monitoring, use of an assessment tool, coordinating follow-up care by a single health care professional, multidisciplinary care and follow-up care for more than 1 year. We therefore developed a new longterm care model for stroke patients and caregivers living at home after hospitalization or inpatient rehabilitation. This model involved the availability of long-term care for all stroke patients. A coordinating stroke care professional who collaborates with a multidisciplinary team, provided a structured assessment procedure by using an assessment tool, including 5 regular home visits over a period of 18 months leading to further follow-up care (such as advice, healthcare facilities and physical aids) or referral to other healthcare professionals (such as a physiotherapist or an occupational therapist). The present study evaluated the effectiveness of this long-term care model in terms of the quality of life (QoL) of stroke patients and their caregivers. We expected that the QoL (primary outcome) would be higher and more improved in the group of patients and caregivers receiving the intervention (i.e. according to our chronic care model) than in the control group receiving care as usual. We also expected a difference in favor of the intervention 
group in terms of the secondary outcome domains of daily life functioning, social activities, emotional functioning and caregiver's burden.

\section{Methods}

\section{Design}

The study used a non-randomized, controlled trial design, comparing 2 regional stroke services (intervention vs. control) over a period of 18 months. No changes to the methods were made ad5fter trial commencement.

\section{Study participants}

Consecutive stroke patients being discharged home from hospital or inpatient rehabilitation in the regions of Maastricht (intervention) and Eindhoven (control), both in the Netherlands, were eligible for participation in the study. Participants of the intervention group were included between 14 April 2008 and 31 December 2009, and participants of the control group were included between 1 September 2008 and 30 June 2010. Inclusion criteria were: a diagnosis of stroke (confirmed by a neurologist); aged 50 years or older; living in the catchment area of the regional home care organization; and having sufficient command of Dutch. Exclusion criteria for patients were living in a nursing home before the stroke and a life expectancy of less than 3 months. The caregivers of the stroke patients were also asked to participate, based on the following criteria; being the primary caregiver of the stroke patient, being 18 years or older and having sufficient command of Dutch. The followup measurements were ended if the patient or caregiver refused to participate further, or if the patient moved to a nursing home or outside of the catchment area of the home care organization.

\section{Intervention}

The model for long-term care after stroke was developed for the Maastricht region, involving the following elements. All stroke patients were referred to a stroke care coordinator (SCC) after being discharged home from hospital or inpatient 
rehabilitation. The SCCs were nurses from home care services specialized in stroke. The SCC visited the stroke patients at home 1-2 weeks and 3, 6, 12 and 18 months after discharge. More home visits were offered as needed. During each home visit the SCC administered a structured assessment tool (which we developed for the study) to assess a broad spectrum of stroke-related problems (activities of daily living, instrumental activities of daily living, social activity, cognition, communication, psycho-emotion, fatigue, secondary prevention, medical consumption, medical condition, caregivers' strain and provision of information). Based on these assessments, the SCC provided suitable follow-up care during the home visits, such as giving information and advice or referred the patient to physiotherapists, occupational therapists and other healthcare professionals. After each home visit the SCC sent a written report to the patient's general practitioner. The SCC could consult a multidisciplinary team of the nursing home (physician, physiotherapist, occupational therapist, speech therapist, social worker and psychologist) for advice as needed. The actual care for the included patients was recorded during the study period.

\section{Control}

The participants of the control group received the usual care provided in the Eindhoven region. Stroke patients with few or no residual effects were discharged home without follow-up care. Patients with more severe residual effects were discharged home and referred to a SCC of the home care service or of the stroke aftercare center. Patients who were referred to the SCC of the home care service received their first home visit 6 weeks after being discharged home. Patients referred to the stroke aftercare center had their first consult with a SCC at the center after 3 months. Subsequently, one or more home visits or consultations could be provided as needed. No structured assessment procedure and pre-defined follow-up measurements were available. The actual care for the included patients was recorded during the study period. 


\section{Procedure}

Shortly after being discharged home from hospitalization or inpatient rehabilitation, a SCC or nurse recruited the patient and their caregiver for the study. Patients and caregivers who agreed to participate were asked to give informed consent. After consent, patients and their caregivers were interviewed by the researcher to administer the outcome measures at baseline. The first interview with the researcher was arranged within 2-4 weeks at the patient's home after being discharged home (T0) and 6 (T6), 12 (T12) and 18 months (T18) later. The measurements of the study were performed independently and unrelated to the home visits of the care model, but they could affect each other, considering the time periods of the home visits and the study measurements. Medical records of the hospital were explored to gather information about the stroke and previous stroke history. This study was approved by the medical ethics committee of the Maastricht University Medical Centre.

\section{Outcome measures}

The primary outcome measure for patients was the Stroke Adapted Sickness Impact Profile-30 (SASIP-30) as a measure of QoL (0-30; $\geq 10$ representing reduced QoL). ${ }^{12}$ Secondary outcome measures were the Barthel Index (BI) to measure activities of daily living $(A D L)^{13}(0-20 ;<10$ representing $A D L$ dependency), the Frenchay Activities Index (FAl) to measure social activities ${ }^{14}$ (0-45; 0-15 representing inactivity), and the Hospital Anxiety Depression Scale (HADS) to measure depression and anxiety ${ }^{15}$ (0-21; $\geq 11$ representing depression or anxiety disorder). The primary outcome measure for caregivers was the Life Satisfaction questionnaire-9 (LiSAT-9) as a measure of the QoL (1-9; no norms were available, therefore we used the reference values of stroke patients of a study with a mean of 4.5 and standard deviation of 0.8 ; a higher score representing greater satisfaction). ${ }^{16}$ The secondary outcome measures were the HADS and the Caregivers Strain Index (CSI) to measure caregiver's burden ${ }^{17}(0-13 ;>7$ representing caregiver's strain). All measures have good reliability and validity. No outcome measures were changed after trial commencement. 


\section{Statistical analysis}

Means, standard deviations or percentages were used to describe participants' and disease characteristics. Differences in these characteristics between the intervention and control group were analyzed by independent samples t-tests and $x^{2}$ tests, where appropriate. Non-parametric tests were used, in case normality assumptions were violated, by which medians and percentiles were presented. To determine the effects of the intervention, mean change scores were calculated using baseline measures as a reference. Due to skewed distributions and a small number of participants, the median change scores were presented. Differences in median change scores were tested using Mann-Whitney U-tests. In addition, within group differences were analyzed using Wilcoxon signed rank-tests. Patients and caregivers were included in the analyses when they had taken part in one or more follow-up measurements.

To check for possible confounding, participant characteristics were entered as covariates in linear regression analyses where the mean change score was the dependent variable and the group was the primary independent variable, for each follow-up measurement. The influences of the following patient characteristics were checked stepwise for confounding: sex, age, comorbidity, marital status, education, type of stroke, institution of discharge, and time between stroke and discharge. The following caregiver characteristics were checked stepwise for confounding: sex, age, number of hours of caregivers' activities, relationship, and education. A variable was considered a strong confounder when inclusion of the variable in the linear regression model changed the coefficient of the independent variable group by more than half of its standard error. When the covariate was not a strong confounder, the covariate was removed and other covariates were entered in the model. When a confounder was identified at one of the 3 mean change scores (T6-TO, T12-T0 or T18T0) of a dependent variable, a correction was applied to all 3 mean change scores of this dependent variable. 
Figure 4.1: Flow-diagram of the inclusion of stroke patients and the follow-up measurements

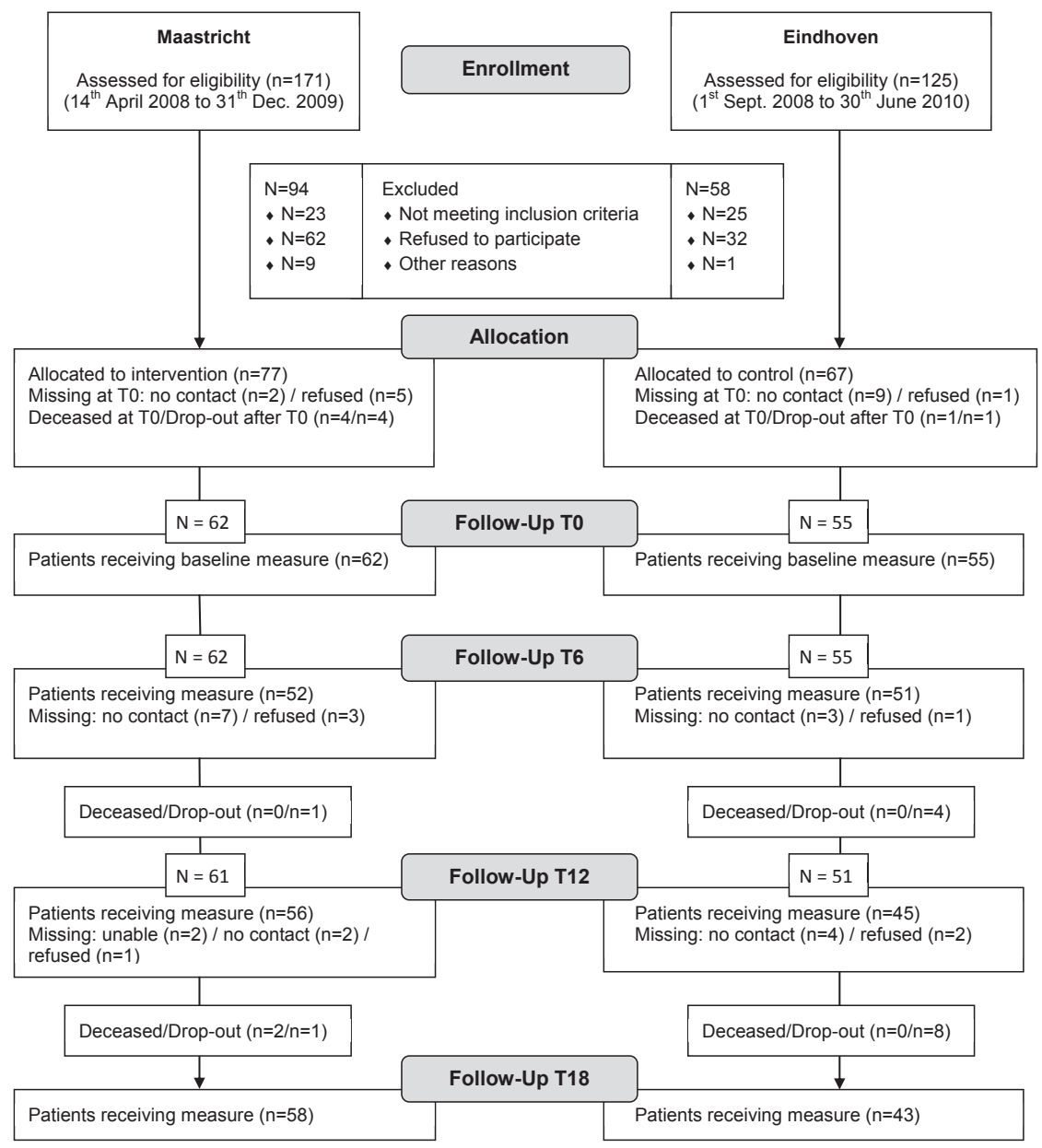

A power calculation, assuming an independent samples t-test, indicated a minimal sample size of 76 patients per group to obtain a power of $80 \%$ for an effect size of 0.5 on the scores of the SASIP-30 (medium effect)18, with 2-sided alpha of 0.05. This calculation accounts for an expected drop-out rate of 15\%. SPSS (version 18) was used for all statistical analyses. Two sided p-values smaller than 0.05 were considered significant. 
Figure 4.2: Flow-diagram of the inclusion of caregivers and the follow-up measurements

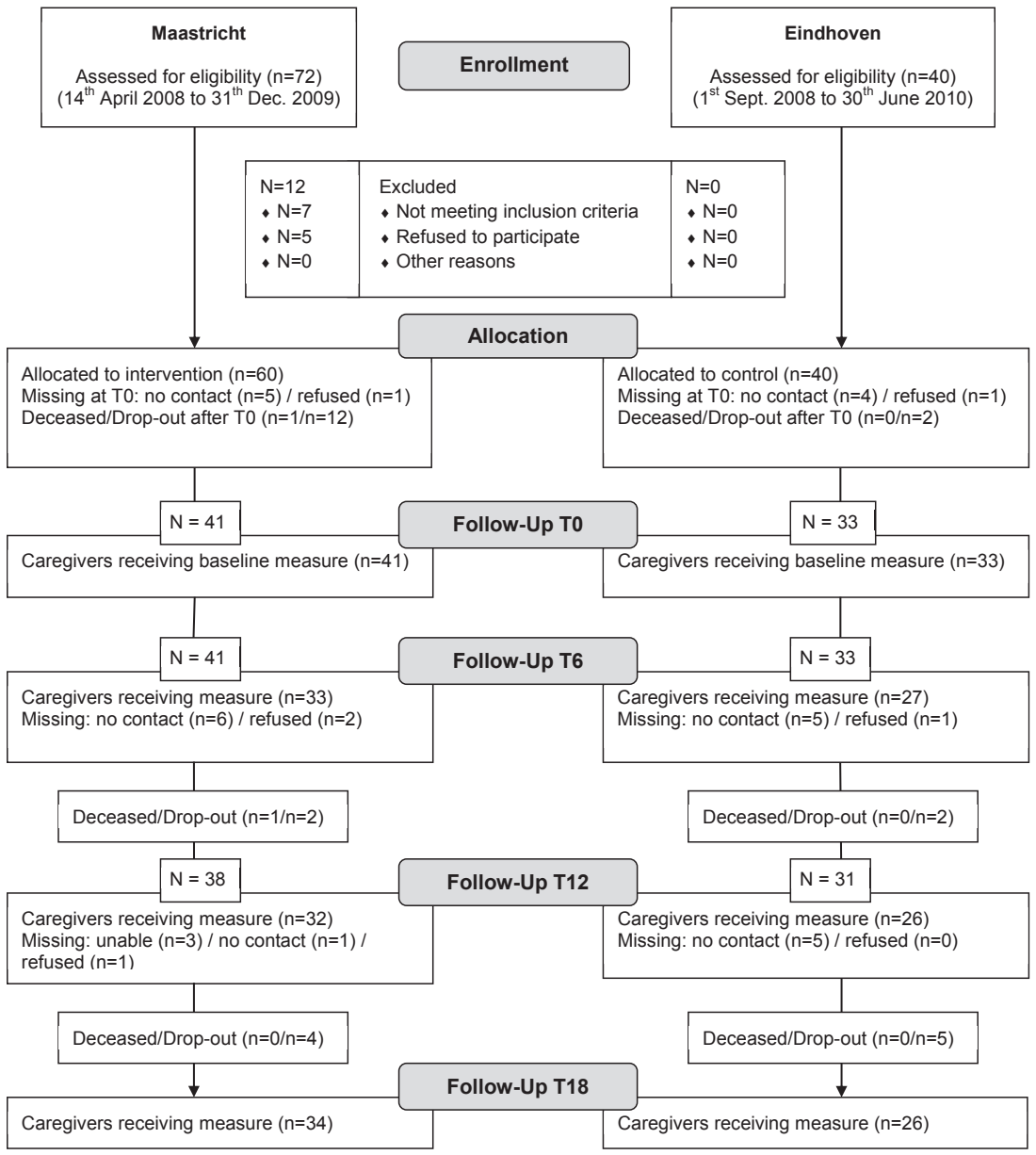

\section{Results}

\section{Participant's characteristics}

In the Maastricht region, the results of 62 patients and 41 caregivers were included in the analyses. In the Eindhoven region, the results of 55 patients and 33 caregivers were included in the analyses. Figure 4.1 shows the inclusion process of the patients and their follow-up measurements and figure 4.2 presents the inclusion process and follow-up measurements of the caregivers. Patient characteristics are given in table 4.1. The patients in the intervention group had more comorbidity than the control group, particularly with regard to locomotor apparatus. 
Table 4.1: Patients' characteristics

\begin{tabular}{|c|c|c|c|c|}
\hline & & Intervention & Control & p-value \\
\hline Number & & 62 & 55 & \\
\hline Age & (mean in years $+S D$ ) & $72.7(10.0)$ & $71.1(8.4)$ & $0.364(t)$ \\
\hline Gender & (male/\%) & 32 / $51.6 \%$ & $31 / 56.4 \%$ & $0.607\left(X^{2}\right)$ \\
\hline \multirow[t]{2}{*}{ Time since stroke } & (median in months) & 2.0 & 1.0 & $0.955(U)$ \\
\hline & (IQR) & $1-3$ & $1-3$ & \\
\hline \multirow{2}{*}{$\begin{array}{l}\text { Marital status } \\
(\mathrm{N} / \%)\end{array}$} & Couple & 32 / 51.6\% & 32 / $58.2 \%$ & $0.476\left(X^{2}\right)$ \\
\hline & Single & 30 / 48.4\% & 23 / 41.8\% & \\
\hline \multirow[t]{4}{*}{ Education (N/\%) } & Low & $29 / 47.5 \%$ & 23 / 41.8\% & \\
\hline & Middle & $21 / 34.4 \%$ & 19 / 34.5\% & $0.722\left(X^{2}\right)$ \\
\hline & High & $11 / 18.1 \%$ & $13 / 23.6 \%$ & \\
\hline & Missing (N) & 1 & - & \\
\hline \multirow[t]{4}{*}{ Stroke type (N/\%) } & Infarction & $51 / 82.3 \%$ & 48 / 90.6\% & $0.199\left(X^{2}\right)$ \\
\hline & Bleeding & $11 / 17.7 \%$ & $5 / 9.4 \%$ & \\
\hline & Missing $(\mathrm{N})$ & - & 2 & \\
\hline & Thrombolysis & $9 / 14.8 \%$ & $8 / 14.5 \%$ & $0.993\left(X^{2}\right)$ \\
\hline \multirow{4}{*}{$\begin{array}{l}\text { Stroke location } \\
\text { (N/\%) }\end{array}$} & Left hemisphere & $26 / 41.9 \%$ & 27 / 50.0\% & \\
\hline & Right hemisphere & $24 / 38.7 \%$ & 22 / $40.7 \%$ & $0.294\left(X^{2}\right)$ \\
\hline & Others & 12 / 19.4\% & $5 / 9.3 \%$ & \\
\hline & Missing $(N)$ & - & 1 & \\
\hline \multirow{7}{*}{$\begin{array}{l}\text { Previous history } \\
(\mathrm{N} / \%)\end{array}$} & Patients with other diseases & $51 / 83.6 \%$ & 37 / 67.3\% & $0.040\left(X^{2}\right)$ \\
\hline & Cardiovascular diseases & $24 / 38.7 \%$ & $18 / 32.7 \%$ & $0.233\left(X^{2}\right)$ \\
\hline & Locomotor apparatus & $16 / 25.8 \%$ & $3 / 5.5 \%$ & $0.001\left(X^{2}\right)$ \\
\hline & Previous cerebrovascular event & $8 / 12.9 \%$ & $8 / 14.5 \%$ & $0.823\left(X^{2}\right)$ \\
\hline & Pulmonary diseases & $5 / 8.1 \%$ & $7 / 12.7 \%$ & $0.540\left(X^{2}\right)$ \\
\hline & Diabetes & $5 / 8.1 \%$ & $7 / 12.7 \%$ & $0.479\left(X^{2}\right)$ \\
\hline & Patient $>1$ other diseases & $25 / 40.3 \%$ & 16 / 29.6\% & $0.006(U)$ \\
\hline \multirow{2}{*}{$\begin{array}{l}\text { Discharged from } \\
(\mathrm{N} / \%)\end{array}$} & Hospital & $44 / 71.0 \%$ & 47 / $85.5 \%$ & \\
\hline & Inpatient rehabilitation & $18 / 29.0 \%$ & $8 / 14.5 \%$ & $0.060\left(X^{2}\right)$ \\
\hline \multicolumn{5}{|l|}{ Baseline outcome } \\
\hline \multicolumn{5}{|l|}{ Primary outcome } \\
\hline \multirow[t]{4}{*}{ SASIP-30 } & $\mathrm{N}$ & 61 & 55 & \\
\hline & Median & 8.0 & 6.0 & $0.135(U)$ \\
\hline & IQR & $5-13$ & $3-6$ & \\
\hline & $\mathrm{N} / \%$ above cut-off score $(\geq 10)$ & $26 / 41.9 \%$ & 17 / 30.9\% & \\
\hline \multicolumn{5}{|c|}{ Secondary outcome } \\
\hline \multirow[t]{4}{*}{$\mathrm{BI}$} & $\mathrm{N}$ & 62 & 55 & \\
\hline & Median & 20.0 & $20.0(5-20)$ & $0.267(U)$ \\
\hline & IQR & $18.5-20$ & $19-20$ & \\
\hline & $\mathrm{N} / \%$ below cut-off score $(<10)$ & $4 / 6.5 \%$ & $1 / 1.8 \%$ & \\
\hline \multirow[t]{4}{*}{ FAI } & $\mathrm{N}$ & 62 & 55 & \\
\hline & Median & 17.5 & 27.0 & $<0.001(U)$ \\
\hline & IQR & $9-25$ & $20-32$ & \\
\hline & $\mathrm{N} / \%$ below cut-off score $(\leq 15)$ & $25 / 40.3 \%$ & $6 / 10.9 \%$ & \\
\hline \multirow[t]{4}{*}{ HADS anxiety } & $\mathrm{N}$ & 61 & 55 & \\
\hline & Median & 4.0 & 4.0 & $0.643(U)$ \\
\hline & IQR & $1-8$ & $2-7$ & \\
\hline & $\mathrm{N} / \%$ above cut-off score $(\geq 11)$ & $4.0 / 6.5 \%$ & $5 / 9.1 \%$ & \\
\hline
\end{tabular}




\begin{tabular}{llccc}
\hline HADS depression & $\mathbf{N}$ & 61 & $\mathbf{5 5}$ & \multirow{2}{*}{$0.376(\mathrm{U})$} \\
& Median & 4.0 & 3.0 & \\
& IQR & $2-7.5$ & $2-7$ & \\
& N/\% above cut-off score $(\geq 11)$ & $5.0 / 8.1 \%$ & $3 / 5.5 \%$ & \\
\hline
\end{tabular}

SD, standard deviation; $t$, t-test; $\mathrm{X}^{2}$, chi-square test; $\mathrm{U}$, Mann-Whitney $\mathrm{U}$ test; $\mathrm{n}$, number; SASIP-30, Stroke Adapted Sickness Impact Profile-30; BI, Barthel Index; FAI, Frenchay Activities Index; HADS, Hospital Anxiety Depression Scale; IQR, interquartile range.

Table 4.2 summarizes the caregiver characteristics and showed that caregivers in the control region provided more care regarding transfer and mobility to stroke patients than caregivers in the intervention region. There were no differences found in the baseline characteristics and scores of the dropped-out patients.

Table 4.3 shows the 6 major problems that were identified using the structured assessment tool by the SCC during the follow-up visits in the intervention group. Fatigue, cognitive complaints and instrumental activities of daily living problems were mentioned by more than half of the patients during the first 2 visits in the first 6 months and by more than one-third of the patients at later visits.

Table 4.3: The six major problems identified during the follow-up home visits

\begin{tabular}{lccccc}
\hline & & \multicolumn{4}{c}{ months } \\
& $0-1$ & $2-4$ & $5-7$ & $11-13$ & $17-19$ \\
& $\%$ & $\%$ & $\%$ & $\%$ & $\%$ \\
\hline Fatigue & 78 & 64 & 44 & 48 & 39 \\
Instrumental ADL & 61 & 61 & 41 & 41 & 28 \\
Medical status & 50 & 43 & 32 & - & 28 \\
Cognition & 46 & 50 & 29 & 38 & 33 \\
Social activity & 46 & 50 & - & 41 & \\
Lack of information & 41 & - & - & - & - \\
Communication & - & 43 & 24 & 38 & 33 \\
ADL & - & - & 29 & - & - \\
Psycho-emotional & - & - & - & 34 & 17 \\
\hline
\end{tabular}

ADL: activities of daily living

\section{Received care}

Patients in the intervention group received a mean of 3.9 home visits and $11 \%$ received care longer than 18 months. In the control group, 30 patients received no follow-up care, 15 patients received care from the SCCs (mean 2.4 home visits over a 
Table 4.2: Caregivers' characteristics

\begin{tabular}{|c|c|c|c|c|}
\hline & & Intervention & Control & p-value \\
\hline Number & & 41 & 33 & \\
\hline Age & (mean in years + SD) & $63.7(14.5)$ & $64.9(11.1)$ & $0.638(t)$ \\
\hline Gender & (male/\%) & $10 / 24.4 \%$ & $9 / 27.3 \%$ & $0.097\left(X^{2}\right)$ \\
\hline \multirow[t]{3}{*}{ Relationship (N/\%) } & Spouse & $29 / 70.7 \%$ & 27 / $81.8 \%$ & \\
\hline & Child & $9 / 22 \%$ & $5 / 15.2 \%$ & - \\
\hline & Other & $3 / 7.3 \%$ & $1 / 3 \%$ & \\
\hline \multirow[t]{2}{*}{ Marital status (N/\%) } & Couple & $35 / 85.4 \%$ & $29 / 87.9 \%$ & - \\
\hline & Single & $6 / 14.6 \%$ & 4 / $12.1 \%$ & \\
\hline \multirow[t]{3}{*}{ Education (N/\%) } & Low & $17 / 41.5 \%$ & $10 / 30.3 \%$ & \\
\hline & Middle & 17 / $41.5 \%$ & 14 / $42.4 \%$ & $0.471\left(X^{2}\right)$ \\
\hline & High & $7 / 17.1 \%$ & $9 / 27.3 \%$ & \\
\hline \multirow[t]{2}{*}{ Caregivers' activities } & Hours a week (median) & 10 & 8.5 & $0.677(U)$ \\
\hline & IQR & $4.8-17.5$ & $1-18.8$ & \\
\hline Type of activity & Personal care & $10 / 24.4 \%$ & $5 / 15.2 \%$ & $0.359\left(X^{2}\right)$ \\
\hline \multirow[t]{4}{*}{ performed (N/\%) } & Mobility and transport & $20 / 48.8 \%$ & $24 / 72.7 \%$ & $0.006\left(X^{2}\right)$ \\
\hline & House holding activities & $26 / 63.4 \%$ & $22 / 66.7 \%$ & $0.502\left(X^{2}\right)$ \\
\hline & Finances and mail & $14 / 34.1 \%$ & $16 / 48.5 \%$ & $0.132\left(X^{2}\right)$ \\
\hline & Others & $6 / 14.6 \%$ & $1 / 3.0 \%$ & - \\
\hline \multicolumn{5}{|l|}{ Baseline outcome } \\
\hline \multicolumn{5}{|l|}{ Primary outcome } \\
\hline \multirow{4}{*}{ LiSAT-9 } & $\mathrm{N}$ & 41 & 33 & \\
\hline & Median & 4.9 & 5.1 & $0.036(U)$ \\
\hline & IQR & $4-5.2$ & $4.8-5.4$ & \\
\hline & $\mathrm{N} / \%$ below cut-off score $(<4.5)$ & $14 / 34.1 \%$ & $4 / 12.1 \%$ & \\
\hline \multicolumn{5}{|l|}{ Secondary outcome } \\
\hline \multirow[t]{4}{*}{ HADS anxiety } & $\mathrm{N}$ & 41 & 33 & \\
\hline & Median & 5.0 & 3.0 & $0.003(U)$ \\
\hline & IQR & $3-9$ & $1-6$ & \\
\hline & $\mathrm{N} / \%$ above cut-off score $(\geq 11)$ & $5 / 12.2 \%$ & $4 / 12.1 \%$ & \\
\hline \multirow[t]{4}{*}{ HADS depression } & $\mathrm{N}$ & 41 & 33 & \\
\hline & Median & 4.0 & 2.0 & $0.035(U)$ \\
\hline & IQR & $2-7$ & $0.5-5$ & \\
\hline & $\mathrm{N} / \%$ above cut-off score $(\geq 11)$ & $6 / 14.6 \%$ & $2 / 6.1 \%$ & \\
\hline \multirow[t]{4}{*}{ CSI } & $\mathrm{N}$ & 37 & 33 & \\
\hline & Median & 4.0 & 4.0 & \\
\hline & IQR & $1-6$ & $1-6.5$ & $0.781(U)$ \\
\hline & $\mathrm{N} / \%$ above cut-off score $(\geq 7)$ & $7 / 18.9 \%$ & $8 / 24.2 \%$ & \\
\hline
\end{tabular}

$\mathrm{SD}$, standard deviation; $\mathrm{t}$, t-test; $\mathrm{X}^{2}$, chi-square test; $\mathrm{N}$, number; $\mathrm{U}$, Mann-Whitney $\mathrm{U}$ test; LiSAT-9, Life Satisfaction questionnaire-9; HADS, Hospital Anxiety Depression Scale; CSI, Caregivers Strain Index.

mean period of 5.5 months) and 10 patients received care from the stroke aftercare center (mean 1.1 consults over a mean period of 3.5 months). 


\section{Primary outcome}

Patients. Table 4.4 lists the median scores of the patients in both groups, for each follow-up measurement. The intervention group had a higher score on the SASIP than the control group at 18 months follow-up, although the difference was not significant. Median change scores showed a decline over time in both groups on the SASIP, but the difference between the 2 groups regarding these changes was not significant (T6-T0, $\mathrm{p}=0.055$; T12-T0, $\mathrm{p}=0.354$; T18-T0, $\mathrm{p}=0.416$ ) (table 4.5).

Caregivers. Table 4.6 shows that there was a significant difference in caregiver's median scores on the LiSAT-9 at the 18 months follow-up, in favor of the control group $(p=0.005)$. Median change scores for the LiSAT-9 showed no change from baseline over time in either of the groups (table 4.7).

\section{Secondary outcomes}

Patients. Median changes in the outcomes of the FAl scores indicated significant changes from baseline at $6(p<0.001), 12(p=0.006)$ and 18 months $(p<0.001)$ (table 4.5). Patients in the intervention group showed a positive change whereas the control group showed a negative change. Sub-analyses of the median scores at baseline and T6 within the 2 groups showed that the levels of social activities improved significantly within the first 6 months in the region of Maastricht $(p<0.001)$, but a significant decrease was found in the region of Eindhoven $(p=0.033)$. After 6 months, the median FAl scores of both group were stable (i.e. no significant changes) and comparable (table 4.4). The median BI scores were high at each follow-up measure in both groups (60-85\% having the maximum score), which shows that the majority of patients were (almost) fully independent in terms of ADL. With regard to median changes over time, there were no significant differences between the groups as regards the $\mathrm{BI}$ outcome. There were no differences between the 2 groups in terms of the HADS anxiety scale. There was a significant change in the HADS depression scale scores between T12 and T0 ( $p=0.048)$ in favor of the intervention group. 
Caregivers. Table 4.6 shows the median scores for the secondary outcome measures for caregivers, and table 4.7 shows the median change scores. Caregivers in the intervention group had higher median scores on the HADS anxiety and depression scale at most of the follow-up measures compared with the control group, but the differences were not significant. The CSI scores remained low at each follow-up measurement and there were no significant differences between the groups.

The changes in the caregiver's scores on the HADS depression scale between baseline and 6 months follow-up differed significantly between the groups in favor of the intervention group $(p=0.028)$. There were no other significant differences between the 2 groups as regards the changes over time.

\section{Confounding factors}

Patients. The analyses to identify confounding factors indicated that comorbidity and the institution of discharge had a strong influence on the outcome in terms of SASIP scores. The effect of the intervention on the BI outcome was changed when the institution of discharge was included in the analysis. The HADS anxiety scale score was influenced by comorbidity and type of stroke. There were no patient characteristics that influenced the effect of group on the FAI score or the HADS depression scale score. The correction for confounding patient characteristics did not change the differences in outcomes between the 2 groups.

Caregivers. The effect of the intervention on the LiSAT-9 scores was not influenced by any of the caregiver characteristics. The effect of the intervention on the outcome in terms of the HADS anxiety and depression scale and the CSI were all influenced by the number of hours of caregivers' activities. The difference in outcome between the groups did not change after correction for the confounding variable. 
Table 4.4: Median scores of the outcomes of patients at baseline and the follow-up measures

\begin{tabular}{|c|c|c|c|c|c|c|c|c|c|}
\hline \multirow{2}{*}{\multicolumn{2}{|c|}{ Primary outcome }} & \multicolumn{2}{|c|}{ TO } & \multicolumn{2}{|c|}{ T6 } & \multicolumn{2}{|c|}{ T12 } & \multicolumn{2}{|c|}{ T18 } \\
\hline & & Intervention & Control & Intervention & Control & Intervention & Control & Intervention & Control \\
\hline \multicolumn{2}{|c|}{ SASIP-30 N } & 61 & 55 & 52 & 51 & 56 & 45 & 58 & 43 \\
\hline & Median & 8.0 & 6.0 & 5.0 & 5.0 & 6.5 & 5.0 & 6.0 & 4.0 \\
\hline & IQR & $5-13$ & $3-6$ & $2-13$ & $2-11$ & $3-12$ & $2.5-12$ & $3-10$ & $1-9$ \\
\hline \multicolumn{10}{|c|}{ Secondary outcomes } \\
\hline \multirow[t]{3}{*}{$\overline{\mathrm{BI}}$} & $\mathrm{N}$ & 62 & 55 & 52 & 51 & 56 & 45 & 58 & 43 \\
\hline & Median & 20.0 & 20.0 & 20.0 & 20.0 & 20.0 & 20.0 & 20.0 & 20.0 \\
\hline & IQR & $18.5-20$ & $19-20$ & $19-20$ & $19-20$ & $18-20$ & $19.5-20$ & $19-20$ & $20-20$ \\
\hline \multirow[t]{3}{*}{ FAl } & $\mathrm{N}$ & 62 & 55 & 51 & 51 & 55 & 45 & 58 & 43 \\
\hline & Median & $17.5^{\mathrm{a}}$ & $27.0^{\mathrm{a}}$ & 24.0 & 24.0 & 22.0 & 25.0 & 24.0 & 23.0 \\
\hline & IQR & $9-25$ & $20-32$ & $20-31$ & $16-31$ & $16-30$ & $19-31$ & $14-28$ & $17-30$ \\
\hline \multirow[t]{3}{*}{ HADS A } & $\mathrm{N}$ & 61 & 55 & 52 & 51 & 55 & 45 & 58 & 43 \\
\hline & Median & 4.0 & 4.0 & 3.0 & 2.0 & 2.0 & 3.0 & 2.0 & 2.0 \\
\hline & IQR & $1-8$ & $2-7$ & $1-7$ & $1-6$ & $0-6$ & $1-6.5$ & $1-5$ & $1-5$ \\
\hline \multirow[t]{3}{*}{ HADS D } & $\mathrm{N}$ & 61 & 55 & 52 & 51 & 55 & 45 & 58 & 43 \\
\hline & Median & 4.0 & 3.0 & 3.5 & 3.0 & 3.0 & 4.0 & 3.0 & 2.0 \\
\hline & IQR & $2-7.5$ & $2-7$ & $1-8$ & $1-7$ & $1-7$ & $1-8$ & $1-7$ & $0-6$ \\
\hline
\end{tabular}

SASIP-30, Stroke Adapted Sickness Impact Profile-30, N, number; IQR, interquartile range; $\mathrm{BI}$, Barthel Index; FAI, Frenchay Activities Index; HADS A, Hospital Anxiety Depression Scale Anxiety subscale; HADS D, Hospital Anxiety Depression Scale - Depression subscale.

a. significant differences between groups

Table 4.5: Median change scores of the outcomes of patients at baseline and the follow-up measures

\begin{tabular}{|c|c|c|c|c|c|c|c|}
\hline \multirow{2}{*}{\multicolumn{2}{|c|}{ Primary outcome }} & \multicolumn{2}{|c|}{ T6 - T0 } & \multicolumn{2}{|c|}{$\mathrm{T} 12-\mathrm{T} 0$} & \multicolumn{2}{|c|}{ T18 - T0 } \\
\hline & & Intervention & Control & Intervention & Control & Intervention & Control \\
\hline \multirow[t]{3}{*}{ SASIP-30 } & $\mathrm{N}$ & 51 & 51 & 55 & 45 & 57 & 43 \\
\hline & Median & -2.0 & 0.0 & -2.0 & 0.0 & -2.0 & -1.0 \\
\hline & IQR & -5 to 0 & -3 to 2 & -4 to 1 & -3.5 to 2 & -4 to 1 & -5 to 2 \\
\hline \multicolumn{8}{|c|}{ Secondary outcomes } \\
\hline \multirow[t]{3}{*}{$\mathrm{Bl}$} & $\mathrm{N}$ & 52 & 51 & 56 & 45 & 58 & 43 \\
\hline & Median & 0.0 & 0.0 & 0.0 & 0.0 & 0.0 & 0.0 \\
\hline & IQR & 0 to 0.8 & 0 to 0 & -1 to 0 & 0 to 0 & 0 to 0 & 0 to 0 \\
\hline \multirow[t]{3}{*}{ FAl } & $\mathrm{N}$ & 51 & 51 & 55 & 45 & 58 & 43 \\
\hline & Median & $6.0^{\mathrm{a}}$ & $-3.0^{\mathrm{a}}$ & $3.0^{\mathrm{a}}$ & $-1.0^{\mathrm{a}}$ & $3.5^{\mathrm{a}}$ & $-4.0^{\mathrm{a}}$ \\
\hline & IQR & 0 to 13 & -8 to 4 & -4 to 10 & -5.5 to 2 & -3.3 to 9.3 & -9 to 0 \\
\hline \multirow[t]{3}{*}{ HADS A } & $\mathrm{N}$ & 51 & 51 & 54 & 45 & 57 & 43 \\
\hline & Median & 0.0 & -1.0 & -1.0 & -1.0 & -1.0 & -1.0 \\
\hline & IQR & -3 to 2 & -3 to 1 & -3 to 1 & -3 to 1 & -3.5 to 1 & -3 to 1 \\
\hline \multirow[t]{3}{*}{ HADS D } & $\mathrm{N}$ & 51 & 51 & 54 & 45 & 57 & 43 \\
\hline & Median & -1.0 & 0.00 & $0.0^{\mathrm{a}}$ & $0.0^{\mathrm{a}}$ & -1.0 & 0.0 \\
\hline & IQR & -3 to 1 & -2 -to 2 & -2.3 to 1 & -1 to 3 & -2.5 to 1 & -2 to 1 \\
\hline
\end{tabular}

SASIP-30, Stroke Adapted Sickness Impact Profile-30, N, number; IQR, interquartile range; $\mathrm{BI}$, Barthel Index; FAl, Frenchay Activities Index; HADS A, Hospital Anxiety Depression Scale Anxiety subscale; HADS D, Hospital Anxiety Depression Scale - Depression subscale.

a. significant differences between groups 
Table 4.6: Median scores of the outcomes of caregivers at baseline and the follow-up measures

\begin{tabular}{|c|c|c|c|c|c|c|c|c|c|}
\hline \multirow{2}{*}{\multicolumn{2}{|c|}{ Primary outcome }} & \multirow{3}{*}{$\begin{array}{r}\text { T0 } \\
\text { Intervention } \\
41\end{array}$} & \multirow{2}{*}{ Control } & \multicolumn{2}{|l|}{ T6 } & \multicolumn{2}{|l|}{ T12 } & \multicolumn{2}{|c|}{ T18 } \\
\hline & & & & Intervention & Control & Intervention & Control & Intervention & Control \\
\hline \multirow[t]{3}{*}{ LiSAT-9 } & $\mathrm{N}$ & & 33 & 33 & 27 & 32 & 26 & 34 & 26 \\
\hline & Median & $4.9^{\mathrm{a}}$ & $5.1^{\mathrm{a}}$ & 4.9 & 5.0 & 5.0 & 5.0 & $4.7^{\mathrm{a}}$ & $5.0^{\mathrm{a}}$ \\
\hline & IQR & $4.0-5.2$ & $4.8-5.4$ & $4.5-5.0$ & $4.8-5.2$ & $4.6-5.2$ & $4.4-5.4$ & $4.4-5.0$ & $4.9-5.3$ \\
\hline \multicolumn{10}{|c|}{ Secondary outcomes } \\
\hline \multirow[t]{3}{*}{ HADS A } & $\mathrm{N}$ & 41 & 33 & 30 & 27 & 31 & 26 & 34 & 26 \\
\hline & Median & $5.0^{\mathrm{a}}$ & $3.0^{\mathrm{a}}$ & 5.0 & 4.0 & 4.0 & 3.0 & 4.0 & 2.0 \\
\hline & IQR & $3-9$ & $1-6$ & $3-11$ & $1-8$ & $1-6$ & $1.8-6$ & $1-9.3$ & $1-5$ \\
\hline \multirow[t]{3}{*}{ HADS D } & $\mathrm{N}$ & 41 & 33 & 30 & 27 & 31 & 26 & 34 & 26 \\
\hline & Median & $4.0^{a}$ & $2.0^{\mathrm{a}}$ & 2.5 & 3.0 & 2.0 & 2.0 & 2.0 & 2.0 \\
\hline & IQR & $2-7$ & $0.5-5$ & $1-8$ & $1-5$ & $0-5$ & $1-4.3$ & $1-7$ & $0.8-3.3$ \\
\hline \multirow[t]{3}{*}{$\mathrm{CSI}$} & $\mathrm{N}$ & 37 & 33 & 32 & 27 & 31 & 26 & 34 & 26 \\
\hline & Median & 4.0 & 4.0 & 2.0 & 3.0 & 3.0 & 3.5 & 2.0 & 2.0 \\
\hline & IQR & $1-6$ & $1-6.5$ & $1-4$ & $1-5$ & $1-5$ & $0.8-7.3$ & $0.8-5$ & $0-6$ \\
\hline
\end{tabular}

LiSAT-9, Life Satisfaction questionnaire-9; N, number; IQR, interquartile range; HADS A, Hospital Anxiety Depression Scale - Anxiety subscale; HADS D, Hospital Anxiety Depression Scale - Depression subscale; CSI, Caregivers Strain Index.

a. significant differences between groups

Table 4.7: Median change scores of the outcomes of caregivers at baseline and the follow-up measures

\begin{tabular}{|c|c|c|c|c|c|c|c|}
\hline \multirow{2}{*}{\multicolumn{2}{|c|}{ Primary outcome }} & \multicolumn{2}{|c|}{ T6 - T0 } & \multicolumn{2}{|c|}{ T12 - T0 } & \multicolumn{2}{|c|}{ T18 - T0 } \\
\hline & & \multirow{2}{*}{$\frac{\text { Intervention }}{33}$} & \multirow{2}{*}{$\frac{\text { Control }}{27}$} & \multirow{2}{*}{$\frac{\text { Intervention }}{32}$} & \multirow{2}{*}{$\frac{\text { Control }}{26}$} & \multirow{2}{*}{$\frac{\text { Intervention }}{34}$} & \multirow{2}{*}{$\frac{\text { Control }}{26}$} \\
\hline LiSAT-9 & $\mathrm{N}$ & & & & & & \\
\hline & Median & 0.0 & -0.1 & 0.0 & -0.1 & 0.0 & -0.1 \\
\hline & IQR & -0.2 to 0.4 & -0.3 to 0.2 & -0.2 to 0.6 & -0.7 to 0.2 & -0.5 to 0.6 & -0.2 to 0.1 \\
\hline \multicolumn{8}{|c|}{ Secondary outcomes } \\
\hline \multirow[t]{3}{*}{ HADS A } & $\mathrm{N}$ & 30 & 27 & 31 & 26 & 34 & 26 \\
\hline & Median & 0.0 & 1.0 & -2.0 & 0.0 & -2.5 & 0.0 \\
\hline & IQR & -2.3 to 3 & -1 to 2 & -5 to 1 & -1.3 to 2.3 & -4.3 to 1 & -2.3 to 2.3 \\
\hline \multirow[t]{3}{*}{ HADS D } & $\mathrm{N}$ & 30 & 27 & 31 & 26 & 34 & 26 \\
\hline & Median & $-1.0^{\mathrm{a}}$ & $0.0^{\mathrm{a}}$ & -1.0 & 0.0 & -1.0 & 0.0 \\
\hline & IQR & -2.3 to 0 & 0 to 1 & -2 to 1 & -1 to 1 & -4 to 0 & -2.3 to 1 \\
\hline \multirow[t]{3}{*}{ CSI } & $\mathrm{N}$ & 30 & 27 & 28 & 26 & 31 & 26 \\
\hline & Median & -1.0 & -1.0 & -1.0 & 0.0 & -1.0 & -0.5 \\
\hline & IQR & -3.3 to 1 & -4 to 0 & -2 to 1 & -3 to 1 & -4 to 1 & -3.3 to 1 \\
\hline
\end{tabular}

LiSAT-9, Life Satisfaction questionnaire-9; N, number; IQR, interquartile range; HADS A, Hospital Anxiety Depression Scale - Anxiety subscale; HADS D, Hospital Anxiety Depression Scale - Depression subscale; CSI, Caregivers Strain Index.

a. significant differences between groups 


\section{Discussion}

The results of our study showed that the QoL of the patients has improved over time in both groups. However, there were no significant differences in the change over time between the 2 groups. The Qol of the caregivers in the control group was higher than in the intervention group after 18 months, but there was no significant difference in the changes since baseline between the groups. Patients of the intervention group showed a significant increase in social activities after 18 months compared with baseline, whereas the social activities of the patients in the control group decreased. The levels of depression of the caregivers in the intervention group changed positively and different than the levels of depression of the caregivers in the control group within the first 6 months after baseline.

The positive effects on the levels of social activities in the intervention group, of which most effects were shown in the first 6 months, are consistent with earlier studies that showed an improvement in social activities within the first year after a stroke. $^{19,20}$ This increased level of social activities is an important gain, because it remains stable over time: approximately $76 \%$ of the stroke patients maintained their level of social activities 3 years post-stroke. ${ }^{21}$ Moreover, other studies have indicated that social inactivity is positively associated with depression and lower levels of QoL. ${ }^{22}$ The differences in changes in the level of social activities between the intervention and control group within the first 6 months could also be explained by difference in comorbidity. Patients in the intervention group had more locomotor problems and could therefore be more inactive at baseline than patients in the control group. Follow-up care in the intervention could have been more focused on improving the physical condition of patients, which might have led to being more socially active. Jansen and colleagues (2012) have recommended that stroke care professionals should direct special attention to patients who are inactive at an early stage after stroke. ${ }^{21}$ The level of social activities of both groups after 6 months, seems to be in line with other studies that have measured social activity in stroke patients at home. ${ }^{1,21}$ The lack of effect could also have a methodological explanation, because the total number of participating patients was lower that the calculated 
sample size. Lack of effect on the QoL of stroke patients was also found by Boter and colleagues $^{23}$ studying the effect of follow-up care by means of telephone follow-up consultations performed by specialized stroke nurses. They concluded that follow-up consultations and giving attention and advice alone may not have been enough, and adequate follow-up care should be offered in addition to assessing problems in daily functioning. In the present study, follow-up care was offered to the patients and their caregivers, but the patients received a mean of 3.9 visits instead of the intended 5, 23\% received care for 18 months and the follow-up initiated by the SCC after assessment was not as good as intended. This could have reduced the effect of the intervention on the QoL. Perhaps, more attention should have been paid to the follow-up care in addition to assessment. More details about organizational limitations will be discussed in the process evaluation, which was performed parallel to this study. In addition, part of our control group also received intensive follow-up care, which was developed during the study period, because of the increasing emphasis on more follow-up care for stroke patients in the Netherlands. Interestingly, many patients with relatively good functional outcomes participated in our study.

This study has several strengths and limitations, which should be considered when interpreting the results. A strength of this study is that it is one of the first controlled studies on long-term care for stroke patients. Furthermore, this study addresses a broad spectrum of stroke-related problems, which were not measured previously in other intervention studies. Thirdly, stroke patients in the primary care setting participated in the study and the study had a reasonable sample size. There are also several limitations. First, the study did not have a randomized design and the results of 2 groups from 2 different regions could be affected by regional differences, which could explain the baseline differences between groups. Next, there may be a population bias because patients with good functional recovery consented to participate. Furthermore, we lost several data due to drop-out of patients and caregivers during the study period. Most patients dropped-out at the beginning of the study because the study put too much burden on the patients early after stroke. 
This drop-out could have caused a selection bias. In the control region, there was also drop-out due to difficulties during the inclusion period and 8 patients were not interviewed, due to organizational problems. In addition, the follow-up care was developed in the control region during the study period, and this might have decreased the contrast between the 2 groups in our study. Such changes over time cannot be prevented in studies with a longitudinal design, but researchers should be aware of this. Based on our study, we would suggest tight organization in the control region, with a rapid inclusion, consistent contact persons and intensive monitoring during the inclusion period.

Our study shows that the long-term care model is effective in terms of social activities but not on QoL of stroke patients. We would like to highlight that screening of stroke-related problems could be the first step in providing adequate care. A more structured guideline for referral to stroke care professionals could be necessary in order to to gain a substantial additional improvement in the QoL of patients and caregivers. Future research should therefore investigate adequate follow-up care in addition to problem assessment as part of the integrated care pathway. Specific program have already been evaluated and showed positive results, such as cognitive rehabilitation $^{24}$ for cognitive problems and cognitive behavioral therapy for the treatment of fatigue ${ }^{25}$, which are 2 of the main long-term problems. 


\section{References}

1. Patel MD, Tilling K, Lawrence E, Rudd AG, Wolfe CD, McKevitt C. Relationships between long-term stroke disability, handicap and health-related quality of life. Age Ageing 2006;35:273-279.

2. Rasquin SM, Lodder J, Ponds RW, Winkens I, Jolles J, Verhey FR. Cognitive functioning after stroke: a one-year follow-up study. Dement Geriatr Cogn Disord 2004;18:138-144.

3. Morrison V, Pollard B, Johnston M, MacWalter R. Anxiety and depression 3 years following stroke: demographic, clinical, and psychological predictors. J Psychosom Res 2005;59:209-213.

4. Schepers VP, Visser-Meily AM, Ketelaar M, Lindeman E. Prediction of social activity 1 year poststroke. Archives of physical medicine and rehabilitation 2005;86:1472-1476.

5. Visser-Meily A, Post M, van de Port I, van Heugten C, van den Bos T. Psychosocial functioning of spouses in the chronic phase after stroke: improvement or deterioration between 1 and 3 years after stroke? Patient Educ Couns 2008;73:153-158.

6. van den Bos GA, Triemstra AH. Quality of life as an instrument for need assessment and outcome assessment of health care in chronic patients. Qual Health Care 1999;8:247-252.

7. Visser-Meily JM, van den Bos GA, Kappelle LJ. Better acute treatment induces more investments in chronic care for stroke patients. Int J Stroke 2009;4:352-353.

8. Murray J, Young J, Forster A, Herbert G, Ashworth R. Feasibility study of a primary care-based model for stroke aftercare. Br J Gen Pract 2006;56:775-780.

9. Dierick-van Daele AT, Metsemakers JF, Derckx EW, Spreeuwenberg C, Vrijhoef HJ. Nurse practitioners substituting for general practitioners: randomized controlled trial. J Adv Nurs 2009;65:391-401.

10. Allen KR, Hazelett S, Jarjoura D, Wickstrom GC, Hua K, Weinhardt J, et al. Effectiveness of a postdischarge care management model for stroke and transient ischemic attack: a randomized trial. J Stroke Cerebrovasc Dis 2002;11:88-98.

11. Ryan T, Enderby P, Rigby AS. A randomized controlled trial to evaluate intensity of community-based rehabilitation provision following stroke or hip fracture in old age. Clin Rehabil 2006;20:123-131.

12. Van de Port IG, Ketelaar M, Schepers VP, Van den Bos GA, Lindeman E. Monitoring the functional health status of stroke patients: the value of the Stroke-Adapted Sickness Impact Profile-30. Disabil Rehabil 2004;26:635-640.

13. de Haan R, Limburg M, Schuling J, Broeshart J, Jonkers L, van Zuylen P. Klinimetrische evaluatie van de Barthel-index, een maat voor beperkingen in het dagelijks functioneren. [Clinimetric evaluation of the Barthel Index, a measure of limitations in dailly activities]. Ned Tijdschr Geneeskd 1993;137:917-921 (in Dutch).

14. Schuling J, de Haan R, Limburg M, Groenier KH. The Frenchay Activities Index. Assessment of functional status in stroke patients. Stroke 1993;24:1173-1177. 
15. Mondolo F, Jahanshahi M, Grana A, Biasutti E, Cacciatori E, Di Benedetto P. The validity of the hospital anxiety and depression scale and the geriatric depression scale in Parkinson's disease. Behav Neurol 2006;17:109-115.

16. Visser-Meily A, Post M, Schepers V, Lindeman E. Spouses' quality of life 1 year after stroke: prediction at the start of clinical rehabilitation. Cerebrovasc Dis 2005;20:443-448.

17. van Exel NJ, Scholte op Reimer WJ, Brouwer WB, van den Berg B, Koopmanschap $M A$, van den Bos GA. Instruments for assessing the burden of informal caregiving for stroke patients in clinical practice: a comparison of CSI, CRA, SCQ and selfrated burden. Clin Rehabil 2004;18:203-214.

18. Cohen J. Statistical power analysis for the behavioral science. 2 ed. Hillsdale: Lawrence Erlbaum Associates; 1988.

19. Desrosiers J, Demers L, Robichaud L, Vincent C, Belleville S, Ska B. Short-term changes in and predictors of participation of older adults after stroke following acute care or rehabilitation. Neurorehabilitation and neural repair 2008;22:288297.

20. Horgan NF, O'Regan M, Cunningham CJ, Finn AM. Recovery after stroke: a 1-year profile. Disabil Rehabil 2009;31:831-839.

21. Jansen HE, Schepers VP, Visser-Meily JM, Post MW. Social activity one and three years post-stroke. Journal of rehabilitation medicine: official journal of the UEMS European Board of Physical and Rehabilitation Medicine 2012;44:47-50.

22. Landreville P, Desrosiers J, Vincent C, Verreault R, Boudreault V. The role of activity restriction in poststroke depressive symptoms. Rehabilitation psychology 2009;54:315-322.

23. Boter H. Multicenter randomized controlled trial of an outreach nursing support program for recently discharged stroke patients. Stroke 2004;35:2867-2872.

24. Rasquin SM, Bouwens SF, Dijcks B, Winkens I, Bakx WG, van Heugten CM. Effectiveness of a low intensity outpatient cognitive rehabilitation programme for patients in the chronic phase after acquired brain injury. Neuropsychological rehabilitation 2010;20:760-777.

25. Zedlitz AM, Rietveld TC, Geurts AC, Fasotti L. Cognitive and graded activity training can alleviate persistent fatigue after stroke: a randomized, controlled trial. Stroke 2012;43:1046-1051. 


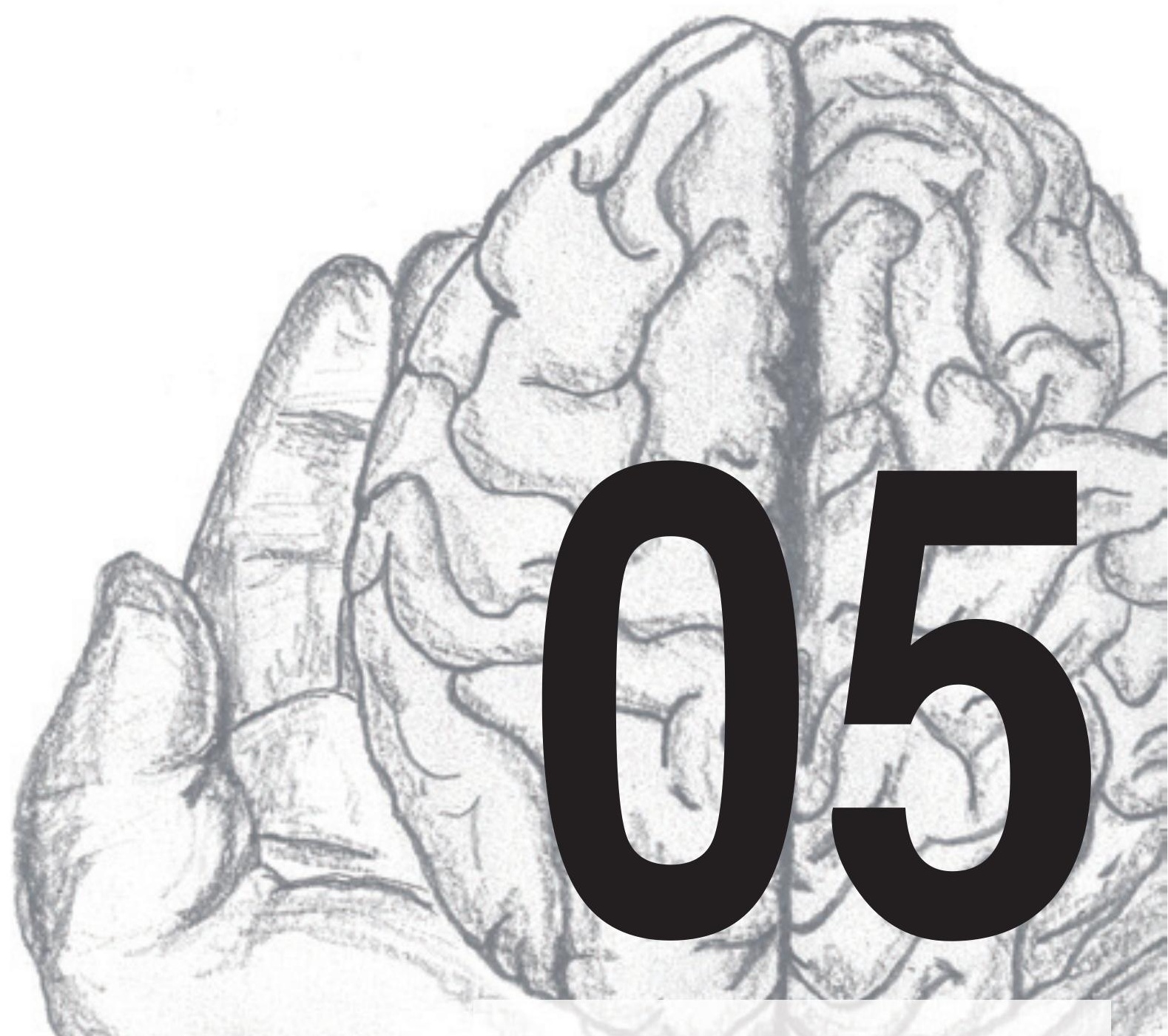

A process evaluation of a strokespecific follow-up care model for stroke patients and caregivers; a longitudinal study

Manon Fens, George Beusmans, Martien Limburg, Liesbeth van Hoef, Jolanda van Haastregt, Job Metsenmakers \& stidin Caroline van Heugten. Submitted 


\begin{abstract}
Background: There is a need for follow-up care, but there is no consensus about the way to organise it. An intervention providing follow-up care for stroke patients and caregivers showed favourable effects on the level of social activities, but no other effects were found. Objective: To examine process-related factors that could have influenced the effectiveness of the intervention. Design: The study has a longitudinal design and focused on qualitative and quantitative outcomes. Setting: Home situation after hospitalisation or inpatient rehabilitation. Participants: 77 stroke patients, 59 caregivers and 4 stroke care coordinators (SCCS) participated in the study. Intervention: The intervention consists of a maximum of five home visits to patients and caregivers during a period of 18 months post-discharge. The home visits are conducted by a SCC using a structured assessment tool. Methods: Data on the organisational characteristics of and the satisfaction with the intervention were collected by means of structured assessments, interviews and self-administered questionnaires at 1, 6, 12 and 18 months of follow-up. The intervention was provided between April 2008 and June 2011. Results: Patients received an average of 3.8 home visits (SD 1.4) and 55\% of them had a follow-up period of a maximum of 18 months. There were 1074 problems identified and the SCCs initiated 363 follow-up care and referral options. Stroke patients and caregivers were very satisfied with the intervention. The SCCs were satisfied with the assessment tool, but would like to see a structured referral system. Conclusion: The intervention was only partially performed in accordance with the protocol and was positively evaluated by patients, caregivers and SCCs. It is recommended to add a structured referral system to the intervention.
\end{abstract}

Keywords: nurses, stroke, follow-up care, process assessment 


\section{Background}

Many stroke patients experience motor, cognitive and psycho-emotional deficits or problems with daily activities and social participation ${ }^{1-3}$, which are often persistent. Their caregivers are also affected by the consequences of stroke and often experience psychological and emotional problems. ${ }^{4,5}$ Stroke patients as well as their caregivers have a need for long-term care ${ }^{6}$, but this long-term care is complex because many functions can be affected and many health care professionals may be involved.

Previous studies have evaluated different long-term care models for stroke patients, but only a few have shown significant favourable effects. ${ }^{7,8}$ Allen and colleagues (2002) evaluated a standardised assessment for stroke patients one month after being discharged home, followed by an individual care plan developed by a multidisciplinary team. ${ }^{7}$ They found that quality of life had improved after three months. Another study compared the effect of an intensive face-to-face therapy with that of a less intensive face-to-face therapy for patients living at home after hospitalisation, both of which were provided by a multidisciplinary team. The intensive therapy proved more effective in terms of quality of life. ${ }^{8}$ The care models that were reported to be effective were however, very heterogeneous in terms of type of care, professionals involved, and duration and intensity of care, which makes comparisons difficult and extracting effective elements impossible. ${ }^{9}$ There does not seem to be consensus about the best way to organise follow-up care for stroke patients who are discharged home. Based on previous research ${ }^{6,10}$ and practicebased evidence, we suggest that stroke patients should be monitored regularly for at least one year after hospitalisation or inpatient rehabilitation, as they can experience persistent problems. We therefore developed an intervention for stroke patients being discharged home from hospitalisation or inpatient rehabilitation, and their caregivers. The intervention consists of five home visits by a stroke care coordinator (SCC) employed by the home care services, using a structured assessment procedure to assess stroke-related problems and to offer adequate follow-up care. This intervention was implemented in the Maastricht area, the Netherlands, and 
compared with regular care in a control area (Eindhoven, the Netherlands) to evaluate its effectiveness in a non-randomised controlled trial design. Although the results showed that the intervention had a favourable effect on the levels of social activities of stroke patients, no significant favourable effects between the intervention and control group were found regarding quality of life, activities of daily life, depression and anxiety, or caregiver strain. ${ }^{11}$ Alongside the effect evaluation study, we performed a process evaluation to assess whether all stroke patients had received the intervention, whether the intervention was carried out in accordance with the protocol and whether the care provided was feasible and evaluated favourably by patients, caregivers and care professionals.

\section{Methods}

\section{Aim}

The aim of this study was to examine process-related factors that may have influenced the effectiveness of the intervention. This evaluation was divided into two parts. The first part focused on the discharge destination of stroke patients after hospitalisation or inpatient rehabilitation and evaluated (1) whether each stroke patient had been referred to the SCC to receive the intervention after being discharged home. The second part of the evaluation concentrated on the intervention and evaluated (2) to what extent the intervention was performed in accordance with the protocol, (3) the outcomes of the structured assessment procedure and to what extent the assessment resulted in follow-up care, (4) the opinion of the patients and caregivers about the intervention, and (5) the opinion of the SCCs about the intervention.

\section{Design}

The study had a longitudinal mixed methods design and focused on both quantitative and qualitative outcomes. 


\section{Participants}

This process evaluation focused on stroke patients and their caregivers in the Maastricht area who participated in the intervention group of the trial. ${ }^{11}$ Patients were included if they had been diagnosed with a stroke, were aged 50 years or older, and were living in the community in the catchment area of the home care services performing the intervention. The caregivers were included if they were 18 years or older and were the primary caregiver of the included stroke patient. All four SCCs of the home care services providing the care were asked to participate in the process evaluation.

\section{Intervention}

The intervention consists of five home visits to stroke patients and their caregivers by the SCC over a period of 18 months. The first home visit had to be performed within one month after discharge, followed by visits at 3, 6, 12 and 18 months after discharge. During each home visit, the SCC used a standardised assessment tool, the Assessment tool for the Consequences After Stroke (ACAS), to identify problems within the broad spectrum of stroke-related problems. This assessment tool was developed during this study as part of the intervention. This assessment tool consists of items relating to the domains of activities of daily life ( $A D L)$, instrumental activities of daily life (IADL), social activities, cognition, communication, psycho-emotional status, fatigue, secondary prevention, medical consumption, medical condition, caregiver strain and provision of information. Each domain has a hierarchical structure and starts with a brief question to explore whether the patient is experiencing a problem that can be further explored by means of validated questionnaires as needed. The assessment provides a broad overview of the patient's needs, so follow-up care can subsequently be provided. The SCC can contact the patient's general practitioner (GP) for advice about referral options. They can also consult a multidisciplinary team for advice about patients experiencing complex problems. This team, consisting of a nursing home physician, physiotherapist, speech therapist, occupational therapist and rehabilitation 
physician, was specifically established for this intervention. The intervention was conducted between April 2008 and June 2011.

\section{Data collection}

\section{Part 1}

Availability of the intervention

The registration systems of the hospital, inpatient rehabilitation setting and home care services were used to assess whether all stroke patients had been referred to home care services after being discharged home. The researcher checked how many patients were discharged home after hospitalisation or inpatient rehabilitation during the study period, and how many of these patients were referred to the home care services to receive the intervention.

\section{Part 2}

\section{Performance of the intervention}

The researcher explored the data collected with the standardised assessment tool (ACAS), as recorded by the SCCs, of each patient participating in the study, to collect data about the timing of the home visits, the number of home visits, and the duration of the follow-up period. These data were used to evaluate whether the home visits and follow-up period were implemented in accordance with our suggested intervention.

\section{Assessment and follow-up care}

The number and type of problems that were reported by the patients and caregivers during the home visits were recorded by the SCCS on a structured assessment form. On this form, the nurses also registered the follow-up care they initiated for each patient. Furthermore, the SCCs registered whether they used the additional validated questionnaires during the assessments. 


\section{Opinions of patients and caregivers}

Patients' and caregivers' satisfaction with care provided was measured using the Satisfaction with Stroke-Care questionnaire (SASC-19). The researcher interviewed the participants and caregivers one month after the patient had been discharged home (TO), and subsequently every six months after the baseline measurement for the entire 18 month follow-up period (i.e. T6, T12 and T18). These measurements were scheduled to take place shortly after a home visit by the SCC when possible. Patients were instructed to indicate how satisfied they were with the care that they were receiving. Caregivers were also asked to complete the SASC-19 and were also instructed to indicate their satisfaction with the care that they were receiving. The SASC-19 consists of two parts, with a total of 19 items: part one contains items about hospital care, while part two contains items about care after hospitalisation. Each item has a 4-point scale, ranging from 0 (totally disagree) to 3 (totally agree). For the purpose of our study, four items of part one were changed regarding the care referred to by the items (from hospital care to care by the SCCs; items 1, 2, 3 and 5). In part two, inpatient rehabilitation was added to hospital care for items 9, 13, 15, 16 and 17.

The way the intervention was organised was evaluated by presenting patients and caregivers with a self-administered questionnaire after 18 months. The patients and caregivers were both asked to answer the same questions, consisting of 16 multiplechoice questions (agree-disagree or too short-too long), two open-ended questions (likes and dislikes about the care) and one question asking to rate the way the intervention was organised (1 (bad) -10 (excellent)). The multiple-choice questions addressed aspects such as the timing of the first home visit, the expertise of the SCC, the use of validated questionnaires by the SCC, the number of home visits, the duration of the home visits and the location of the home visits. The researcher asked

the patients and caregivers to return the questionnaires by post. If the questionnaire was not returned, the researcher called the patient and caregiver to remind them. 


\section{Opinion of the stroke care coordinators}

The SCCS received a questionnaire at the end of the study period to assess their opinion on the organizational characteristics of the intervention that they provided. The questionnaire consisted of four parts; part one focused on the elements of the intervention (7 items); part two addressed aspects of the use of the assessment tool (9 items); part three consisted of two items about the working conditions; and part four addressed the multidisciplinary collaboration between the health care professionals (6 items).

\section{Ethical considerations}

The medical ethics committee of the university approved this study and all patients and caregivers gave informed consent.

\section{Data analysis}

Means and standard deviations or percentages were used to describe participants' and disease characteristics. The quantitative data about the structured assessments (such as the number of home visits and the duration of the follow-up period), as reported by the SCCs, are presented as means, standard deviations, frequencies and percentages. The data from the assessments (such as the type of problem and the follow-up care initiated) are presented as frequencies and percentages. The sum scores of the SASC-19 could not be interpreted, because many items were not applicable and could not be scored. Therefore we used the average degree of satisfaction reported by each participant, to obtain an estimate of the satisfaction with care. The average degree of satisfaction was calculated for each patient and caregiver by dividing the sum score by the number of items which were scored (i.e. a relative score; we considered a score between 0 and 1.5 as total to moderate dissatisfaction and a score between 1.6 and 3 as moderate to total satisfaction). SPSS (version 18) was used for all statistical analyses. 


\section{Validity and reliability}

The ACAS tool administrated by the SCCs has good content and criterion validity and has been rated as feasible for use in health care, which was evaluated in this study. The SASC-19 has good validity. ${ }^{12}$ The questionnaire about the organisational characteristics of the intervention was developed specifically for this study and tailored to the elements of the intervention.

\section{Results}

Figure 5.1: Flow chart of $(A)$ the referral of stroke patients to home care services and $(B)$ the inclusion process

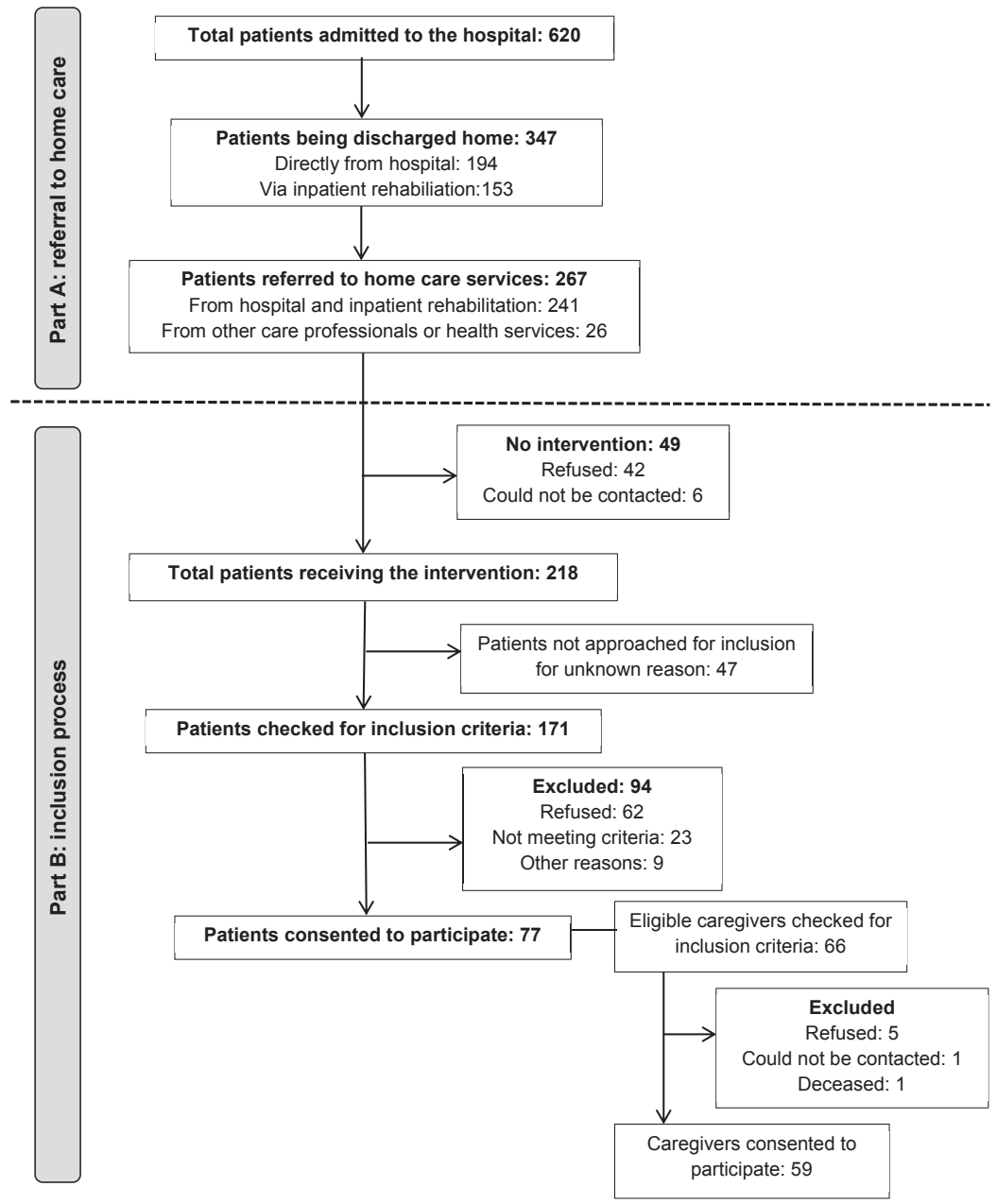




\section{Part 1}

\section{Availability of the intervention}

The first part of the process-evaluation focused on the discharge destination of stroke patients after hospitalisation or inpatient rehabilitation. Figure 5.1-part A shows that out of a total of 620 stroke patients, who were admitted to the stroke unit of the hospital during the inclusion period, 347 patients were discharged home, 241 of them being referred to home care services (69\% of the total number of stroke patients). In addition, there were 26 patients who were referred to the home care services by other health care professionals, such as physiotherapists, GPs and nurse practitioners, who were left out of consideration for the evaluation about the availability of the intervention. The total of 267 patients that were referred to the home care services received the intervention, which was implemented as regular care in the Maastricht area at the beginning of the study period.

\section{Part 2}

\section{Participants and response}

The second part of the evaluation concentrated on the intervention and figure 5.1part B provides an overview of the inclusion process of the trial. There were 218 patients who received the intervention, 77 patients of whom consented to participate in the evaluation. These included patients had 66 eligible caregivers, of whom 59 of them consent to participate. These patients and caregivers also participated in the effect evaluation. ${ }^{11}$

The structured assessment forms of all 77 included patients were available. The SASC-19 was administered to 69 patients at T0 (90\%), 59 at T6 (77\%), 61 at T12 (79\%) and 64 at T18 (83\%). There were 13 patients who did not fill in the SASC-19 at the end of the study, for various reasons; four had died within the 18-month period, four had been admitted to a nursing home during the study, four had dropped out because of the intensity of the follow-up measurement, and one had severe dementia after 18 months. A total of 51 patients (66\%) responded to the questionnaire about the evaluation of the care model. The remaining 26 patients did 
not return the questionnaire, 13 of them for the reasons mentioned above. The other 13 had various reasons for not responding: seven patients failed to respond after having been reminded by the researcher and six could not recall the care that they had received.

Table 5.1: Participants' characteristics at baseline

\begin{tabular}{llc}
\hline & & Patients \\
\hline Number & & 77 \\
Age & (mean in years + SD) & $72.5(9.6)$ \\
Gender & (male/\%) & $41 / 53.2 \%$ \\
Time since stroke & (mean in months + SD ) & $1.8(1.4)$ \\
Discharged from (N/\%) & Hospital & $52 / 67.5 \%$ \\
& Inpatient rehabilitation & $25 / 32.5 \%$ \\
& & Caregivers \\
\hline Number & & 59 \\
Age & (mean in years + SD) & $61.5(14.7)$ \\
Gender & (male/\%) & $18 / 30.5 \%$ \\
Relationship & Spouse & $36 / 61.0 \%$ \\
& Child & $17 / 28.8 \%$ \\
& Other & $6 / 10.2 \%$ \\
\hline
\end{tabular}

$\mathrm{N}$, number; SD, standard deviation

Fifty-four caregivers filled in the SASC-19 at T0 (92\%), 38 at T6 (64\%), 36 at T12 (61\%) and 38 at T18 (64\%). There were 21 caregivers who did not receive the SASC-19 at the end of the study period, for various reasons; eight caregivers dropped out for personal reasons $(\mathrm{N}=5)$ or because of the intensity of the follow-up measurements $(\mathrm{N}=3)$, for six caregivers the intervention was ended because the patients died during the study $(\mathrm{N}=4)$ or were admitted to a nursing home $(\mathrm{N}=2)$, three caregivers dropped out for unknown reasons, two caregivers died and two caregivers could not be reached. The questionnaire about the evaluation of the intervention was filled in by 29 caregivers (49\%) at the 18 -month follow-up. Thirty caregivers did not return the questionnaires, for various reasons, including the reasons mentioned above by the 21 patients: seven caregivers failed to respond after the reminder, and two caregivers could not recall the care that they had received. Demographic data and characteristics of patients and caregivers are shown in table 5.1. All four SCCS returned the questionnaire about the organisational characteristics of the intervention that they provided. 


\section{Performance of the intervention}

Table 5.2 illustrates the number of home visits and the follow-up period. Forty-nine patients received fewer than the suggested five home visits. There were several reasons for this: in some cases the SCC considered that no further follow-up care was needed $(\mathrm{N}=24)$, seven patients ended the intervention at their own initiative, three patients died, five patients were transferred to a home for the elderly, for eight patients the reasons are unknown and two patients received four home visits within the 18-month study period and were still receiving the intervention at the end of this period. Eight patients received more than five home visits, for the following reasons: one patient experienced more problems and needed more care, three patients had had a recurrent stroke and for four patients the reasons remained unknown.

Table 5.2: Overview of the home visits and follow-up period during the study period ( $N=77)$

\begin{tabular}{|c|c|c|}
\hline Home Visits ( $\mathrm{N}=5$ ) & $\mathbf{N}$ & $\%$ \\
\hline Range (N) & $1-7$ & \\
\hline Average home visits (SD) & $3.8(1.5)$ & \\
\hline One home visit & 7 & $9 \%$ \\
\hline Two home visits & 10 & $13 \%$ \\
\hline Three home visits & 12 & $16 \%$ \\
\hline Four home visits & 20 & $26 \%$ \\
\hline Five home visits & 20 & $26 \%$ \\
\hline Six or more home visits & 8 & $10 \%$ \\
\hline
\end{tabular}

\section{Follow-up period (18 months intended)}

$\begin{array}{rcc}\text { Range (months) } & 1-27 & \\ \text { Mean (months, SD) } & 13.3(6.9) & \\ \text { Maximum follow-up period of 1 month } & 6 & 7 \% \\ \text { Maximum follow-up period of 3 months } & 5 & 12 \% \\ \text { Maximum follow-up period of 6 months } & 9 & 19 \% \\ \text { Maximum follow-up period of 12 months } & 15 & 40 \% \\ \text { Maximum follow-up period of 18 months } & 31 & 14 \% \\ \text { Follow-up period longer than 18 months } & 11 & \\ & & \\ \text { visits and follow-up period in accordance } & & 66 \% \\ \text { 1st home visit within 0-1 month } & 66 & 34 \% \\ \text { 2nd home visit within 2-4 months } & 46 & 29 \% \\ \text { 3rd home visit within 5-7 months } & 26 & 21 \% \\ \text { 4th home visit within 11-13 months } & 22 & \\ \text { 5th home visit within 17-19 months } & 16 & \end{array}$

$\mathrm{N}$, number; SD, standard deviation

\section{Home visits and follow-up period in accordance} with the protocol

2nd home visit within 2-4 month 
Thirty-one patients had the maximum follow-up period of 18 months, while 11 patients had a longer follow-up period. There was no relation between the follow-up period and the number of home visits (i.e. some patients had a shorter and more intensive follow-up period, while some patients had a longer and less intensive follow-up period). With regard to receiving the suggested home visit at the suggested time during the follow-up period, the first home visit was provided within one month for 66 patients. Subsequently, one out of four patients received the suggested home visits at the suggested time during the follow-up.

Table 5.3: The six main problems of patients and caregivers assessed at the predetermined follow-up home visits

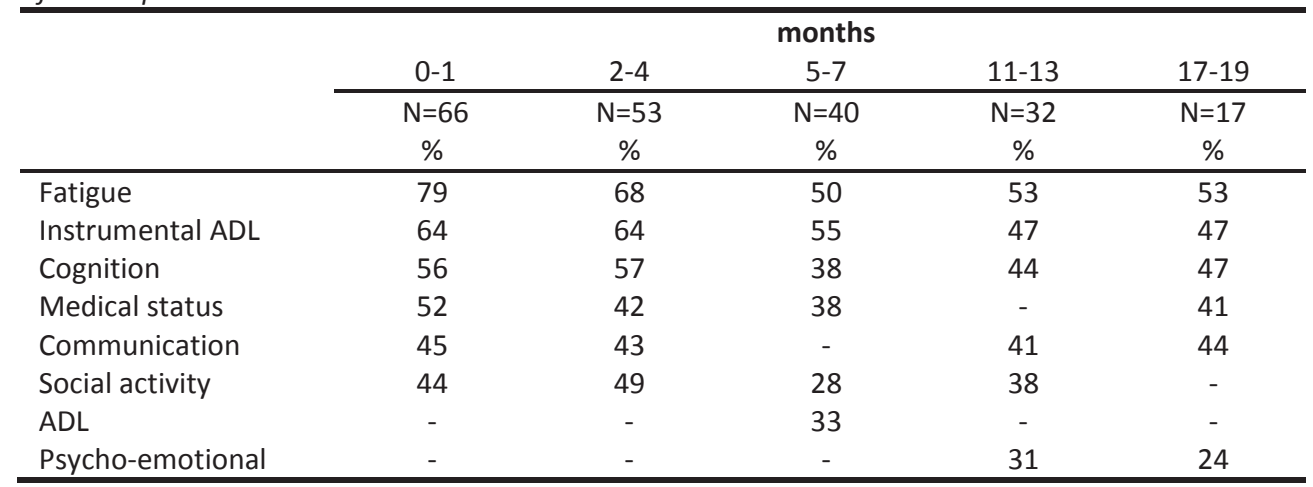

$\mathrm{N}$, number; $A D L$, activities of daily life

The assessment and follow-up care

The SCCs administered the assessment tool during each home visit. A total of 1074 problems were identified during all assessments of all patients $(\mathrm{N}=293)$. The stroke patients experienced an average of six problems at one to three months after discharge, a number which decreased to four problems after six months, increased to five after 12 months and decreased again to three after 18 months. Table 5.3 shows the main problems, experienced by the stroke patients and caregivers, with fatigue remaining the most important problem throughout the 18-month follow-up period. Seventy-four percent of all identified problems were further explored by means of the validated questionnaires. The problem domain of fatigue was further explored in $52 \%$ of the cases. Reasons for not further exploring the problem domains were unknown. 
Based on all assessments performed, the SCCs provided supportive listening ( $N=104)$, provided advice and information $(\mathrm{N}=88)$, on aspects like lifestyle changes, coping with fatigue and rules about driving a car after a stroke, and initiated help for caregivers $(\mathrm{N}=18)$. In addition to the care directly initiated by the hospital or inpatient rehabilitation service, they referred patients and caregivers to speech therapists $(N=11)$, occupational therapists $(N=9)$, physiotherapists $(N=8)$ and sometimes a dietician, social worker or psychologist $(\mathrm{N}=28)$. They also arranged health care facilities (such as social alarm devices and personal transfer; $\mathrm{N}=33$ ), physical aids (such as wheel chair, adjusted shoes, mobility scooter; $N=24$ ), home care (such as help with housekeeping; $\mathrm{N}=20$ ) and home adjustments (such as a stair lift, handrails in toilet and shower; $N=20$ ). The SCCs initiated on average four to five follow-up care and referral options to each patient.

The SCCs had contacts with general practitioners 48 times, the most common reasons being referral of patients to other health care professionals for consultation or therapy, medical problems and use of medication. The SCCs also had contacts with the nurse practitioner at the hospital $(N=26)$, the neurologist $(N=15)$, physiotherapists $(\mathrm{N}=10)$ and occupational therapists $(\mathrm{N}=8)$ for information and advice. Other health care professionals they contacted were rehabilitation physicians $(\mathrm{N}=4)$, psychologists $(\mathrm{N}=4)$, cardiologists $(\mathrm{N}=2)$, a speech therapist $(\mathrm{N}=1)$ and home services $(\mathrm{N}=1)$. The SSCs did not consult the multidisciplinary team during the followup period

\section{Opinions of patients and caregivers}

Patients: The average scores on the SASC-19 indicate that patients were satisfied with the intervention during the follow-up period (average scores ranging from 1.9 to 2.6) (table 5.4). About 93\% indicated that they had received all the help they needed during the 18-month period. The results also showed that $33 \%$ of the patients received insufficient information about financial resources and aids within the first few weeks after being discharged home. 
With regard to the way the intervention was organised, 14 patients (30\%) indicated that the first home visit should have taken place sooner after their discharge home (they received their first home visit within one to six weeks after being discharged). This was not related to whether patients had been discharged from the hospital $(\mathrm{N}=7)$ or from inpatient rehabilitation $(\mathrm{N}=7)$. About $8 \%$ of the patients would have preferred more home visits and $6 \%$ of the patients would have preferred a longer duration of the intervention. In addition, eight patients (16\%) were of the opinion that the face-to-face contact with the SCC could be replaced by telephone contacts. All patients who filled in the questionnaire were satisfied with the duration of each home visit. With regard to improving their functioning in daily life, which was one of the major goals of the intervention, $65 \%$ of the patients said that the home visits and follow-up care they had received had improved their daily life functioning. They commented that they had received enough attention from the SCC and that the SCC gave useful advice and arranged effective follow-up care. Patients rated the care at an average of 8.6 out of 10 (i.e. very good).

Table 5.4: Mean SASC-19 scores at the follow-up measurements ${ }^{a}$

\begin{tabular}{llcccc}
\hline Patients & & T0 & T6 & T12 & T18 \\
\hline SASC-19, part 1 & N & 68 & 54 & 54 & 53 \\
& Mean (SD) & $2.4(0.4)$ & $2.5(0.5)$ & $2.5(0.5)$ & $2.6(0.5)$ \\
& Score >1.5 (\%) & $100 \%$ & $100 \%$ & $100 \%$ & $100 \%$ \\
SASC-19, part 2 & N & 69 & 59 & 61 & 64 \\
& Mean (SD) & $1.9(0.3)$ & $1.9(0.2)$ & $1.9(0.2)$ & $2.0(0.2)$ \\
& Score $>1.5(\%)^{b}$ & $91.3 \%$ & $96.6 \%$ & $95.1 \%$ & $97.9 \%$ \\
Caregivers & & & & 32 & 34 \\
SASC-19, part 1 & N & 47 & 33 & $2.6(0.5)$ & $2.6(0.5)$ \\
& Mean (SD) & $2.4(0.5)$ & $2.5(0.5)$ & $2.6(\%)$ & $94,1 \%$ \\
SASC-19, part 2 & Score >1.5 (\%) & $97.9 \%$ & $100 \%$ & $96.9 \%$ & 38 \\
& N & 54 & 38 & 36 & $2.0(0.4)$ \\
& Mean (SD) & $1.9(0.4)$ & $2.0(0.4)$ & $2.1(0.3)$ & $97,4 \%$ \\
\hline
\end{tabular}

$\mathrm{N}$, number; SD, standard deviation

a. Part 1: items relating to care by stroke care coordinator; part 2: items relating to care after hospitalization or inpatient rehabilitation

b. score of 0-1.5 total to moderate dissatisfaction; score of 1.6-3: moderate to total satisfaction 
Caregivers. Caregivers were satisfied with the care they received after the patient's discharge during the follow-up period (average scores ranging from 1.9 to 2.6) (table 5.4). They had received sufficient help from health care services (91\%) and sufficient emotional support (78\%) during the 18 months follow-up.

With regard to the way the intervention was organised, six caregivers $(22 \%)$ indicated that the first home visit should have taken place sooner after the discharge. Five caregivers would have preferred more home visits within the first months after discharge (17\%). About $68 \%$ of the caregivers reported that care would be inaccessible to them if it was provided at a health centre instead of their own home. Sixty-seven percent of the caregivers reported that the home visits they had received had improved their daily life functioning. The caregivers commented that the SCC had paid sufficient attention to them and that the SCC had discussed each problem satisfactorily. They rated the care at an average of 8.2 out of 10 (i.e. very good).

\section{Opinion of the stroke care coordinators}

All SCCs $(\mathrm{N}=4)$ preferred using the structured assessment procedure for each stroke patient and caregiver compared to their previous work approach, when they had used no structured assessment. They commented that the use of the assessment tool provided structure and an overall picture, and made the care provided during the home visits more efficient. The SCCs were generally satisfied with the frequency and timing of the home visits and the duration of the follow-up period. In several cases the frequency of the home visits and duration of follow-up depended on the patient's individual situation, so the intervention was not performed in accordance with the suggested intervention. Patients with severe aphasia or cognitive impairments were more difficult to interview with the ACAS tool. The SCCs reported that they would have appreciated a more structured procedure to refer patients and caregivers to other follow-up care and stroke care professionals. They were dissatisfied about the lack of contact with general practitioners, whereas the 
collaboration with the other health care professionals was judged to be very easy and positive.

\section{Discussion}

This study aimed to examine process-related factors that could have influenced the effectiveness of our intervention. Firstly, we assessed how many patients were referred to an SCC and found that $69 \%$ of the patients were referred to the home care services for the intervention after being discharged home. One third of the patients were not referred from the hospital or inpatient rehabilitation service to home care services to receive the intervention. These patients may have fully recovered from the stroke during hospitalisation or inpatient rehabilitation. The health care professionals may have considered that no further intervention was needed and discharged the patients home without further care, before the SCC had the opportunity to carry out a structured assessment of the patient's needs. Health care professionals should therefore raise more public support for the referral of stroke patients to the home care services.

Secondly, we explored to what extent the intervention was performed in accordance with the protocol. In the course of the study, it appeared that the SCCs performed the follow-up care in a more flexible way and adapted the number of home visits and follow-up period, indicating that the intervention was only partially performed in accordance with the protocol. Forty-six percent of the patients and caregivers received home visits over a maximum period of 12 months, and $72 \%$ received less than the intended five home visits. The SCCs reported that they considered that some patients had no further need for follow-up care and that they ended the care before the intended 18-month follow-up period. In addition, the number of home visits and the timing of the home visits sometimes differed between patients (i.e. some patients had a shorter and more intensive follow-up period and some had a longer and less intensive follow-up period), suggesting that the intervention should perhaps be tailored to the patient's individual situation, using our protocol as a guideline. The tailored intervention received by patients and caregivers could 
partially explain the limited effectiveness of the intervention ${ }^{11}$, while the effectiveness was measured for the overall group and not measured for the patient's individual situation.

Thirdly, we assessed the outcome of the assessment procedure and the follow-up care provided. The problems of fatigue, cognition, communication and IADL remained the most important problems during the follow-up period. The number of problems experienced by each stroke patient had decreased after 18 months, showing that patients experienced fewer problems and may have less need for follow-up care, as was indicated by the fewer home visits provided by the SCCS and the shorter follow-up period. The SCCs most commonly provided advice, information and supportive listening to patients and caregivers during the home visits. These results are comparable to the study results by Boter and colleagues (2004) showing that nurses who provided three telephone consults and one home visit to stroke patients most commonly provided supportive listening and information. ${ }^{13}$ The SCCs in our study provided follow-up care for only one out of three of the problems identified. Based on the reporting of the SCCS, we could not derive what follow-up care was provided for what type of problem. Perhaps the initiated follow-up care by the SCC could have addressed more than one problem. It is also possible that not all of the initiated follow-up care was properly reported in the assessment forms of each patient. Relatively little follow-up care was initiated to resolve problems such as cognition and fatigue. It is possible that the SCCs were unfamiliar with effective interventions or referral options in the region. Our intervention may also have focused too much on the assessment of stroke-related problems rather than on follow-up interventions or referral of stroke patients, which could explain the limited effectiveness of the intervention. ${ }^{11}$ Perhaps a more structured and systematically organised referral system is required to improve the continuity of follow-up care, as was suggested by the SCCs. Regarding the collaboration with other health care professionals, the SCCs were dissatisfied about the accessibility of and collaboration with the GPs. Several studies have also indicated that not only health care professionals but patients and caregivers as well prefer a more proactive role of their 
GP in providing follow-up care after being discharged home. ${ }^{14,15}$ In addition, the SCCS never consulted the multidisciplinary team which was specifically organised as part of the intervention.

Fourthly, we explored the opinions of patients and caregivers about the intervention. Both groups were very satisfied with the care they had received after being discharged home. Finally, our evaluation of the opinion of the SCCS about the intervention showed that the SCCs were satisfied with the use of the ACAS tool during the home visits, which is in line with the results of a previous study by Murray and colleagues (2006). ${ }^{16}$ They evaluated the feasibility of a follow-up care intervention and found that health care professionals could work in a more consistent manner using a systematic assessment procedure. The SCCs would prefer a more structured referral system combined with the structured assessment procedure.

\section{Limitations}

Our study had several weaknesses. First, there may have been a response bias due to socially desirable answers. We tried to minimise this bias by asking the patients and caregivers to fill in the questionnaire themselves and return it by post. Secondly, there were some missing data during the study period because of drop-out among patients and caregivers, but the reasons for drop-out were hardly related to the way the intervention was organised. Moreover, there was a large group of patients who were not asked to participate in the process evaluation, for unknown reasons. Thirdly, the data on the assessment and follow-up care were based on the clinical notes made by the SCCS, which may not have contained all relevant information. In addition, the SCCs' clinical notes did not enable us to specifically indicate which follow-up care was initiated for what type of problem. Finally, we had changed the word 'hospital' in 'hospital, nursing home or home care services' in several items of the SASC-19. Although, we do not expect that this minor change will have affected the validity of the SASC-19, we have to consider this possibility. 


\section{Conclusion}

The study results show that the intervention was not always performed in accordance with the protocol, but the intervention was offered to patients in a more flexible way, and patients and caregivers were very satisfied with the follow-up care that they received. In addition, the health care professionals were satisfied about providing follow-up care by means of a structured assessment procedure. The results also suggest that the intervention should be tailored to each individual patient that is, adjusted to each patient's needs.

The results of the trial showed that the intervention was effective in improving the levels of social activities ${ }^{11}$, but perhaps more effects could have been found, if sufficient follow-up referral had been provided. We therefore have several recommendations for the way follow-up care should be organised, and for future research. First of all, we believe that the frequency and duration of the follow-up care should be tailored and not be strictly five home visits for a fixed period of 18 months. We also believe that an effective referral system to specific care related to the problems identified may be most important to improve the follow-up care for stroke patients. Therefore, we highly recommend the use of a structured assessment procedure combined with a structured referral system to guarantee the continuity of the follow-up care. In addition, we recommend that the health care professionals performing the assessment should be taught about effective intervention and referral options for problems such as cognition and fatigue. ${ }^{17,18}$ The involvement of GPs should be more fully integrated into the follow-up care. Our recommendations for future research are that the characteristics of patients who need long-term care should be studied to identify prognostic characteristics for long-term care and the recording of long-term care initiated should be registered in a more objective method, independent of the health care professional providing the care. 


\section{References}

1. Morrison, V., Pollard, B., Johnston, M. \& MacWalter, R., 2005. Anxiety and depression 3 years following stroke: demographic, clinical, and psychological predictors. Journal of Psychosomatic Restore 59(4), 209-213.

2. Rasquin, S.M., Lodder, J., Ponds, R.W., Winkens, I., Jolles, J. \& Verhey, F.R., 2004. Cognitive functioning after stroke: a one-year follow-up study. Dementia and Geriatric Cognitive Disorders 18(2), 138-144.

3. Schepers, V.P., Visser-Meily, A.M., Ketelaar, M. \& Lindeman, E., 2005. Prediction of social activity 1 year poststroke. Archives of Physical Medicine and Rehabilitation 86(7), 1472-1474.

4. Carod-Artal, F.J., Ferreira Coral, L., Trizotto, D.S. \& Menezes Moreira, C., 2009. Burden and perceived health status among caregivers of stroke patients. Cerebrovascular Diseases 28(5), 472-480.

5. Visser-Meily, A., Post, M., van de Port, I., van Heugten, C. \& van den Bos, T., 2008. Psychosocial functioning of spouses in the chronic phase after stroke: improvement or deterioration between 1 and 3 years after stroke? Patient Education and Counseling 73(1), 153-158.

6. Visser-Meily, J.M., van den Bos, G.A. \& Kappelle, L.J., 2009. Better acute treatment induces more investments in chronic care for stroke patients. International Journal of Stroke 4(5), 352-353.

7. Allen, K.R., Hazelett, S., Jarjoura, D., Wickstrom, G.C., Hua, K., Weinhardt, J. \& Wright, K., 2002. Effectiveness of a postdischarge care management model for stroke and transient ischemic attack: a randomized trial. Journal of Stroke and Cerebrovascular Diseases 11(2), 88-98.

8. Ryan, T., Enderby, P. \& Rigby, A.S., 2006. A randomized controlled trial to evaluate intensity of community-based rehabilitation provision following stroke or hip fracture in old age. Clinical Rehabilitation 20(2), 123-131.

9. Fens, M., Vluggen, T., van Haastregt, J.C., Verbunt, J.A., Beusmans, G.H. \& van Heugten, C.M., 2013. Multidisciplinary care for stroke patients living in the community: a systematic review. Journal of Rehabilitation Medicine 45(4), 321330.

10.van den Bos, G.A. \& Triemstra, A.H., 1999. Quality of life as an instrument for need assessment and outcome assessment of health care in chronic patients. Quality in Health Care 8(4), 247-252.

11.Fens, M., Van Heugten, C., Beusmans, G., Metsemakers, J.F., Kester, A. \& Limburg, M., 2014. The effect of a stroke-specific follow-up care model on the quality of life of stroke patients and caregivers; a controlled trial. Journal of Rehabilitation Medicine 46(1), 7-15. doi: 10.2340/16501977-1239.

12.Boter, H., De Haan, R.J. \& Rinkel, G.J., 2003. Clinimetric evaluation of a Satisfaction-with-Stroke-Care questionnaire. Journal of Neurology 250(5), 534541.

13.Boter, H., Rinkel, G.J. \& de Haan, R.J., 2004. Outreach nurse support after stroke: a descriptive study on patients' and carers' needs, and applied nursing interventions. Clinical Rehabilitation 18(2), 156-163. 
14.Brotheridge, S., Young, J., Dowswell, G., Lawler, J. \& Forster, A., 1998. A preliminary investigation of patient and carer expectations of their general practitioner in longer-term stroke care. Journal of Evaluation in Clinical Practice 4(3), 237-241.

15.Greenwood, N., Mackenzie, A., Harris, R., Fenton, W. \& Cloud, G., 2011. Perceptions of the role of general practice and practical support measures for carers of stroke survivors: a qualitative study. BMC Family Practice 12, 57.

16.Murray, J., Young, J., Forster, A., Herbert, G. \& Ashworth, R., 2006. Feasibility study of a primary care-based model for stroke aftercare. British Journal of General Practice 56(531), 775-780.

17.Rasquin, S.M., Bouwens, S.F., Dijcks, B., Winkens, I., Bakx, W.G. \& van Heugten, C.M., 2010. Effectiveness of a low intensity outpatient cognitive rehabilitation programme for patients in the chronic phase after acquired brain injury. Neuropsychological Rehabilitation 20(5), 760-777.

18.Zedlitz, A.M., Rietveld, T.C., Geurts, A.C. \& Fasotti, L., 2012. Cognitive and graded activity training can alleviate persistent fatigue after stroke: a randomized, controlled trial. Stroke 43(4), 1046-1051. 

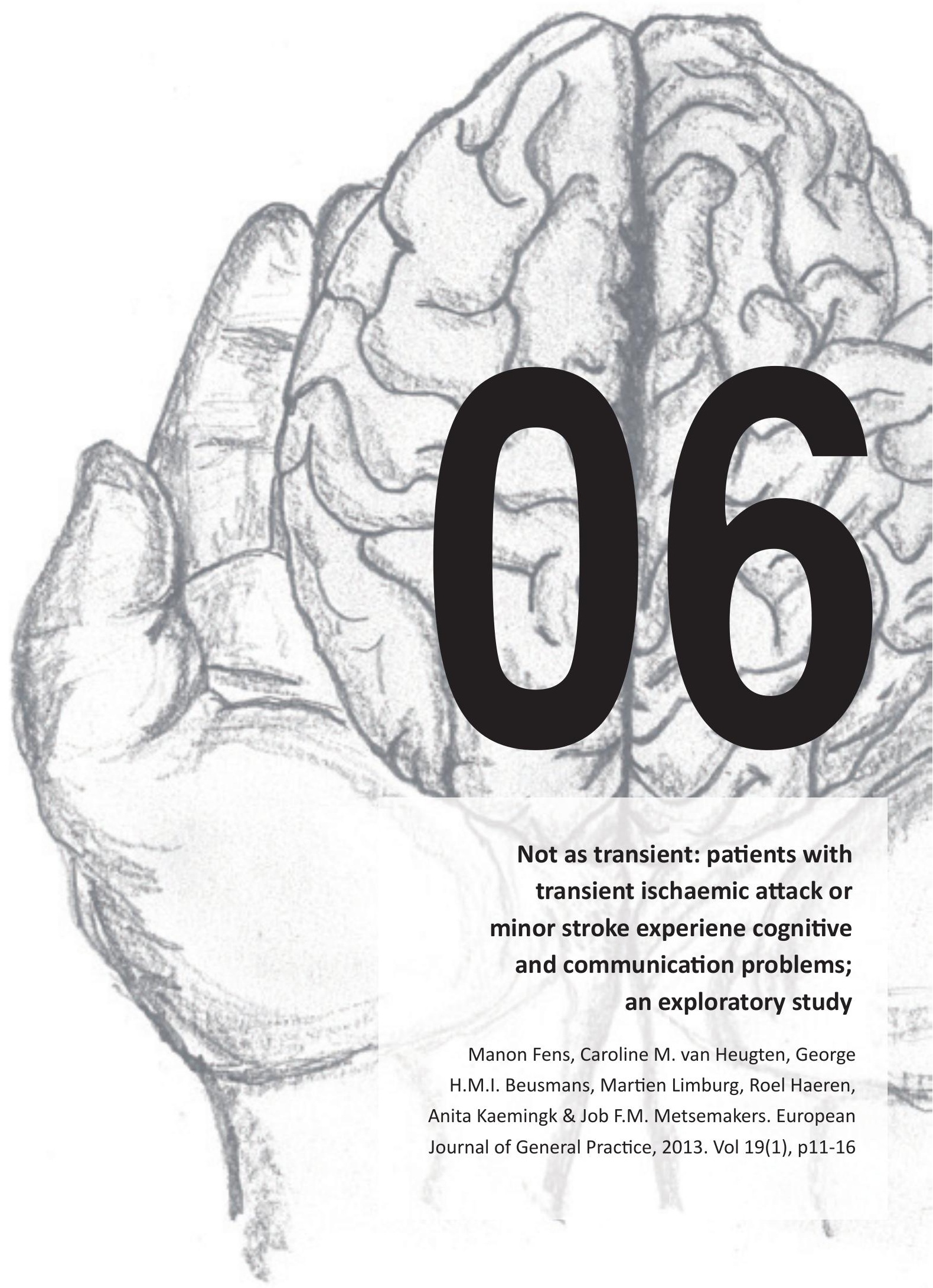

Not as transient: patients with transient ischaemic attack or minor stroke experiene cognitive and communication problems; an exploratory study

Manon Fens, Caroline M. van Heugten, George H.M.I. Beusmans, Martien Limburg, Roel Haeren, Anita Kaemingk \& Job F.M. Metsemakers. European Journal of General Practice, 2013. Vol 19(1), p11-16 


\begin{abstract}
Background: Patients with transient ischemic attack (TIA) or minor stroke generally receive, besides secondary prevention, no regular follow up care after discharge directly home from the Emergency Room or TIA outpatient clinic, because it is believed that they will experience no consequences. Objectives: To explore whether the TIA and minor stroke patients have persistent problems due to the event. Methods: This study has a cross-sectional, comparative non-randomised, exploratory design. Patients with TIA or minor stroke, not requiring hospital admission, and a control group of stroke patients, recently discharged home, were selected and interviewed with a questionnaire by telephone or home visit, between one and eight months after the event. Patients with angina pectoris (AP) were recruited as a second control group. Results: Data showed that 51\% of the TIA and minor stroke patients and $71 \%$ of the stroke patients experienced five or more problems, as opposed to $32 \%$ of the patients with AP. Between 39 to $49 \%$ of the TIA, minor stroke and the stroke patients reported cognitive and communicative difficulties. Moreover, the TIA and minor stroke patients had more cognitive deficits ( $n=27,49 \%$ ) and communicative limitations $(n=23,42 \%)$ than the AP group $(n=7,10 \%$ and $n=4,6 \%$, respectively). Conclusion: About half of the TIA and minor stroke patients experienced problems regarding cognition and communication, which were specific to the event. General practitioners should be aware of these potential problems and monitor patients regularly. Future research should focus on prognostic indicators to identify patients at risk.
\end{abstract}

Keywords: general practice, transient ischaemic attack , minor stroke , cognitive function, communication, rehabilitation 


\section{Introduction}

Patients who survive a stroke often experience problems in the long-term because of their stroke, which can be related to physical deficits ${ }^{1,2}$ and also to psycho-emotional and cognitive limitations. ${ }^{3,4}$ Patients diagnosed with a transient ischemic attack (TIA) or minor stroke only receive follow-up care focused on secondary prevention, after discharge from the emergency room (ER) or TIA outpatient clinic. ${ }^{5}$ General practitioners usually manage this follow-up care, because they are the primary health care professionals for non-hospitalized patients. National (such as the Dutch and British guidelines for General Practitioners and Physicians) ${ }^{6,7}$ and international guidelines (such as Helsingborg declaration) for the management of stroke care also primarily focus on the management of secondary prevention of TIA and minor stroke patients to prevent a subsequent stroke. There is, however, no attention for other problems after the event, because it is believed that TIA and minor stroke patients experience no further consequences. Follow-up care for other consequences is, therefore, not structurally organized. There are indications that these patients experience problems because of the incident and that this initial belief should be revised. Previous research has indicated that TIA and minor stroke patients experience high levels of fatigue ${ }^{8}$, have subtle problems in activities of daily life ${ }^{9}$, have an increased risk of depression ${ }^{10}$, and are affected in emotional, social and physical functioning. ${ }^{11}$ However, these studies have not evaluated whether patients experienced problems with cognition and communication, which are often impaired after stroke This raises the possibility that TIA and minor stroke patients could also experience other stroke-related problems shortly after the event and that care should be provided at an earlier stage.

As far as we know, there is no study investigating a complete spectrum of strokerelated problems in outpatients with a TIA or minor stroke within six months after the event. The aim of this study was, therefore, to explore whether this group of patients experienced problems after discharge home directly from the ER or TIA outpatient clinic. We used a questionnaire that was developed to measure a wide range of stroke-related problems. In addition, two other groups were selected to 
verify whether these problems are indeed related to TIA or minor stroke (not requiring hospital admission). We included a group of stroke patient recently being discharged home after hospitalisation or inpatient rehabilitation and a group of patients with angina pectoris (AP), also visiting the ER or outpatient clinic without subsequent hospital admission. These groups were studied to answer the question whether patients with TIA and minor stroke experience similar problems as the stroke patients and whether they report different problems than the patients with AP.

\section{Methods}

\section{Study design}

This study has a cross-sectional, comparative non-randomised, exploratory study. The medical ethics committee of the Maastricht University Medical Centre+ approved this study (METC 07-4-051).

\section{Selection of study participants}

The patient registration database of the department of Neurology of the Maastricht University Medical Centre+ was used to select patients of the experimental group (i.e TIA or minor stroke patients). Patients were selected if they had a TIA or minor stroke not requiring hospital admission; if they had visited the ER or TIA outpatient clinic between 1 January and 30 June 2008; and were aged 50 years or older. TIA was defined as a sudden onset of cerebrovascular neurological deficits, the clinical symptoms of which disappear within $24 \mathrm{~h}$ after onset. The diagnosis was based on clinical symptoms, MRI-imaging and the judgement of an experienced neurologist. Patients were considered to have a minor stroke, when they had a Rankin Score of $1^{12}$

The control group of stroke patients participated in a longitudinal study on the effectiveness of long-term care. Between April 2008 and December 2009, patients were selected from the registration of home care services based on diagnosis of stroke (based on clinical symptoms, MRI-imaging and the judgement of an 
experienced neurologist), age of 50 years and older, and recently being discharged home from hospital or inpatient rehabilitation.

For the second control group, we selected patients with another vascular condition and common risk factors. The patients of the control group were selected from the patient registration database of the department of cardiology of the Maastricht University Medical Centre+. These patients were selected based on a diagnosis of angina pectoris (AP) not requiring hospital admission, a visit to the ER or outpatient clinic of cardiology between 1 November 2010 and the 30 May 2011, and the age of 50 years or older. AP was defined as having a history of chest pain or discomfort, elicited by physical activity, psychological stress or occurring at rest, lasting for a maximum of $15 \mathrm{~min}$. The diagnosis of AP was based on clinical symptoms, ECGimages and the judgement of an experienced cardiologist.

\section{Measurements}

All patients in the three groups received the patient information by letter explaining the purpose of the study. To acquire informed consent, patients were contacted by telephone after one week. The interview was subsequently held by telephone or home visit depending on the patient's preference and the questionnaire was administered. All stroke patients were interviewed at home by a stroke care coordinator. The questionnaire used for the interviews is part of a larger assessment tool, developed to assess stroke-related problems in stroke patients, who may need follow-up care after being discharged home from hospital, nursing home or rehabilitation clinic. It consists of 15 questions each related to a specific health care domain, that can be answered by yes (e.g. patient experiences problems) or no (e.g. patient experiences no problems) and the respondent can add comments. Patients were asked whether they experienced new problems after the event or whether preevent existing problems had changed after the event. The assessment tool was validated (regarding content and criterion) with stroke patients in a pilot study and patients, caregivers and health care professionals rated it as feasible in health care. 
The assessment tool, including the questionnaire, is now being used in regular health care.

\section{Outcome}

The outcome of the study was the percentage of reported problems of the participants based on the questionnaire.

\section{Statistical analysis}

Data was analysed using descriptive statistics. Differences in patients' characteristics were analysed by an independent sample t-test and chi-square tests where appropriate. Differences in the responses to the questionnaire between the TIA and minor stroke group on the one hand, and the other two groups on the other hand were analysed using the chi-square test. In case expected cell assumption was violated, the Fisher's exact test was used. The results of the TIA and minor stroke group were compared with the results of the stroke group, to explore whether the results of the TIA and minor stroke group were comparable to stroke patients. Furthermore, the results of the TIA and minor stroke group were compared with the results of the AP group, to investigate whether the results were stroke-related. Posthoc exploratory analysis was conducted to investigate subgroup differences. The analyses were conducted with the Statistical Package for Social Sciences (SPSS, version 18). Alpha was set at 0.05 .

\section{Results}

\section{Study population}

For the TIA and minor stroke group, 67 patients were selected, and 55 patients were successfully interviewed by telephone. 12 patients did not participate for several reasons: 6 patients could not be contacted, 3 patients refused to participate and 3 patients were unable to participate due to hearing or speech problems. For the stroke group, 77 out of 171 patients gave informed consent, of which 62 participated in the longitudinal study. For the control group of AP patients, 99 patients were 
contacted and 72 patients were successfully interviewed. 27 patients of the AP group were not interviewed for several reasons: 16 patients could not be contacted, 7 patients refused participation, 3 patients were unable to participate due to hearing problems, severe mental health problems or hospital admission, and one patient was recently deceased.

The characteristics of the participating patients are shown in table 6.1. TIA and minor stroke patients and AP group were interviewed between two and eight months after being discharged from the ER, TIA outpatient clinic or the cardiology outpatient clinic. There was only a significant difference in the mean age between the TIA and minor stroke group and the two other groups; the stroke patients $(t(115)=-2.550, p$ $=0.012)$ and the AP patients $(\mathrm{t}(125)=-2.600, \mathrm{p}=0.011)$ were older.

Table 6.1: patient's characteristics of the three patient groups; transient ischaemic attack/minor stroke, stroke and angina pectoris

\begin{tabular}{llccc}
\hline & & $\begin{array}{c}\text { TIA/minor } \\
\text { stroke }\end{array}$ & Stroke & Angina pectoris \\
\hline Number of patients & 55 & 62 & 72 \\
Age (mean in years+ SD) & $68(9.8)$ & $73(10.0)$ & $73(9.9)$ \\
Gender (male /\%) & $35 / 64 \%$ & $32 / 52 \%$ & $36 / 50 \%$ \\
Diagnose-subtype (N/\%) & TIA & $35 / 64 \%$ & - & - \\
& Minor stroke & $20 / 36 \%$ & - & - \\
& Stroke & - & $62 / 100 \%$ & - \\
& Angina pectoris & - & - & $72 / 100 \%$ \\
Health care service (N) & Outpatient clinic & 49 & - & 70 \\
& Emergency room & 6 & - & 2 \\
& Hospitalisation / & - & 62 & - \\
inpatient rehabilitation & & & 4.9 \\
\hline
\end{tabular}

TIA, transient ischemic attack; SD, standard deviation; N, number

\section{Outcome}

28 patients of the TIA and minor stroke group (51\%), 44 stroke patients (71\%) and 25 patients of the AP group (35\%) experienced five or more problems. As table 6.2 shows, a high proportion of each group reported fatigue problems. When comparing the TIA and minor stroke patients and the stroke patients, the results show that both group were comparable, for instance in medical condition, cognition, communication and daily schedule. The percentages of problems about the activities of daily life 
$(A D L)$ and the instrumental $A D L$ (IADL) were significantly higher in the stroke patient group.

When comparing the TIA and minor stroke group with the AP group, the TIA and minor stroke group reported significantly more problems in the domains of cognition and communication (table 6.2). For cognition, the TIA and minor stroke group responded deficits mostly with memory $(n=24,44 \%)$ and/or concentration $(n=14$, $26 \%)$. The communication problems of the TIA and minor stroke group were mainly related to difficulties with speech and language comprehension $(n=17,31 \%)$ and in writing $(n=13,24 \%)$. Although the differences were non-significant, patients with a TIA or minor stroke reported different somatic complaints; 7 patients had difficulties with swallowing (13\%) versus 3 patients of the AP group (4\%), 17 patients had pain (31\%) versus 4 patients of the AP group (6\%) and 16 patients complained of dizziness (29\%) versus 14 patients of the AP group (19\%). The TIA and minor stroke group also reported other somatic problems, such as problems with vision, hemiparesis or headaches. 4 out of 8 patients of the AP group mentioned respiratory problems.

Next, a post-hoc exploratory analysis of subgroups was performed. There were differences between TIA patients and minor stroke patients: patients with a minor stroke generally reported more problems compared to TIA patients. Approximately $70 \%$ of the minor stroke patients experience difficulties with communication, whereas $26 \%$ of the TIA patients have communication problems. There were no other differences found between the minor stroke and the TIA patients.

\section{Discussion}

Results in this study show that approximately half of the patients with a TIA or minor stroke experience five or more problems, compared to one third of AP patients. Most problems of the patients with a TIA or minor stroke are related to cognition and communication. A similar proportion of the stroke patient group experienced problems regarding these two domains, but only a small proportion of the AP group reported these complaints. In addition, the AP patients were older than the TIA and minor stroke patients that seem to be in contrast with findings showing that elderly 
Table 6.2. Questionnaire results: 'Yes' responses related to transient ischaemic attack/minor stroke, stroke or angina pectoris

\begin{tabular}{|c|c|c|c|c|c|}
\hline Domain: & $\begin{array}{c}\text { TIA/minor } \\
\text { stroke (1) } \\
\mathrm{N}=55 \\
\mathrm{~N}(\%)\end{array}$ & $\begin{array}{l}\text { Stroke } \\
\begin{array}{c}(2) \\
N=62 \\
N(\%)\end{array}\end{array}$ & $\begin{array}{c}\text { Angina } \\
\text { pectoris } \\
\text { (3) } \mathrm{N}=72 \text {, } \\
\mathrm{N}(\%)\end{array}$ & $\begin{array}{c}1 \text { vs. } 2 \\
\text { Sign. } \\
(p=0.05)\end{array}$ & $\begin{array}{l}1 \text { vs.3 } \\
\text { Sign. } \\
(p=0.05)\end{array}$ \\
\hline \multicolumn{6}{|l|}{ Activities of daily life } \\
\hline $\begin{array}{l}\text { Do you need help with washing, getting } \\
\text { dresses or walking staircases? } \\
\text { Instrumental ADL }\end{array}$ & $4(7 \%)$ & $16(26 \%)$ & $7(10 \%)$ & 0.008 & 0.627 \\
\hline $\begin{array}{l}\text { Do you need help with housekeeping } \\
\text { activities (such as cleaning, cooking or } \\
\text { groceries)? }\end{array}$ & $9(16 \%)$ & 39 (63\%) & $20(28 \%)$ & $<0.001$ & 0.129 \\
\hline \multicolumn{6}{|l|}{ Hobbies/social activities } \\
\hline $\begin{array}{l}\text { Do you have problems relating to hobbies, } \\
\text { going out or visiting people? }\end{array}$ & $19(35 \%)$ & $29(47 \%)$ & $19(26 \%)$ & 0.156 & 0.320 \\
\hline \multicolumn{6}{|l|}{ Daily schedule } \\
\hline $\begin{array}{l}\text { Do you have difficulties to find daily } \\
\text { activities to do? }\end{array}$ & $12(22 \%)$ & $11(18 \%)$ & $22(31 \%)$ & 0.641 & 0.270 \\
\hline \multicolumn{6}{|l|}{ Cognition } \\
\hline $\begin{array}{l}\text { Do you have daily problems with memory, } \\
\text { concentration or performing multiple } \\
\text { activities simultaneously? } \\
\text { Communication }\end{array}$ & $27(49 \%)$ & $30(48 \%)$ & $7(10 \%)$ & 0.713 & $<0.001$ \\
\hline $\begin{array}{l}\text { Do you have problems with reading, } \\
\text { writing, speech or speech comprehension? } \\
\text { Psycho-emotional }\end{array}$ & $23(42 \%)$ & $24(39 \%)$ & $4(6 \%)$ & 0.987 & $<0.001$ \\
\hline $\begin{array}{l}\text { Do you feel down, anxious, useless or } \\
\text { depressed? }\end{array}$ & $20(36 \%)$ & 19 (31\%) & $17(24 \%)$ & 0.687 & 0.117 \\
\hline \multicolumn{6}{|l|}{ Fatigue } \\
\hline Do you often experience severe fatigue? & $33(60 \%)$ & $49(79 \%)$ & $36(50 \%)$ & 0.004 & 0.262 \\
\hline Risk management: smoking/drinking & & & & & \\
\hline $\begin{array}{l}\text { Do you smoke, drink alcohol, exercise or } \\
\text { have overweight? }\end{array}$ & $17(31 \%)$ & $12(19 \%)$ & $25(35 \%)$ & 0.163 & 0.651 \\
\hline \multicolumn{6}{|c|}{ Risk management: check blood pressure/cholesterol } \\
\hline $\begin{array}{l}\text { Have your blood pressure and cholesterol } \\
\text { levels not been checked regularly? }\end{array}$ & $1(2 \%)$ & 24 (39\%) & $3(4 \%)$ & $<0.001$ & 0.633 \\
\hline \multicolumn{6}{|c|}{ Medical condition: sleep/swallow/pain/dizziness } \\
\hline $\begin{array}{l}\text { Do you have problems relating to sleeping, } \\
\text { swallowing, pain or dizziness? } \\
\text { Medical condition: others }\end{array}$ & $28(51 \%)$ & 31 (50\%) & 25 (35\%) & 0.862 & 0.067 \\
\hline Do you have other medical complaints? & $13(24 \%)$ & $14(23 \%)$ & $8(11 \%)$ & 0.909 & 0.060 \\
\hline Relationship relatives & & & & & \\
\hline $\begin{array}{l}\text { Are there problems in the relationship with } \\
\text { close relatives? } \\
\text { Intimacy partner }\end{array}$ & $3(5 \%)$ & $7(11 \%)$ & $4(6 \%)$ & 0.034 & 0.980 \\
\hline $\begin{array}{l}\text { Do you experience intimacy or sexual } \\
\text { problems between you and your partner? } \\
\text { Information provision }\end{array}$ & $7(13 \%)$ & $3(5 \%)$ & $7(10 \%)$ & 0.412 & 0.592 \\
\hline $\begin{array}{l}\text { Did you receive insufficient information } \\
\text { about consequences of or about services } \\
\text { available after the event? }\end{array}$ & $10(18 \%)$ & $25(40 \%)$ & $12(17 \%)$ & 0.003 & 0.823 \\
\hline
\end{tabular}

TIA, transient ischemic attack; N, number; $A D L$, activities of daily life 
experience more problems. These results, therefore, suggest that the reported problems of cognition and communication were related to cerebrovascular events and were specific to the TIA and minor stroke and not attributable to age differences.

\section{Strengths and limitations of the study}

This is the first study exploring a broad spectrum of stroke-related consequences in patients with a TIA or minor stroke. The value of the results of the TIA and minor stroke patients are strengthened by comparing their results with patients who have the same vascular condition and common risk factors. In addition, the problems of the group of stroke patients also showed that the problems of the TIA and minor stroke patients were related to a cerebrovascular event.

Alternatively, we are aware that the results in this study are based on self-report, which means that the reported problems could be an overestimate or underestimate of the actual problems. We are also aware that we analysed the TIA and minor stroke patients together. TIA and minor stroke are different cerebrovascular events from a neurological perspective, but TIA and minor stroke are treated as a similar cerebrovascular event from the viewpoint of general practitioners. In addition, separate analyses of the TIA and minor stroke patients also revealed no large differences. Another limitation is that we have no concurrent control group. Finally, no previous assessment of problems was performed, but we discriminated between TIA, minor stroke, stroke, angina pectoris and other possible causes by asking the patients to indicate whether they experienced new problems after the event or whether already existing problems have changed after the event.

\section{Comparison with existing literature}

A high level of fatigue was found in $63 \%$ of the patients with a TIA or minor stroke, which is in line with the results of Winward and colleagues, who found a percentage of $56 \%$ in minor stroke patients and $29 \%$ in TIA patients. ${ }^{8}$ In addition, previous studies did not assess problems with cognition and communication, which appeared to be a major problem in the population studied. A recent study showed that 
cognitive decline is an independent predictor of stroke, which could possibly also explain the high incidence of reported cognitive problems. ${ }^{13}$ An incidence of depression in TIA and minor stroke patients was also found by Luijendijk and colleagues, who highlight that more attention is needed to the potential problems after TIA and minor stroke. ${ }^{10}$

\section{Implications for future research or clinical practice}

We want to increase awareness of the potential problems that patients with a TIA or minor stroke can experience. TIA and minor stroke quickly seem to recover fully from a neurological point of view and consequently do not get a specific follow-up. Now we can conclude that quite some problems can be detected after several months, indicating that TIA and minor stroke are not as transient or lead to full recovery as we believed. There are indications that TIA and minor stroke patients experience benefit from therapy after hospitalization. ${ }^{14}$ Although it is unclear whether this therapy is also effective for non-hospitalized patients, it does show that rehabilitation options are available. An early detection of stroke-related problems in this group of patients is therefore important. Since TIA and minor stroke patients are non-hospitalized, general practitioners or practice nurse could play a major role in this early detection during their regular check-up for secondary prevention. Findings are based on an exploratory study and further controlled research is required. Future research should examine prognostic indicators to identify patient with TIA or minor stroke who are at risk of experiencing these problems.

\section{Conclusion}

Most of the TIA and minor stroke patients reported problems of cognition and communication. Stroke patients also experience these problems, but patients with AP did not, indicating that these problems are specific to the cerebrovascular event. Care professionals should be aware of potential cognitive and communicative difficulties and identify patients at risk by monitoring them systematically and regularly. 


\section{References}

1. Cramer SC. Changes in motor system function and recovery after stroke. Restor Neurol Neurosci. 2004;22:231-8.

2. Patel MD, Tilling K, Lawrence E, Rudd AG, Wolfe CD, McKevitt C. Relationships between long-term stroke disability, handicap and health-related quality of life. Age Ageing. 2006;35:273-9.

3. Lightbody CE, Baldwin R, Connolly M, Gibbon B, Jawaid N, Leathley M, et al. Can nurses help identify patients with depression following stroke? A pilot study using two methods of detection. J Adv Nurs. 2007;57:505-12.

4. Morrison V, Pollard B, Johnston M, MacWalter R. Anxiety and depression 3 years following stroke: demographic, clinical, and psychological predictors. J Psychosom Res. 2005;59:209-13.

5. de Lau LM, den Hertog HM, van den Herik EG, Koudstaal PJ. Predicting and preventing stroke after transient ischemic attack. Expert Rev Neurother. 2009;9:1159-70.

6. Intercollegiate Stroke Working Party. National clinical guideline for stroke, 3rd edition. London: Royal College of Physicians, 2008.

7. NHG-Guideline Stroke 2008, developed by the Dutch College of General Practitioners (NHG)

8. Winward C, Sackley C, Metha Z, Rothwell PM. A Population-Based Study of the Prevalence of Fatigue After Transient Ischemic Attack and Minor Stroke. Stroke. 2009;40:757-61.

9. Verbraak ME, Hoeksma AF, Lindeboom R, Kwa VI. Subtle Problems in Activities of Daily Living after a Transient Ischemic Attack or an Apparently Fully Recovered Non-disabling Stroke. J Stroke Cerebrovasc Dis. 2012;21:124-30.

10. Luijendijk HJ, Stricker BH, Wieberdink RG, Koudstaal PJ, Hofman A, Breteler MM, et al. Transient ischemic attack and incident depression. Stroke. 2011;42:1857-61.

11. Duncan PW, Samsa GP, Weinberger M, Goldstein LB, Bonito A, Witter DM, et al. Health status of individuals with mild stroke. Stroke. 1997;28:740-5.

12. van Swieten JC, Koudstaal PJ, Visser MC, Schouten HJ, van Gijn J. Interobserver agreement for the assessment of handicap in stroke patients. Stroke. 1988;19:604-7.

13. Wiberg B, Lind L, Kilander L, Zethelius B, Sundelof JE, Sundstrom J. Cognitive function and risk of stroke in elderly men. Neurology. 2010;74:379-85.

14. Arts ML, Kwa VI, Dahmen R. High Satisfaction with an Individualised Stroke Care Programme after Hospitalisation of Patients with a TIA or Minor Stroke: A Pilot Study. Cerebrovasc Dis. 2008;25:566-71. 


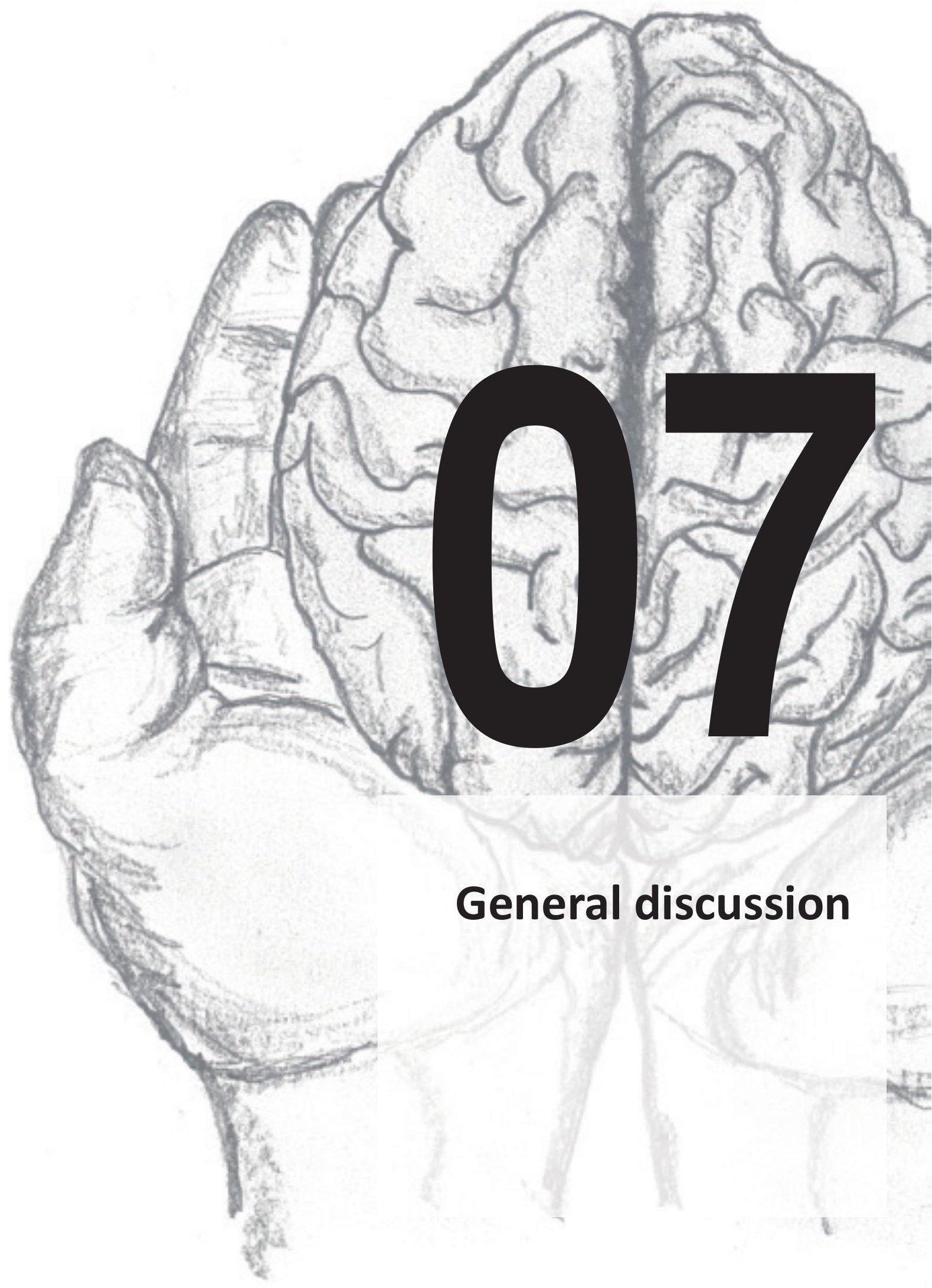


122 | Chapter 7: General discussion 


\section{Introduction}

In this study we focused on long-term care for stroke patients after being discharged home from hospital or inpatient rehabilitation. We developed a structured assessment instrument and compared the structured long-term care process using this instrument with conventional long-term care. We consider care as long-term when it is provided for more than six months after discharge home. In this study, we 1) examined which long-term care interventions were effective for stroke patients living at home after hospitalization or inpatient rehabilitation, 2) studied the feasibility of a newly developed structured assessment tool for use in clinical practice, 3) evaluated the effectiveness of a structured long-term intervention in improving quality of life of stroke patients and their caregivers, 4) evaluated the way that the long-term intervention was organized in terms of process, 5) examined the opinion of stroke patients, their caregivers and the health care professionals about the care received or provided, and 6) assessed whether patients with a TIA or minor stroke also experienced stroke-related problems due to the event. In the general discussion, the main findings of the study are summarized, methodological strengths and limitations are reported, and clinical implication and suggestions for future research are addressed.

\section{Main Findings}

\section{The effectiveness of long-term care interventions}

We have performed a systematic review to evaluate which multidisciplinary interventions were effective for stroke patients after hospitalization or inpatient rehabilitation in terms of quality of life, activities of daily life or social participation. ${ }^{1}$ Two out of a total of fourteen studies showed favorable effects on the quality of life of stroke patients. The first intervention entailed a nurse who performed an assessment and discussed the results of the assessment with a multidisciplinary team, after which further follow-up care was offered to stroke patients. The second intervention contained an intensive rehabilitation program consisting of face-to-face contacts between stroke patients and a multidisciplinary team versus a less intensive 
rehabilitation program as a control intervention. These two interventions differed from each other in terms of type of intervention, health care professionals being involved and in intensity and duration of the intervention. None of the studies had effect on social participation or activities of daily life. The quality of the fourteen studies ranged from $35 \%$ to $73 \%$ on the scale from $0-100 \%$ of the CONSORT statement. Based on the results of the review, there is little evidence on the effectiveness of short term follow-up care interventions for stroke patients, which should be the focus of future research as well as improving the methodological quality.

Since we have completed the search strategy of our review, there were several new review studies evaluating home based interventions for stroke patients. Different types of home based rehabilitation and care coordinated interventions were reviewed. Rehabilitation interventions were most effective in improving the quality of life. ${ }^{2}$ The rehabilitation intervention was provided in the first six months after stroke and the long-term effect is unknown. A review of Allison and colleagues (2012) also showed that the follow-up care interventions provided by stroke support workers, care coordinators or case managers, which also included mono-disciplinary interventions, had no effect on activities of daily life and quality of life. ${ }^{3}$ Some of the included studies were effective on other domains, such as improved levels of depression, less use of health care resources, high satisfaction with emotional support and increased knowledge of stroke by caregivers. Several included studies in our review were also effective on other domains, such as feeling less socially isolated, increased knowledge of stroke, and less visits from health care specialists $^{4,5,6}$, but these outcome measures were not considered as the focus of our review. Moreover, all the above review studies remarked that the interventions were very different from each other which made a comparison of the interventions difficult. Furthermore the quality of this type of studies should be improved significantly. 


\section{The feasibility of the structured assessment in health care}

As part of the intervention, we have developed the Assessment tool for the Consequences After Stroke (ACAS) to structurally assess stroke-related problems. The ACAS contains twelve domains; activities of daily life, instrumental activities of daily life, social activity, cognition, communication, psycho-emotion, fatigue, secondary prevention, medical consumption, medical condition, caregivers' strain and provision of information. Each domain has a stepwise structure and starts with brief initial questions for each domain, which can be further explored using additional questions or validated measurement instruments as needed. The feasibility of the ACAS was evaluated in a pilot study of 14 patients, 12 caregivers and 15 health care professionals. The results showed that the ACAS had good content validity (the content validity ratio ranged from 0.36 to 1.00 on a scale of -1 to +1 and a critical value of 0.54 ) and moderate to good criterion validity (the sensitivity ranged from $0 \%$ to $100 \%$ and the specificity ranged between $72.7 \%$ to $100 \%)$. Severe fatigue and cognitive limitations were some of the major problems identified by the use of ACAS. The evaluation of an adjusted version in a larger group of stroke patients in regular health care showed comparable results. The use of the ACAS benefitted the stroke care coordinators (SCCs) of home care services in providing long-term care to stroke patients. The SCCs could better assess stroke-related problems and detect these problems at an earlier stage. Health care professionals considered the assessment tool feasible in health care. Patients as well as caregivers expressed their positive opinion about the use of the ACAS. ${ }^{7}$

Similar results were recently found by Rothwell and colleagues (2013), who developed and evaluated the assessment tool called the Greater Manchester Stroke Assessment Tool (GM-SAT). ${ }^{8}$ The ACAS and the GM-SAT both assess a similar spectrum of stroke-related problems, of which the ACAS measures these problem domains in twelve items and the GM-SAT in 35 items. Compared to the GM-SAT, the domains in the ACAS are further specified by means of the validated measurement instruments, which provides specification for the referral options. Although the GMSAT was evaluated as positive, the researchers stated that the feasibility of the 
assessment tool should be further tested in the field of stroke, which has already been done for the ACAS. Comprehensive assessment tools were also developed for other target populations, such as the Comprehensive Frailty Assessment Tool (CFAI), which identifies frailty in elderly people. ${ }^{9}$ Use of the CFAl showed that frailty was more than just physical deficits, but elderly also experienced psychological and social problems. Just like the ACAS, the CFAI could detect more problems at an earlier stage, which indicates the value of using comprehensive assessment tools in health care.

\section{The effects of a new follow-up care model for stroke-specific problems}

The effectiveness of the intervention was evaluated in a non-randomized controlled trial, comparing the intervention region of Maastricht and the control region of Eindhoven. The intervention consisted of five home visits to stroke patients, for a period of 18 months. The SCC used the ACAS during each home visit to assess the stroke related-problems and to provide adequate long-term care. Patients and caregivers in the control group received the care as usual. The outcome domains were quality of life, activities of daily life, level of social activity, depression, anxiety and caregiver's burden, which were measured at baseline, 6, 12 and 18 months. The results showed that there were no differences in the quality of life between the patients in the intervention group and the control group. The intervention increased the levels of social activities in the region of Maastricht after 18 months, whereas the levels of social activities decreased in the control group. There were no further effects in terms of activities of daily life, anxiety and depression. With regard to caregivers, there were no differences in the quality of life, depression, anxiety and caregiver's strain between both groups. ${ }^{10}$

In a recent study by Wang and colleagues (2013) an education and rehabilitation program were evaluated in which patients received lectures about stroke and were offered discussion and support groups from therapists and nurses on how to cope with activities of daily life. ${ }^{11}$ They have found that patients gained more knowledge about stroke, which was related to an increase in social participation. While 
searching for effective interventions for stroke patients, we could broaden our view to interventions that are offered to patients with acquired brain injury. For instance, patients with acquired brain injury, which also included stroke patients, were offered an advisory program, in which patients received education and skills training to facilitate activities of daily life and caregivers were trained to assist the patient. Health care professionals monitored the training by means of home visits and telephone interviews. The results showed a positive effect on the activities of daily life of stroke patients, but does require the active involvement of the caregiver. ${ }^{12}$

\section{Process evaluation of the new follow-up care model}

To gain more insight into process-related factors that could have influenced the effectiveness of our new intervention, a process-evaluation was performed in parallel to the effect evaluation. ${ }^{13}$ The assessments of all patients were analyzed. Based on the results of the assessment, stroke patients most frequently reported problems concerning fatigue, cognition and activities of daily life over the period of 18 months. Furthermore, during the study it appeared that the intervention was only partially performed and that the intervention should be more flexible in terms of adjustment to patients' specific needs. The SCCs made good use of the ACAS but missed a structured referral system to tackle the problems that they have found. The results of our process-evaluation cannot be compared with other studies, because there are no other studies available who performed an effect evaluation combined with a process-evaluation. Most interventions are evaluated in terms of effect and cost reduction. ${ }^{14,15}$

\section{The opinion of patients, caregivers and stroke care coordinators}

As part of the process-evaluation, the opinion of patients, caregivers and the stroke care coordinators was assessed. Patients and caregivers received a questionnaire to measure the satisfaction with care at baseline, 6, 12 and 18 months. Furthermore, patients, caregivers and the SCCs also filled in a self-generated questionnaire at the end of the study to evaluate the way the intervention was organized. Patients and 
caregivers were satisfied with the care that they received during the study period. Patients commented that the SCCs gave good advice and organized effective longterm care. The caregivers reported that they received sufficient attention and emotional support by the SCCs and that each problem was discussed satisfactorily. A survey among stroke patients showed that about half of the patients had unmet needs after five years, of whom 39\% reported unmet needs regarding memory, fatigue and concentration. ${ }^{16}$ This requires an instrument that can identify the patients' needs and based on our study results, the ACAS seems to be the appropriate instrument to do so.

\section{Long-term problems in patients with TIA or minor stroke}

Patients who suffered a TIA or minor stroke seem to have no residual effects of the event, but there were several indications that they do experience problems. Therefore, a cross-sectional study was performed to evaluate long-term problems of patients with TIA or minor stroke. This group of patients was compared with a control group of stroke patients and a second control group of patients with angina pectoris (AP). All patients were assessed with the brief initial questions of the ACAS between 2-8 months after the event. The data indicated that more than half of the patients with a TIA, minor stroke and stroke experienced five or more problems, compared to one third of the patients with AP. Cognitive and communicational limitations were major problems (39\%-49\%) for TIA, minor stroke and stroke patients, whereas $6 \%-10 \%$ of the patients with AP experienced these problems. This indicated that cognitive and communicational deficits were related to the event and follow-up care should be provided to patients with TIA and minor stroke. ${ }^{17}$

During the last few years more studies on cognitive limitations in patients with TIA and minor stroke have been performed. A recent study by Bocti and colleagues (2013) assessed cognitive impairments and indicated that $55 \%$ of the TIA and minor stroke patients experienced problems after three months, which is comparable to our findings. ${ }^{18}$ They emphasized the inclusion of a short cognitive assessment in clinical practice for TIA and minor stroke patients. The identification of these 
problems also requires the provision of follow-up care for this groups of patients. Home-based stroke prevention programs have been developed, which showed favorable effects in raising the awareness of life style modifications and identifying health signals. ${ }^{19}$ The current interventions that are provided to TIA and minor stroke patients primarily focus on the identification of predictors for long-term problems and on the development of prevention strategies for stroke. There are no studies evaluating follow-up interventions or therapies which are targeted on the TIA and minor stroke patients to meet their specific needs for care. This should be an important focus for future research.

\section{Methodological considerations}

This study poses several methodological considerations. There are only a few studies that have evaluated the effect of long-term care for stroke patients. Our study is therefore a valuable addition in the field of research evaluating the effectiveness of multidisciplinary long-term intervention for stroke patients after being discharged home. This study is also one of the few studies that have evaluated the intervention in terms of effectiveness as well as process.

Another important aspect of our study is the development of the assessment tool ACAS. The ACAS is a complete and innovative structured assessment tool which is different from the already existing tools. The tool is stroke specific and covers a full spectrum of stroke-related problems. ${ }^{20,21,22}$ In addition, the ACAS has been tested in regular health care and is ready for clinical use. ${ }^{7,23}$

We have performed a non-randomized controlled trial comparing an intervention and a control region to evaluate the effect of our intervention. A randomized controlled trial (RCT) is most often the choice of design for studies evaluating the effect of a new intervention, but this was not appropriate for our study for several practical reasons. Randomizing patients to an intervention and a control group in the same region posed a methodological and an ethical considerations. In the region of Maastricht, we utilized the existing follow-up and long-term care to implement our intervention model. The two SCCs of home care services were the most adequate 
health care professionals to perform the intervention, but the SCCs could not provide both the intervention and the control condition within the same region and the study period without study contamination. Not offering long-term care to stroke patients in this region was considered unethical. A waiting-list control study was not possible due to time-constraints. A control condition of 18-months followed by an intervention of 18 months, extended the study period beyond the available time and financial capacities.

Our study probably has a selection bias. First of all, there was a large group of patients who was not referred to home care services for the intervention after discharge home from hospital or inpatient rehabilitation. It is possible that these patients had no residual deficits and the health care professionals considered that the patients did not need the intervention. In addition, the SCCs of home care services did not ask each patient who received the intervention to participate in the effect and process evaluation for unknown reasons. The SCCs may have excluded patients with more severe problems and considered them unable to participate. Finally, several patients refused to participate because the intervention and evaluation were too much of a burden to them.

There are also several limitations with regard to the outcome measures. Quality of life, the primary outcome measure, is a very broad term and there are many factors, besides the intervention that we offered, that can affect the quality of life. We have selected a questionnaire which is specific for stroke patients, but stroke-related problems are not the only conditions that determine the quality of life. For instance, psychosocial factors could partially predict the quality of life of which depressive status and self-esteem were the strongest predictors. ${ }^{24}$ The last few years, it has become apparent that cognitive limitations, communicational problems and sever fatigue were major problems of stroke patients. Our study has also shown that many patients experienced these stroke-related problems after being discharged home. There were no specific outcome measures for these domains included in our study to determine the effect of the intervention. A possible explanation with regard to the experience of fatigue could be that many patients as well as care professionals are 
often unaware of the frequency of this problem related to stroke. ${ }^{25}$ In addition, social participation has also become an important goal in stroke rehabilitation next to functional recovery. However, the results of our review have shown that none of the included studies have measured the social participation of stroke patients. This outcome measure was also not included in our study, because we have measured the level of social activity. The social activity is related to the social participation, but the level of social activity was measured as the frequency of performed activities and is dependent on the physical abilities of the patients, while the social participation is more focused on the interaction with and the involvement of patients to the community.

During the study period, it was difficult to execute the standardized intervention. First of all, in some cases the SCCs did not assess every domain of the assessment tool during each home visit or they administered an additional validated measurement instrument on their own initiative which is not in accordance with the instructions of the tool. Furthermore, the reports of the SCCs about initiated longterm care and additional remarks were often limited, which made it difficult to interpret these reports properly. Besides standardizing the intervention, it was also difficult to standardize the organization of care due to organizational problems of the home care service and the stroke service of the region Maastricht. Finally, the followup care in the control region in Eindhoven was innovated during the study to keep up with national developments, which resulted in setting up the stroke care center specifically aimed at follow-up care. We monitored this development and evaluated both types of follow-up care to minimize the influence of the innovated care in the control region Eindhoven.

\section{Implications for clinical practice}

During the study, we have gathered valuable information and knowledge of longterm care for stroke patients and their caregivers. The results of the study have shown that there were many patients who experienced stroke-related problems. The type and number of problems varied across patients and therefore all stroke patients 
should be structurally and repeatedly assessed for the broad spectrum of strokerelated problems after being discharged home from hospitalization or inpatient rehabilitation for more than one year. The screening can be performed with use of the ACAS and should be administered by health care professionals who are able to carry out this assessment. Several important qualities of the care professional have to be considered. First of all, the care professional should be knowledgeable about the consequences of stroke. In addition, when he screens patients and caregivers on their limitations, the health care professional should be able to provide multifaceted long-term care. It is also important that the health care professional has frequent contact with other multidisciplinary care professionals. Finally, performing the assessment implies that the professional is the coordinator of the long-term care and the most important source of information for patients, caregivers and other health care professionals.

We also believe that patients with a TIA or minor stroke should also receive more follow-up care, because they experience more problems than was initially expected. Domains such as cognition, communication and fatigue were in particular major problems. ${ }^{17}$ The ACAS instrument can also be used here and it is important that these patients are monitored more frequently. Not all patients experience problems, therefore follow-up research should be initiated to determine prognostic indicators for patients who are at risk.

Improving the physical functioning of stroke patients is one of the major goals of stroke rehabilitation, but should not be the only goal from the perspective of the patients. This is in line with the results of our study because fatigue, cognition, communication and instrumental activities of daily life were the major problems of the stroke patients and not physical functioning. ${ }^{13}$ During the last few years, it has become clear that it is important for stroke patients to participate in social interactions. The World Health Organization has stated that successful rehabilitation is the reintegration of patients into the social network and the participation of patients in the community. ${ }^{26}$ To improve long-term care for stroke patients, the goal 
of rehabilitation as well as long-term care should therefore also focus on social participation, of which good physical functioning can be an important part. ${ }^{27}$

Our final important recommendation for clinical practice is the development of a structured referral system to improve the continuity of long-term care to stroke patients and their caregivers after assessment. We believe that screening for strokerelated problems is not enough and that adequate referral to other health care professionals is required to provide optimal long-term care. It is of importance that the health care professionals who carry out the assessment are aware of and have knowledge of the available options of referral in the region and have good cooperation with the different health care professionals.

There is still much discussion about how long-term care should be organized, but health care professionals do agree that long-term care needs to be improved. Based on this study, we have several considerations on how to change the way that the health care is organized. Changing the organization of health care is not an automatic process; but requires the cooperation of many different health care organizations and health care professionals. Clear and proper agreements should be stated between all involved health care professionals, with special emphasis on long-term care. It is also recommended that there is a health care professional who is able to maintain the focus of the involved professionals on the agreements made and on new improvements. In the field of long-term care after stroke there are many different health care professionals involved. It is therefore also important that stroke patients have a single health care professional where they can turn to for help and advice and who can coordinate the long-term care for the patient. ${ }^{28}$

\section{Future research}

The focus on improvements and developments in the long-term care for stroke patients has increased during the last several years but more improvements are still desired by the health care professionals. Therefore, there should be more high quality studies evaluating long-term care for stroke patient after discharge home from hospitalization or inpatient rehabilitation. Based on this study, future research 
should consider the following pitfalls; standardization of the control condition, inclusion of social participation as an outcome measure, and reporting a clear description of the intervention in the article.

The feasibility and clinical use of the ACAS was tested positive in a group of stroke patients receiving home visits by a SCC after hospitalization or inpatient rehabilitation. In the clinical field in the Netherlands, there is an increasing interest in the ACAS by health care professionals who provide home visits to stroke patients, as well as health care professionals providing long-term care in an outpatient clinic. Future research could examine the feasibility of the assessment tool in an outpatient clinic setting. It has also become apparent that general practitioners should be more aware of the consequences after stroke. ${ }^{29}$ It would therefore be of interest whether general practitioners could (perhaps) use a shorter version of the ACAS to identify patients at risk and refer them if necessary to home care services for a complete assessment and long-term care.

The results of this study have indicated that the intervention had no effect on the quality of life of stroke patients, but was effective in terms of levels of social activities. We have evaluated only a part of the care provided, because the evaluation was mainly focused on the care provided by the SCCS and not on the longterm care provided by other health care professionals. We believe that the structured assessment of stroke-related problems is very valuable to provide adequate long-term care, as indicated in this study, but subsequent care could be needed to reach a further positive effect. It is therefore important that future research will evaluate the effect of long-term care provided by all health care professionals.

This study focused on the evaluation of the effect of the intervention. The intervention required intensive care of the SSCs and other health care professionals and a cost-effectiveness evaluation of the intervention is of interest for future research. The design and procedure of this study could be used as a guideline for other studies. 
During the study, it appeared to be difficult to standardize the intervention. Furthermore, the control condition was also altered to keep up with national innovations of long-term care. Future research should take the clinical practice into account by developing of and setting out the intervention. The clinical practice is difficult to control, but is essential for interpreting the result of the intervention.

\section{Final remarks}

To conclude, it is important to make a clear distinction between follow-up care and long-term care. Shortly after being discharged home from the hospital, rehabilitation organization and/or home care services, patients receive care which is usually organized during the first six months after the event. This care is the continuity of the care provided during hospitalization and inpatient rehabilitation and we consider this care as follow-up care. Follow-up care for stroke patients is most often adequately organized, but patients still have a need for care after the first six months, which should be considered as the long-term care and still needs to be organized. In this study we have shown that it is possible to organize a long-term care model and we have also indicated that this long-term care can be effective. 


\section{References}

1. Fens M, Vluggen T, van Haastregt JC, Verbunt JA, Beusmans GH, van Heugten CM. Multidisciplinary care for stroke patients living in the community: a systematic review. Journal of Rehabilitation Medicine. 2013, 45(4), 321-330.

2. Graven C, Brock K, Hill K, Joubert L. Are rehabilitation and/or care co-ordination interventions delivered in the community effective in reducing depression, facilitating participation and improving quality of life after stroke? Disabil Rehabil. 2011, 33(17-18), 1501-1520.

3. Allison R, Shelling L, Dennett R, Ayers T, Evans PH, Campbell JL. The effectiveness of various models of primary care-based follow-up after stroke: a systematic review. Prim Health Care Res Dev. 2011, 12(3), 214-222.

4. Burton C, Gibbon B. Expanding the role of the stroke nurse: A pragmatic clinical trial. J Adv Nursing. 2005, 52, 640-650.

5. Mayo NE, Nadeau L, Ahmed S, White C, Grad R, Huang A, et al. Bridging the gap: The effectiveness of teaming a stroke coordinator with patient's personal physician on the outcome of stroke. Age Ageing. 2008, 37,32-38.

6. Allen K, Hazelett S, Jarjoura D, Hua K, Wright K, Weinhardt J, et al. A randomized trial testing the superiority of a postdischarge care management model for stroke survivors. J Stroke Cerebrovasc Dis. 2009, 18, 443-452.

7. Fens M, Beusmans G, Limburg M, Metsemakers J, van Hoef L, van Heuten C. Development of the Assessment tool for long-term Consequences After Stroke (ACAS) to detect long-term stroke-related problems: a developmental and feasibility study. Submitted.

8. Rothwell K, Boaden R, Bamford D, Tyrrell PJ. Feasibility of assessing the needs of stroke patients after six months using the GM-SAT. Clin Rehabil. 2013, 27(3), 264271.

9. De Witte N, Gobbens R, De Donder L, Dury S, Buffel T, Schols J, Verté D. The comprehensive frailty assessment instrument: Development, validity and reliability. Geriatr Nursing. 2013, 34(4), 274-281.

10.Fens M, Van Heugten C, Beusmans G, Metsemakers JF, Kester A, Limburg M. The effect of a stroke-specific follow-up care model on the quality of life of stroke patients and caregivers; a controlled trial. Journal of Rehabilitation Medicine. 2014, 46(1), 7-15. doi: 10.2340/16501977-1239.

11. Wang L, Chen CM, Liao WC, Hsiao CY. Evaluating a community-based stroke nursing education and rehabilitation programme for patients with mild stroke. Int J Nurs Pract. 2013, 19(3), 249-256.

12. Grill E, Ewert T, Lipp B, Mansmann U, Stucki G. Effectiveness of a communitybased 3-year advisory program after acquired brain injury. Eur J Neurol. 2007, 14(11), 1256-1265.

13.Fens $M$, Beusmans $G$, Limburg $M$, van Hoef $L$, van Haastregt J, Metsemakers J, van Heugten C. A stroke-specific follow-up care model for stroke patients and caregivers; a process evaluation with a longitudinal design. Submitted. 
14. Gladman J, Whynes D, Lincoln N. Cost comparison of domiciliary and hospitalbased stroke rehabilitation. DOMINO Study Group. Age Ageing. 1994, 23(3), $241-$ 245.

15. Björkdahl A, Sunnerhagen KS. Process skill rather than motor skill seems to be a predictor of costs for rehabilitation after a stroke in working age; a longitudinal study with a 1 year follow up post discharge. BMC Health Serv Res. 2007, 7, 209.

16. McKevitt C, Fudge N, Redfern J, Sheldenkar A, Crichton S, Rudd AR, Forster A, Young J, Nazareth I, Silver LE, Rothwell PM, Wolfe CD. Self-reported long-term needs after stroke. Stroke. 2011, 42(5), 1398-1403.

17. Fens $M$, van Heugten CM, Beusmans GHMI, Limburg $M$, Haeren R, Kaemingk $A$, Metsemakers JFM. Not as transient: patients with transient ischaemic attack or minor stroke experience cognitive and communication problems; an exploratory study. European Journal of General Practice. 2013, 19(1), 11-16.

18. Bocti C, Legault V, Leblanc N, Berger L, Nasreddine Z, Beaulieu-Boire I, Yaneva K, Boulanger JM. Vascular Cognitive Impairment: Most Useful Subtests of the Montreal Cognitive Assessment in Minor Stroke and Transient Ischemic Attack. Dement Geriatr Cogn Disord. 2013, 36(3-4), 154-162.

19. Sit JW, Yip VY, Ko SK, Gun AP, Lee JS. A quasi-experimental study on a communitybased stroke prevention programme for clients with minor stroke. J Clin Nurs. 2007, 16(2), 272-281.

20. Reynolds T, Thornicroft G, Abas M, Woods B, Hoe J, Leese $M$, et al. Camberwell Assessment of Need for the Elderly (CANE). Development, validity and reliability. Br J Psychiatry. 2000, 176, 444-452.

21. Edwards DF, Hahn MG, Baum CM, Perlmutter MS, Sheedy C, Dromerick AW. Screening patients with stroke for rehabilitation needs: validation of the poststroke rehabilitation guidelines. Neurorehabil Neural Repair. 2006, 20(1), 42-48.

22. van Heugten C, Rasquin S, Winkens I, Beusmans G, Verhey F. Checklist for cognitive and emotional consequences following stroke (CLCE-24): development, usability and quality of the self-report version. Clin Neurol Neurosurg. 2007, 109(3), 257-262.

23. Murray J, Forster A, Young J. Survey to investigate the role of the community stroke care coordinator. Br J Community Nurs. 2008, 13(1), 31-36.

24. Teoh V, Sims J, Milgrom J. Psychosocial predictors of quality of life in a sample of community-dwelling stroke survivors: a longitudinal study. Top Stroke Rehabil. 2009, 16(2), 157-166.

25. Crosby GA, Munshi S, Karat AS, Worthington E, Lincoln NB. Fatigue after stroke: frequency and effect on daily life. Disabil Rehabil. 2012, 34(8), 633-637.

26. Scott CL, Phillips LH, Johnston M, Whyte MM, MacLeod MJ. Emotion processing and social participation following stroke: study protocol. World Health Organization. International Classification of Functioning,Disability and Health. Geneva: WHO, 2001.

27. Mayo NE, Bronstein D, Scott SC, Finch LE, Miller S. Necessary and sufficient causes of participation post-stroke: practical and philosophical perspectives. Qual Life Res. 2013, [Epub ahead of print]. 
28. Hare R, Rogers $H$, Lester $H$, McManus R, Mant J. What do stroke patients and their carers want from community services? Fam Pract. 2006, 23(1), 131-136.

29. Greenwood N, Mackenzie A, Harris R, Fenton W, Cloud G. Perceptions of the role of general practice and practical support measures for carers of stroke survivors: a qualitative study. BMC Fam Pract. 2011, 12, 57. 


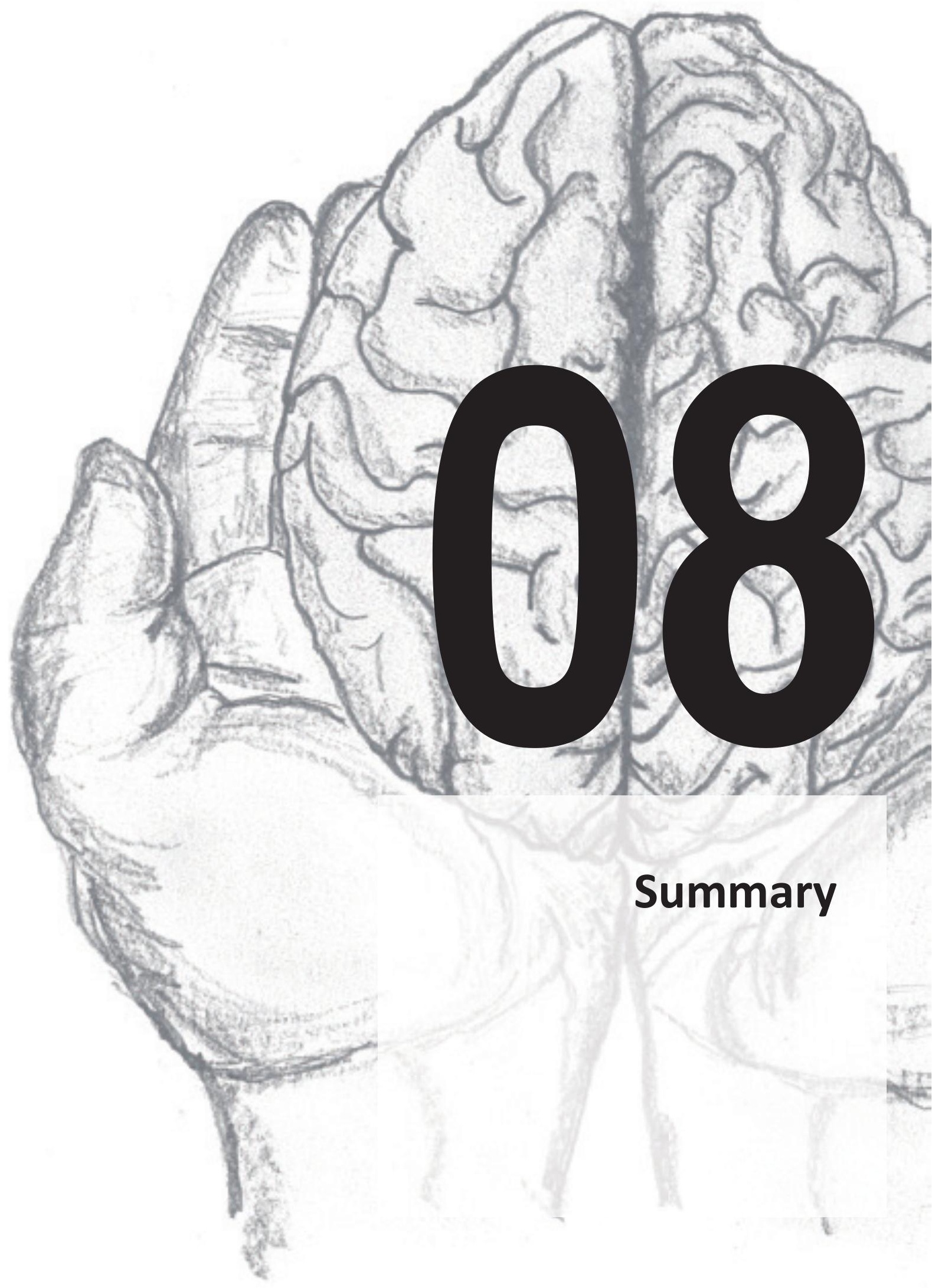


140 | Summary 


\section{Introduction}

Each year about 40.000 people in the Netherlands suffer their first stroke or cerebrovascular accident (CVA). Patients often experience long-term problems due to the event, such as physical complaints, cognitive and communicational problems, feelings of depression, being severely fatigued and limitation in social activities. The caregivers are often also affected by the consequences of the stroke; for instance they could experience burden or a depression. Care for stroke patients in the Netherlands is properly organized within the first year after stroke; specialized stroke units are organized in most hospitals to provide adequate acute care. Furthermore regional stroke services are organized in which different health care organizations participate and agreements are made about the way the stroke care is organized. The long-term care for stroke patients is however insufficiently organized and it is unclear in what way this care should be organized. In this thesis, different studies are described in which the way the long-term care should be organized is the primary focus.

\section{The main findings}

A systematic review was performed to evaluate what type of multidisciplinary interventions were effective for stroke patients (chapter 2). Databases Pubmed, Embase, Cinhl and Cochrane were searched from January 1980 until July 2012 using the following selection criteria; randomized controlled trials focused at multidisciplinary interventions for stroke patients, being discharged home after hospitalization or inpatient rehabilitation. The effectiveness of the interventions was determined using outcome measures for the domains of quality of life, activities of daily living and social participation. Out of 1498 studies found, 14 studies met the selection criteria, which were checked by two researchers to independently extract research data and to independently assess the quality of the studies. Two interventions showed positive effects in terms of improving the quality of life; one intervention contained a telephonic screening carried out by a specialized nurse within one week after being discharged home. A biopsychological screening was 
performed one month later, which was focused on stroke-related problems. The results of these screenings were discussed with a multidisciplinary team to develop a care plan for each individual patient. The second intervention consists out of minimum six personal contacts a week in which patients receive therapy from a multidisciplinary team during a period of 12 weeks. This care was compared with a less intensive care program containing maximum three personal contacts a week for a period of 12 weeks. Both interventions were effective but differed considerably in organization, health care professionals involved, intensity and duration. The review also showed that none of the interventions were effective on the domains of activities of daily living; the domain of social participation was not assessed in any of the included studies. There are little indications for which type of multidisciplinary care is effective for stroke patients being discharged home. The methodological quality of the 14 included studies ranged between 35\% and 73\% (on a scale from 0\%$100 \%)$. This indicates a need for more high-quality research. Future research should focus on the effectiveness of multidisciplinary interventions and on improving the quality of the studies.

To assess the long-term stroke-related problems after being discharged home, a structured assessment tool was developed (Assessment tool for the Consequences After Stroke, ACAS), which was based on a literature search and several consults with health care professionals involved in stroke care. The assessment tool has a stepwise structure and contains 12 domains of stroke-related problems. Each domain starts with a brief initial question to assess whether the patients experiences a problems, which can be further explored using validated measurement instruments. The ACAS was evaluated in terms of feasibility, content validity and criterion validity (chapter 3). The instrument was tested on 14 patients and 12 caregivers and 15 different health care professionals were asked for their professional opinion. To investigate the feasibility of the ACAS, patients, caregivers and the health care professionals received a questionnaire and judged whether the ACAS was feasible for use in clinical practice. All participants considered the assessment tool as feasible in health care. 
The content validity was measured using the content validity ratio (with a range from -1 to +1 ; a value above 0.54 is considered as positive), of which values ranged from 0.36 to 1.00 . The criterion validity was expressed in terms of sensitivity and specificity (the higher, the better). The sensitivity had a range from $0 \%$ to $100 \%$ and the specificity varied between $73 \%$ and $100 \%$. Major problems on the ACAS reported by patients and caregivers were being severely fatigued and having cognitive limitations. Based on the first evaluation some minor changes was applied and an adjusted version was further tested in a second group of 62 stroke patients in regular health care. The results of this group of stroke patients were similar to the result of the first group of patients. The ACAS has a moderate to good content validity and criterion validity and was considered feasible for use in regular health care by all participants.

The effectiveness of the intervention in the region of Maastricht in order to improve the quality of life of stroke patients and their caregivers was evaluated in a nonrandomized controlled trial (chapter 4). The intervention consists of five home visits for patients and their caregivers provided by the stroke care coordinator (SCC) of home care services for a period of 18 months. During each home visit the SCC used the ACAS. The reported problems were discussed with the patients and their caregivers and based on the results advice and specific referral to other health care professionals was provided. The primary outcome measure for the effect evaluation was the quality of life, which was measured at baseline and after 6, 12 and 18 months. The other outcome measures were activities of daily living, level of social activity, depression, anxiety and caregiver's burden. The outcomes measures of the intervention were compared with a control group (regular care) in the region of Eindhoven. Based on the analyses there were no differences between the intervention group ( $N=62)$ and the control group $(\mathrm{N}=55)$ on the quality of life. The level of social activity was however significantly improved in the intervention group after 18 months compared to baseline, whereas the level of social activity was significantly decreased in the control group after 18 months. There were no effects 
found on the other outcome measures. A possible explanation for the lack of effectiveness could be that the intervention was primarily focused on the screening of stroke-related problems using the ACAS and less focused on the adequate referral and further follow-up care.

A process-evaluation was performed in parallel to the effect evaluation to gain insight into the process-related factors that could have affected the effect of the intervention (chapter 5). The assessment of the ACAS of 77 patients and 59 caregivers were analyzed. Patients as well as caregivers received a questionnaire to measure the satisfaction with care after 1, 6, 12 and 18 months. To evaluate the way the intervention was organized patients and caregivers filled in an additional questionnaire at the end of the study period. The involved SCCs $(n=4)$ received a questionnaire about the intervention after 18 months. The analyses of the home visits and the assessment of the ACAS showed that patients and caregivers received on average 3.8 (SD 1.4) home visits and about $55 \%$ of them had a follow-up period of maximum 18 months. The problems most frequently reported problems by patients during the first 18 months after being discharged home regarded the domains of fatigue, cognition, communication, decreased levels of social activity and instrumental activities of daily living. A total of 1074 problems were identified using the assessments, which resulted in 363 actions initiated by the SCCs, mainly supportive listening, providing information and advice, arranging physical aids and referral to other health care professionals. The stroke patients and their caregivers were satisfied with the care that they received. The SCCs have reported that they were very satisfied with the use of the ACAS, but that they missed a structured referral system to other health care professionals. The results showed that the intervention was partially performed in accordance with the initiated protocol, suggesting five home visits for a period of 18 months. Tailored care with a structured assessment procedure and referral system is recommended for stroke patients and their caregivers after being discharged home from the hospital or inpatient 
rehabilitation. Future research should focus on the effectiveness of such type of intervention.

It was recently believed that patients who have experienced a TIA (Transient Ischaemic Attack) or minor stroke have no neurological damage and experience no problems after the event. This group of patients usually received no regular followup care after being discharged home from the TIA outpatient clinic or the emergency room (ER). During the last several years there are more studies which showed that this group of patients experienced problems and indicated that follow-up care is needed. A cross-sectional, inventory study was performed to evaluate whether patients with a TIA or minor stroke experienced problems as a consequence of the event (chapter 6). Patients were selected who had a TIA or minor stroke during the last 6 months not requiring hospital admission. The two control groups consisted out of stroke patients who were recently being discharged home after the hospitalization or inpatient rehabilitation and patients with angina pectoris (AP) who had visited the outpatient clinic of cardiology or the ER. Patients from all three groups were interviewed by telephone or home visit using the brief initial questions of the ACAS between 2-8 months after the event. Based on the data $51 \%$ of the patients with a TIA or minor stroke and $71 \%$ of the stroke patients reported more than 4 problems compared to $32 \%$ of the patients with AP. Cognitive and communicational problems were indicated by $39 \%$ to $49 \%$ of the patients with a TIA, minor stroke and stroke. Furthermore, TIA and minor stroke patients had more cognitive $(\mathrm{N}=27,49 \%)$ and communicational $(\mathrm{N}=23,42 \%)$ limitations than the patients with AP $(\mathrm{N}=7,10 \%$ and $\mathrm{N}=4,6 \%$; respectively). About half of the group of patients with TIA and minor stroke experienced problems on the domains of cognition and communication, which were specific to the cerebrovascular event. This indicates the need that general practitioners (GP) and practice nurses should be aware of potential problems that TIA and minor stroke patients can experience after the event requiring regular and systematic monitoring. Future research should examine prognostic indicators to 
identify patients with TIA and minor stroke who are at risk of experiencing these problems.

In the last chapter (7) the main findings were discussed and conclusions were summarized. In addition, methodological considerations about the studies that were carried out and implications for further research and clinical practice were reported. There were several methodological considerations with regard to the studies that were performed. An important strength was that this study is one of the first studies about the long-term effects of an intervention for stroke patients living in the community, which evaluated the intervention in terms of effect as well as process. In addition, the assessment tool ACAS was developed which is more complete and comprehensive that the already existing assessment tools, because it contains a broad spectrum of stroke-related problems and is suitable for use in the daily clinical practice. A randomized controlled trial would be the optimal study design but randomizing patients to an intervention and a control group in the same region was methodologically and ethically not possible in our study. Therefore in this study the intervention groups was compared to a control group from a different region. Our review has indicated that there are few high-quality and effective studies, which indicates that this study is a valuable addition in the field of research evaluating longterm interventions for stroke patients. Another methodological consideration is that a possible selection bias, because not all patients from the hospital or inpatient rehabilitation were referred to home care services, not all patients were asked to participate to the study and not all patients have consented to participate. Furthermore the primary outcome measure, the quality of life, can be affected by various factors which were not considered in our study. Limited cognition, communication and being severally fatigued are very common stroke-related problems, as was also shown in our study, but these problems were not measured as part of the effect evaluation of the intervention. Finally, it was difficult the execute the standardized intervention during the study period. Patients received tailor-made care based on the expertise of the SCCs and based on the needs of the patient. In 
addition, the reports by the SCCs about the initiated follow-up care and referral were often difficult to interpret. The follow-up care in the control region was innovated during the study period as a result of national developments in long-term care for stroke patients, such as setting up a stroke care center, which limited the contrast between both regions more than initially expected.

Several recommendations are made based on the results of the described studies. Stroke patients should be structurally screened after being discharged home by a professional health care professional, who is a central source of information for patients and a coordinator of the long-term care after being discharged home. Furthermore a structured referral system should be developed to improve the continuity of follow-up care based on the structured screening of stroke-related problems. Improving the social participation of patients should be an important goal of rehabilitation and long-term care. A good cooperation between all involved health care professionals in the stroke service is needed to realize all these improvements in stroke care. Several recommendation in regard to future research are the following; first of all there should be more research evaluating long-term interventions for stroke patients. Future research should also evaluate the effect of a structural assessment combined with a structured referral system. Furthermore, an important addition to the effect evaluations is to investigate the cost-effectiveness of this type of interventions. A final remark is that it is desirable that follow-up care for patients with a TIA or minor stroke is further studied. 
148 | Summary 


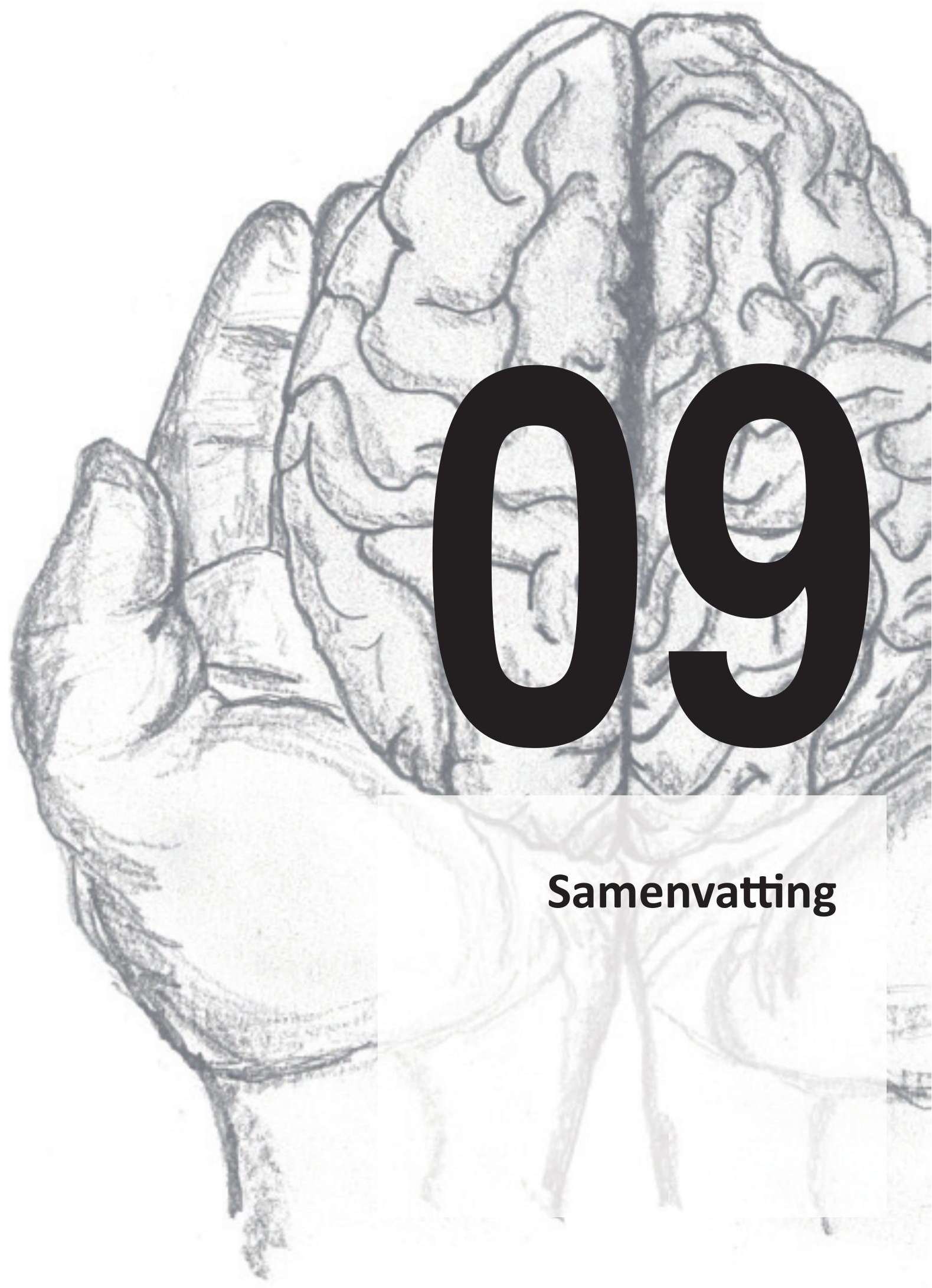


150 | Samenvatting 


\section{Inleiding}

Jaarlijks krijgen ongeveer 40.000 mensen in Nederland een beroerte of cerebrovasculair accident (CVA). Patiënten ervaren vaak nog lang problemen na het doormaken van het CVA, zoals fysieke klachten, cognitieve en communicatieve problemen, depressieve gevoelens, vermoeidheid en sociale beperkingen. Ook de naasten van de patiënten worden getroffen door de gevolgen van het CVA; zij raken bijvoorbeeld overbelast of worden somber. In Nederland is de zorg na een beroerte goed geregeld in het eerste jaar; de meeste ziekenhuizen hebben gespecialiseerde stroke units voor de acute opvang en participeren in regionale stroke services waarin ketenafspraken zijn vastgelegd. De langdurige zorg voor CVA patiënten is nog niet voldoende ontwikkeld en het is onduidelijk hoe deze zorg het best georganiseerd kan worden. In dit proefschrift worden verschillende studies beschreven waarin de inrichting van de zorg op de langere termijn na een beroerte centraal staat.

\section{De hoofdbevindingen}

Een systematische review werd uitgevoerd om te evalueren welke vormen van multidisciplinaire interventies voor CVA patiënten effectief zijn (hoofdstuk 2). Databronnen Pubmed, Embase, Cinahl en Cochrane werden doorzocht van januari 1980 tot juli 2012 met als selectiecriteria; gerandomiseerde effectstudies gericht op multidisciplinaire interventies voor CVA patiënten die naar huis ontslagen zijn vanuit het ziekenhuis of na intramurale revalidatie, waarbij de effectiviteit van de interventies werd vastgesteld op de domeinen kwaliteit van leven, dagelijkse activiteiten en/of sociale participatie. Van de 1498 studies die gevonden werden, voldeden 14 studies aan de selectiecriteria, die vervolgens onafhankelijk door twee onderzoekers werden bekeken om onderzoeksgegevens te achterhalen en om de kwaliteit van de studies te beoordelen. Twee interventie lieten effecten zien op de verbetering van de kwaliteit van leven; één interventie bestond uit een telefonische screening uitgevoerd door een gespecialiseerd verpleegkundige binnen een week na ontslag naar huis; een maand later volgde een biopsychosociale screening gericht op CVA-gerelateerde problemen. De resultaten van deze screenings werden besproken 
binnen een multidisciplinair team, van waaruit een zorgplan opgezet werd voor ieder individuele patiënt. De tweede effectieve interventie bestond uit minimaal zes persoonlijke contacten per week, waarin patiënten therapie aangeboden kregen van een multidisciplinair team gedurende een periode van 12 weken. Deze zorg werd vergeleken met een minder intensief zorgaanbod bestaande uit maximaal 3 persoonlijke contacten per week gedurende een periode van 12 weken. Deze beide interventies zijn effectief, maar zeer verschillend van elkaar met betrekking tot de opzet van zorg, de betrokken zorgverleners, de intensiteit en de frequentie. Uit de evaluatie bleek dat geen enkele studie effecten had gevonden op verbetering van de dagelijkse activiteiten; sociale participatie werd in geen enkele studie gemeten. De resultaten van de review geven dus aan dat er nog weinig indicaties zijn voor welke vorm van multidisciplinaire interventie effectief is voor CVA patiënten die naar huis ontslagen zijn. De kwaliteit van de 14 studies varieerde tussen 35\% en 73\% (op een schaal van 0\%-100\%). Dat betekent dat er betere onderzoeken nodig zijn. Toekomstig onderzoek moet zich dan ook meer richten op de effectiviteit van multidisciplinaire interventies en op kwaliteitsverbeteringen van de studies.

Voor de signalering van lange termijn problemen in de thuissituatie na een CVA is een gestructureerd screeningsinstrument ontwikkeld (Signaleringsinstrument voor de langtermijn Gevolgen na een Beroerte, SIGEB of de Engelstalige benaming, Assessment tool for the Consequences After Stroke, ACAS). De SIGEB is ontwikkeld op basis van literatuuronderzoek en raadpleging van experts vanuit de bij de zorg betrokken disciplines. Het screeningsinstrument kent een getrapte structuur en bevat 12 CVA-gerelateerde probleemdomeinen. leder domein start met een korte startvraag om het problemendomein te screenen, die vervolgens verder verdiept kunnen worden middels valide vragenlijsten. De SIGEB is onderzocht in termen van toepasbaarheid, inhoudsvaliditeit en criterium validiteit (hoofdstuk 3). Hiervoor is het instrument toegepast bij 14 patiënten en 12 naasten en werden 15 experts benaderd voor raadpleging. Om de toepasbaarheid van de SIGEB te onderzoeken ontvingen de patiënten, naasten en zorgverleners vragenlijsten. Alle deelnemers 
beoordeelden de SIGEB als toepasbaar voor zorgverlening. De inhoudsvaliditeit werd gemeten middels de inhoudsvaliditeit ratio (met een range van -1 tot +1 , waarbij een waarde boven 0.54 als positief kan worden beoordeeld), waarvan de waardes varieerden tussen de 0.36 en 1.00. De criterium validiteit werd uitgedrukt in sensitiviteit en specificiteit (hoe hoger, hoe beter). De sensitiviteit had een bereik tussen de $0 \%$ en $100 \%$ en de specificiteit tussen de $73 \%$ en $100 \%$. De meest gerapporteerde problemen op de SIGEB waren ernstige vermoeidheid en cognitieve beperkingen. Op basis van de eerste evaluatie werd een aangepaste versie vervaardigd en onderzocht bij een tweede groep van 62 CVA patiënten in de reguliere zorg. De resultaten van de tweede groep CVA patiënten leverde vergelijkbare resultaten op. De SIGEB heeft een redelijke tot goede inhoudsvaliditeit en criteriumvaliditeit en werd door alle deelnemers als toepasbaar beschouwd voor gebruik in de praktijk.

Om de effectiviteit van een door ons ontwikkelde interventie in de regio Maastricht op de kwaliteit van leven van CVA patiënten en hun naasten te onderzoeken werd een niet-gerandomiseerde, gecontroleerde studie uitgevoerd (hoofdstuk 4). De interventie bestaat uit vijf huisbezoeken bij patiënten en naasten afgelegd door een CVA verpleegkundige van de thuiszorg gedurende een periode van 18 maanden. Tijdens ieder huisbezoek maakt de CVA gespecialiseerde verpleegkundige gebruik van de SIGEB. De gesignaleerde problemen worden met de patiënt en diens naaste besproken en gericht advies en doorverwijzing vindt plaats. Als primaire uitkomstmaat voor de effect studie werd de kwaliteit van leven van patiënten en naasten gemeten op baseline en na 6, 12 en 18 maanden. Verdere uitkomstmaten waren dagelijkse activiteiten, sociale activiteiten, depressie, angst en zorglast. De uitkomsten van de interventie werden vergeleken met een controlegroep (reguliere zorg) in de regio Eindhoven. Uit de analyses kwam naar voren dat er geen verschil was tussen de interventiegroep $(\mathrm{N}=62)$ en de controlegroep $(\mathrm{N}=55)$ met betrekking tot de kwaliteit van leven. Het niveau van sociale activiteiten was echter significant verbeterd na 18 maanden in de interventiegroep ten opzichte van het begin van de 
studie, terwijl dit significant verslechterde in de controlegroep na 18 maanden. Er werden geen effecten gevonden op de andere uitkomstmaten. Een mogelijke verklaring voor het gebrek aan effectiviteit is dat de interventie vooral gericht was op het screenen van CVA gerelateerde problemen middels de SIGEB en minder op adequate doorverwijzing en zorg.

Om inzicht te krijgen in proces-gerelateerde factoren die van invloed zouden kunnen zijn op het effect van de interventie is parallel aan de effectiviteitsevaluatie is een procesevaluatie uitgevoerd (hoofdstuk 5). De SIGEB assessments van 77 patiënten en 59 naasten werden geanalyseerd. Om de tevredenheid met de zorg te meten na 1, 6, 12 en 18 maanden kregen zowel patiënten als naasten een vragenlijst voorgelegd. Ter evaluatie van de organisatie van de interventie kregen patiënten en naasten aan het einde van de studieperiode een extra vragenlijst overhandigd. De betrokken CVA verpleegkundigen $(n=4)$ kregen na 18 maanden een vragenlijst over de interventie. Uit de analyses van de huisbezoeken en de assessments met de SIGEB kwam naar voren dat de patiënten en naasten gemiddeld 3.8 (SD 1.4) huisbezoeken hebben ontvangen en ongeveer $55 \%$ van hen heeft een follow-up periode gehad van maximaal 18 maanden. De meest gerapporteerde problemen door patiënten zijn vermoeidheid, cognitie, communicatie, verminderde sociale activiteiten en instrumentele activiteiten van dagelijks leven gedurende de eerste 18 maanden na ontslag naar huis. In totaal zijn er 1074 problemen geïdentificeerd middels de assessments, waarvoor 363 vervolgacties door de CVA verpleegkundigen zijn ingezet, zoals met name ondersteunend luisteren, informeren en adviseren, aanvraag van hulpmiddelen en verwijzingen. De CVA patiënten en hun naasten waren tevreden met de zorg die zij ontvangen hebben. De CVA verpleegkundigen hebben aangegeven zeer tevreden te zijn met het gebruik van de SIGEB, maar ze missen een gestructureerd verwijssysteem naar andere zorgverleners als vervolgactie op de gesignaleerde problemen. De resultaten laten zien dat de interventie gedeeltelijk was uitgevoerd volgens de initiële opzet, waarbij werd uitgegaan van 5 huisbezoeken gedurende een periode van 18 maanden. Nazorg-op-maat met een gestructureerde 
assessment en verwijssysteem lijkt het meest geschikt voor CVA patiënten en hun naasten na ontslag naar huis vanuit het ziekenhuis of intramurale revalidatie. Toekomstig onderzoek dienst zich op de effectiviteit van een dergelijke interventie te richten.

Tot voor kort werd aangenomen dat patiënten na het doormaken van een TIA (Transient Ischaemic Attack) of lichte beroerte (minor stroke) geen schade ondervinden en geen problemen ervaren. Daarom krijgt deze groep patiënten veelal geen reguliere nazorg na ontslag van de TIA poli of de spoed eisende hulp (SEH). De afgelopen jaren verschenen steeds vaker studies waaruit blijkt dat ook deze groep patiënten problemen ervaart en dat nazorg voor een deel van deze groep patiënten wel gewenst is. Om meer inzicht te krijgen in deze problematiek werd een crosssectionele, inventariserende studie uitgevoerd om te onderzoeken of patiënten met een TIA of lichte beroerte problemen ervaren als gevolg van het incident (hoofdstuk 6). Er werden patiënten geselecteerd die in de afgelopen 6 maanden een TIA of lichte beroerte hadden doorgemaakt, waarvoor een ziekenhuisopname niet vereist was. De twee controlegroepen bestonden uit CVA patiënten, die recentelijk vanuit ziekenhuis of intramurale revalidatie naar huis ontslagen waren en patiënten met angina pectoris (AP), die ook slechts een bezoek aan de poli of spoed eisende hulp van het ziekenhuis hadden gebracht. Patiënten van alle drie de groepen werden geïnterviewd met behulp van de korte startvragen van de SIGEB door middel van telefonisch contact of huisbezoeken tussen 2-8 maanden na het incident. Uit de gegevens bleek dat $51 \%$ van de patiënten met een TIA en lichte beroerte en $71 \%$ van de CVA patiënten meer dan vier problemen rapporteerden ten opzichte van $32 \%$ van de patiënten met AP. Cognitieve en communicatieve problemen werden aangegeven door $39 \%$ tot $49 \%$ van de patiënten met TIA, lichte beroerte en CVA. Daarnaast hadden patiënten met een TIA en lichte beroerte meer cognitieve ( $N=27,49 \%$ ) en communicatieve ( $N=23,42 \%)$ beperkingen dan de patiënten uit de AP groep ( $N=7$, $10 \%$ en $\mathrm{N}=4,6 \%$, respectievelijk). Ongeveer de helft van de patiënten met een TIA of lichte beroerte ervoer problemen op het gebied van cognitie en communicatie, die 
specifiek waren voor het doormaken van het incident. Het is dan ook noodzakelijk dat huisartsen en praktijkondersteuners zich bewust worden van de mogelijke problemen die patiënten na een TIA of lichte beroerte kunnen ervaren en deze groep regelmatig controleren. Onderzoek naar prognostische indicatoren voor patiënten met een verhoogd risico op problemen na het doorgemaakte TIA of lichte beroerte is zeer gewenst.

In het laatste hoofdstuk (7) zijn de belangrijkste bevindingen bediscussieert en conclusies samengevat. Daarnaast zijn methodologische overwegingen bij de uitgevoerde studies en implicaties voor verder onderzoek en de klinische praktijk beschreven.

De volgende methodologische overwegingen kunnen bij het onderzoek gemaakt worden. Een sterk punt is dat deze studie een belangrijke toevoeging is in het onderzoek naar de lange termijn interventies voor CVA patiënten aangezien uit onze review bleek dat er slechts weinig kwalitatief goede en effectieve studies zijn. Verder is onze studie een van weinige studies die zowel het effect als het proces van de interventie heeft geëvalueerd. In deze studie is het screeningsinstrument SIGEB ontwikkeld dat veelomvattender is dan de reeds bestaande screeningsinstrumenten, omdat het een breed scala aan CVA gerelateerde problemen omvat en geschikt is voor gebruik in de dagelijkse klinische praktijk in de thuissituatie. Een veel gebruikt onderzoeksdesign voor een vergelijkingsstudie zoals onze studie is een gerandomiseerd gecontroleerde trial geweest, maar het randomiseren van patiënten in een interventie en een controle groep in dezelfde regio was in methodologisch en in ethisch opzicht niet mogelijk binnen onze studie. Daarom is er in deze studie voor gekozen om een interventiegroep te vergelijken met een controle groep uit een andere regio. Een andere methodologische overweging is dat een geselecteerde groep CVA patiënten heeft deelgenomen aan deze studie, omdat niet alle patiënten vanuit het ziekenhuis en intramurale revalidatie zijn doorverwezen naar de thuiszorg, niet alle patiënten zijn benaderd voor deelname aan de studie en niet alle patiënten hebben ingestemd met deelname aan de studie. De primaire uitkomstmaat, de 
kwaliteit van leven, kan afhankelijk zijn van veel factoren, die in de studie niet zijn meegenomen. Cognitie, communicatie en vermoeidheid zijn veel voorkomende CVA gerelateerde problemen, zo blijkt ook uit deze studie, maar deze problemen zijn niet gemeten als onderdeel van de effectevaluatie van de interventie. Als laatste was het moeilijk om de gestandaardiseerde interventie toe te passen gedurende de hele studieperiode. De rapportages van de gespecialiseerde verpleegkundigen over ingezette vervolgacties en verwijzingen waren vaak lastig te interpreteren. Daarnaast is de nazorg in de controle regio geïnnoveerd gedurende de studieperiode als gevolg van nationale ontwikkelingen in lange termijn zorg voor CVA patiënten, zoals de opzet van een regionaal expertisecentrum voor CVA, waardoor het contrast tussen de beide regio's kleiner was dan aanvankelijk verwacht.

Op basis van de resultaten van de beschreven studies worden de volgende aanbevelingen gedaan. CVA patiënten dienen na ontslag naar de thuissituatie structureel gescreend te worden door een professionele zorgverlener, die tevens het centrale aanspreekpunt van de patiënt en de coördinator van de zorg na ontslag naar de thuissituatie is. Tevens moet er een gestructureerd verwijssysteem worden opgezet, zodat betere vervolgacties kunnen worden ingezet na de gestructureerde screening van problemen. Het verbeteren van de sociale participatie van de patiënt moet een belangrijk doel worden bij het leveren van de zorg. Goede samenwerking tussen alle betrokken zorgverleners in de CVA zorgketen is nodig om deze zorgverbeteringen te realiseren. Enkele aanbevelingen betreffende toekomstig onderzoek zijn de volgende; allereerst dient er meer onderzoek naar de lange termijn interventies voor CVA patiënten te worden uitgevoerd. Toekomstig onderzoek moet het effect van assessment gecombineerd met gestructureerde verwijzing evalueren. Daarnaast is onderzoek naar de kosteneffectiviteit van dergelijke interventies een belangrijke aanvulling op het uitvoeren van een effect-evaluatie. Tevens is het wenselijk dat de follow-up zorg voor patiënten met een TIA of lichte beroerte verder onderzocht wordt.

Tot slot wordt opgemerkt dat er een onderscheid gemaakt dient te worden in nazorg (tot 6 maanden na ontslag naar huis) en lange termijn zorg (start na 6 maanden). 
Nazorg is in de meeste regio's in Nederland goed georganiseerd, maar de lange termijn heeft nog verbeteringen nodig. In deze studie is aangetoond dat het mogelijk is om lange termijn zorg te organiseren en dat deze zorg effectief kan zijn. 


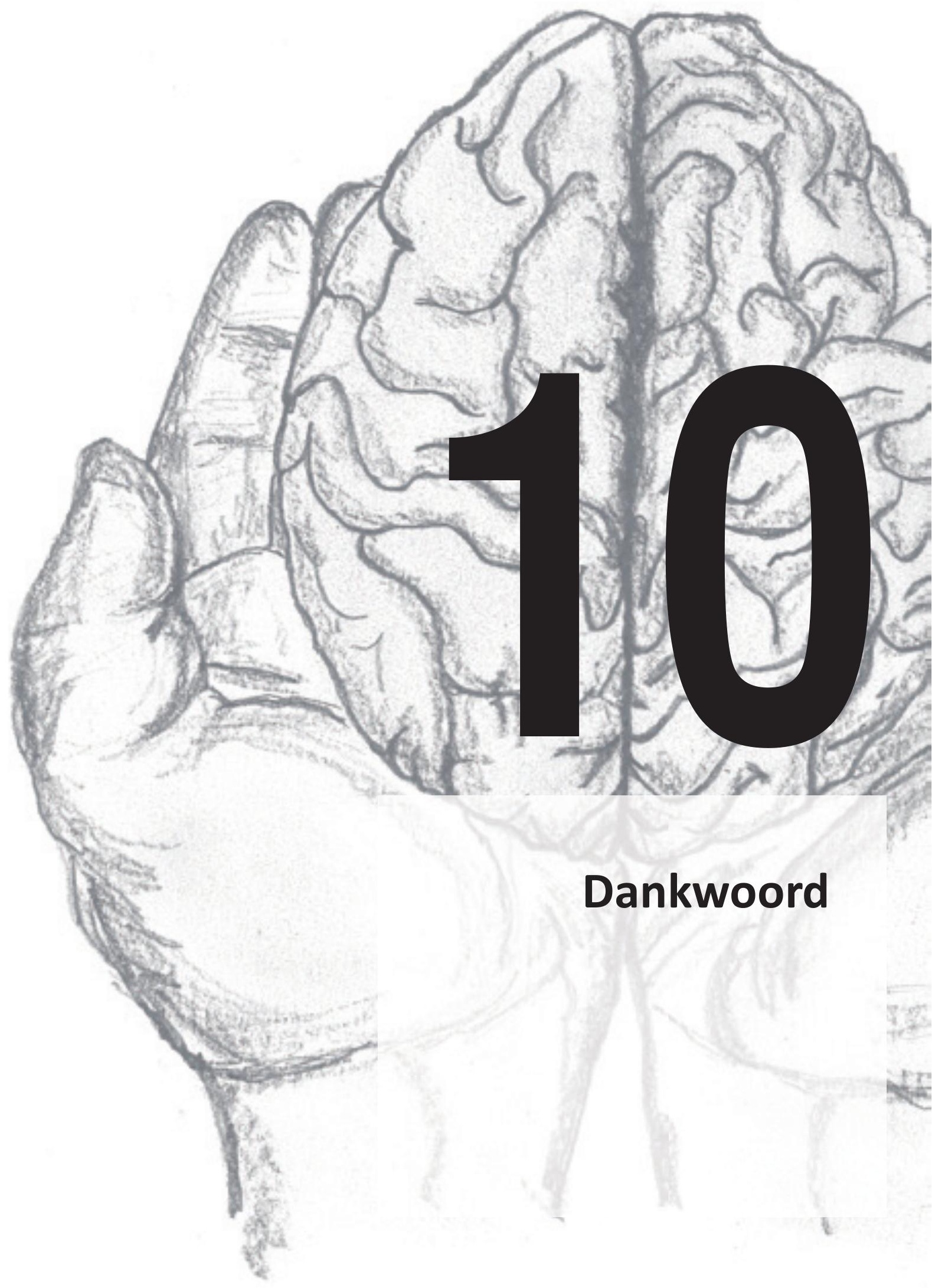


Het moment is aangekomen, het boekje is klaar! De afgelopen zeven jaar is voor mij een zeer waardevolle en leerzame periode geweest. Er is hierin veel veranderd en ik heb hierin veel meegemaakt, zowel op het werk als privé. Vlak na mijn afstuderen was ik nog onervaren toen ik begon aan mijn promotietraject. Met deze nieuwe kennis en ervaring ben ik persoonlijke gegroeid en heb doelen gerealiseerd waarvan ik voorheen niet had gedacht deze te verwezenlijken. Ik ben hier dankbaar voor. Uiteraard heeft deze periode ook moeilijke en stressvolle momenten gehad, maar met een goed portie doorzettingsvermogen en sterke wil kom je hier wel doorheen. Ook thuis is het een veel bewogen tijd geweest, zo begon het met de koop van mijn eerste auto om daarna op eigen benen te staan in mijn appartement. Daar bleef het niet bij. Ik heb mijn Robert gevonden en samen hebben we ons droomhuis gekocht. De mooie momenten bleven komen en ben ik in het huwelijksbootje gestapt. Nu bij de afsluiting van mijn promotie kan ik uitkijken naar de komst van mijn eerste kind. Gezien al deze ervaringen kan ik eigenlijk niets anders dan terugkijken op een mooie en enerverende periode, waarbij ik veel mensen om me heen heb gehad, die ik ieder op eigen wijze wil bedanken.

Uiteraard wil ik mijn dank uiten naar Job Metsemakers, George Beusmans, Caroline van Heugten en Martien Limburg, de vier personen die mij tijdens mijn promotie intensief begeleid hebben. Job: bedankt voor je betrokkenheid als projectleider in het proces en met name ook in de laatste periode naar de promotie toe. Ik heb ook je kritische blik gewaardeerd op de artikelen, waardoor de kwaliteit zeker verbeterd is. George: dit alles begon met een sollicitatiegesprek. Bedankt voor de wekelijkse en intensieve begeleiding tijdens mijn promotie. Ook fijn dat je meegekeken en ondersteund hebt bij de uitgave van de SIGEB. Ik ben blij dat je me deze kans gegeven hebt. Caroline: bedankt voor je adviezen en fijne begeleiding. Je was altijd een van de eerste die feedback gaf. Je hebt je strepen ook verdiend als professor en ik weet dat je je mannetje wel staat. Martien: bedankt voor de begeleiding en deelname aan het project, ook nog vanuit Amsterdam. Via skype was je nu en dan aanwezig voor overleg vanuit je woonkamer, waarbij we af en toe gestoord werden 
door de koekoeksklok. De complimenten die je tussendoor gaf hebben me goed gedaan.

Liesbeth van Hoef, mijn onderzoeksassistent en paranimf. Toen ik als onervaren meid begon heb je me opgevangen op de afdeling en wegwijs gemaakt. Je werkervaring heeft me enorm geholpen en ik heb er veel van geleerd. Het onderzoek was een grote klus, maar zonder jou was het me allemaal niet gelukt. Nu ook als paranimf help je me tot het laatste eind. Dank je wel voor alles.

De co-auteurs wil ik ook bedanken voor de fijne samenwerking. Tom Vluggen bedankt! Het schrijven van een review is een hele klus, maar samen hebben we toch iets goeds neergezet. Deze samenwerking heeft ook een leuk vriendschap opgeleverd en ik hoop dat deze ook blijft bestaan. Jolanda van Haastregt, je expertise op het gebied van proces evaluaties heb ik als een mooie aanwinst beschouwd voor mijn artikel, bedankt. Jeanine Verbunt, bedankt voor je kritische blik op het review artikel. Ook Arnold Kester wil ik bedanken voor zijn statistische kennis en adviezen bij het uitvoeren van de analyses.

Dank gaat ook uit naar Susanne Mengde, de onderzoeksassistent in Eindhoven, voor het uitvoeren van alle interviews bij de controle groep. Het was een fijne samenwerking. Tonnie van der Laar is ook een persoon om niet te vergeten en mijn belangrijke aanspreekpunt voor de keten in Eindhoven. Wanneer ik je belde ging je meteen aan de slag voor me en regelde alles. Geweldig, bedankt! Joke Driessen, bedankt voor het aanleveren van de gegevens van de thuiszorg organisatie Zuidzorg. Ik wil ook diverse student assistenten en collega's bedanken voor hun hulp bij het invoeren van de onderzoeksgegevens en/of het afnemen van telefonisch interviews. Bedankt Anouk Schrantee, Roel Haeren, Anita Kaemingk, Ron Munsters, Monique Bessems en Carla Stessen. 
Heel veel dank gaat ook uit aan de dames van de thuiszorg, Rita Fleur, Marlou Kallen, Ali Offringa en Christel Stevens. Zonder jullie inzet en enthousiasme was het allemaal nooit gelukt. Jullie zijn geweldig en een aanwinst voor de patiënt en de zorg.

Alle deelnemers aan het onderzoek ben ik ook dankbaar, want zonder hen had ik het onderzoek niet uit kunnen voeren.

Ik wil ook al mijn (oud)collega's van de afdeling onderzoek bedanken voor de gezelligheid. Joyce Janssen bedankt. Altijd gezellig om bij je langs te komen, zowel op het werk als na het werk. Suus Benjaminsen, de werkzaamheden en taken voor het Kennisnetwerk CVA NL heb ik altijd met veel plezier gedaan. Bedankt, het is een leuke club om mee te werken. Ron Heijnen, we hebben veel samengewerkt als collega-onderzoekers, maar ook als je onderzoeksassistent. Bedankt voor de fijne samenwerking en succes met de afronding van je promotie. De directeur van de afdeling Hans Fiolet wil ik ook bedanken voor het faciliteren van het onderzoek.

De leden van de beoordelingscommissie en corona worden bedankt voor hun belangstelling en het beoordelen van mijn proefschrift en/of promotie.

Wie ik zeer zeker niet mag en kan vergeten zijn de mensen die altijd al achter me hebben gestaan. Bedankt lieve pap en lieve mam, wat moet ik toch zonder jullie. Jullie zijn altijd een grote steun voor me geweest. Met jullie luisterend oor, opbeurende adviezen en knuffels ben ik tot het einde doorgegaan. Mam, ik vind het ook erg bijzonder dat je mijn paranimf wilde zijn en dat je daarmee tot het allerlaatste naast me staat.

Tineke, Karin en Dominique, jullie zijn niet alleen mijn zussen, maar ook hartsvriendinnen. Niek, jou wil ik in het bijzonder nog bedanken. Je hebt me echt enorm geholpen met de invoer van de SIGEB gegevens... zonder dat je er iets voor terug verwachtte. Bedankt lieve meiden voor jullie liefde en steun. 
Lieve schoonvader, schoonbroers en schoonzus! Altijd geïnteresseerd in mijn werk en in mij. Bedankt.

Als laatste wil ik Robert bedanken, de liefde van mijn leven. Je geeft me zoveel liefde, steun en geduld. Ook heb je nooit gezeurd in al die tijd dat ik 's avonds en in de weekenden heb gewerkt (dat was niet altijd leuk voor jou). Je hebt me altijd de ruimte gegeven om mijn werk te kunnen afronden en ik ben trots dat je hier naast me staat. Nu kunnen we deze periode samen afronden en wachten op de geboorte van onze kleine meid. Er is niets dat mij gelukkiger maakt en ik zal altijd van je houden. 


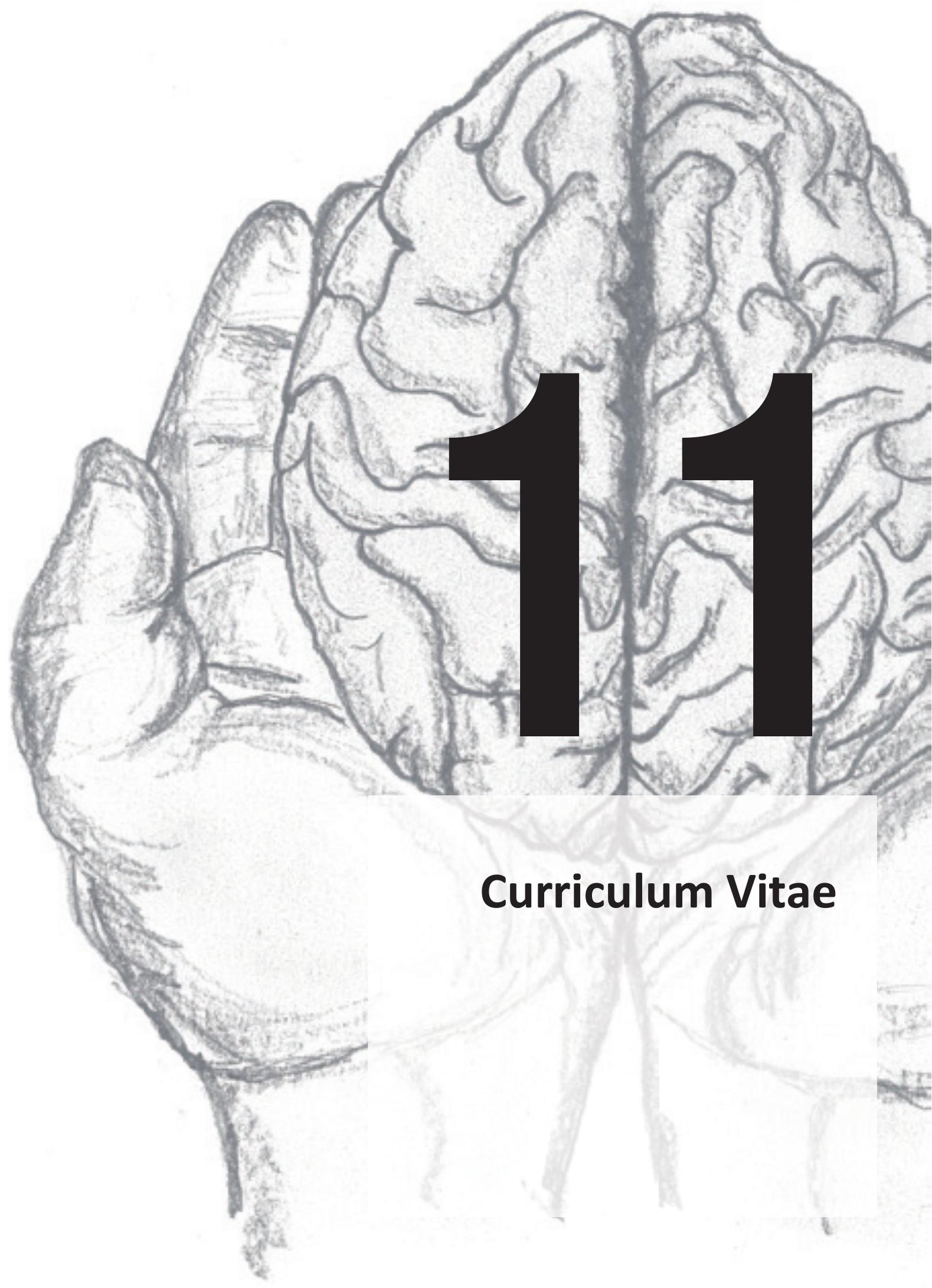


166 | Curriculum Vitae 


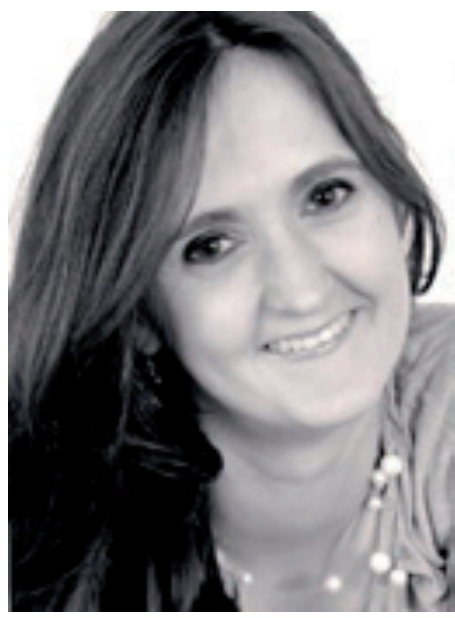

Manon Quint-Fens was born on October 23 ${ }^{\text {rd }}, 1983$ in Heerlen, the Netherlands. In 2002 she finished secondary school (VWO) at Sintermeerten College in Heerlen. Subsequently she studied Psychology at the Maastricht University and successfully gained her bachelor degree in 2005 and her master degree in Neuropsychology one year later.

She worked at the Maastricht University where she tutored in the practicum of the course Psychopathology by the end of 2006, as well during the academic years of 2007-2008 and 2008-2009. In January 2007, Manon was appointed as parttime PhD-student to the department of Integrated Care of the Maastricht University Medical Center. Later that year she joined the work group Benchmark of the Kennisnetwerk CVA NL and was involved in the benchmarking of stroke services in the Netherlands. During her PhD, she participated in courses for English writing skills in science, presenting skills in English and in several statistical courses. Manon gained her certificate Good Clinical Practice in 2010.

She started to work part-time as a research assistant in May 2008 at the department of Integrated Care and organized the inclusion of patients, performed the interviews and executed the data entry.

By the end of 2008 Manon left the work group benchmark to join the work group Care in the Chronic Phase of the Kennisnetwerk CVA NL. She was primarily involved in conducting a national survey about the organization of the care in the chronic phase for stroke patients. These data were analyzed and converted to recommendations for the organization of care in the chronic phase, which was published in 2011.

During the first months of 2012 she was involved in the development of the screening tool 'Beslishulp Beroerte Thuis', initiated by rehabilitation center De Hoogstraat in Utrecht. Later that year Manon worked as research assistant at Vivre to perform the data entry. Furthermore, the Kennisnetwerk CVA NL had asked her assistance to complete the annual report of the benchmark data.

At the start of 2014, the Maastricht University Medical Center reinstalled her as a researcher to perform the analysis of the project CVA APK, a research project initiated by the stroke service Zuid-Kennemerland, the Netherlands. 
168 | Curriculum Vitae 


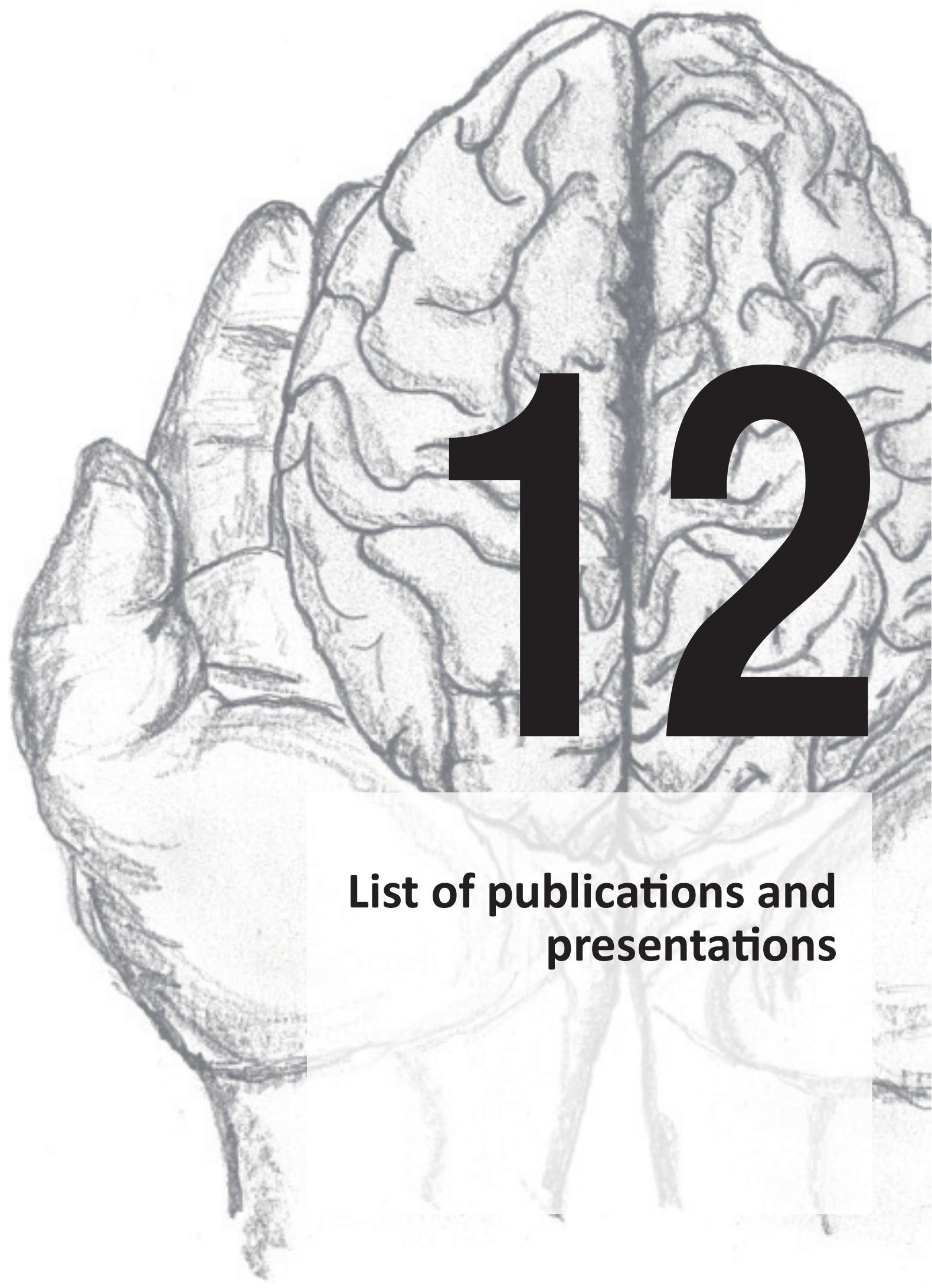


170 | List of publications and presentations 


\section{International publications}

Fens $M$, van Heugten CM, Beusmans GHMI, Limburg $M$, Haeren R, Kaemingk A \& Metsemakers JFM. Not as transient: patients with transient ischaemic attack or minor stroke experience cognitive and communication problems; an exploratory study. European Journal of General Practice, 2013. Vol 19(1), p11-16.

Fens, M., Vluggen, T., van Haastregt, J.C., Verbunt, J.A., Beusmans, G.H. \& van Heugten, C.M. Multidisciplinary care for stroke patients living in the community; a systematic review. Journal of Rehabilitation Medicine, 2013. Vol 45(4), p321-330.

Fens M, Van Heugten C, Beusmans G, Metsemakers JF, Kester A \& Limburg M. The effect of a stroke-specific follow-up care model on the quality of life of stroke patients and caregivers; a controlled trial. Journal of Rehabilitation Medicine, 2014. Vol 46(1), p7-15. doi: 10.2340/16501977-1239.

Fens $M$, Beusmans $G$, Limburg $M$, Metsemakers J, van Hoef L \& van Heuten C. Development of the Assessment tool for long-term Consequences After Stroke (ACAS) to detect long-term stroke-related problems: a developmental and feasibility study. Submitted.

Fens M, Beusmans G, Limburg M, van Hoef L, van Haastregt J, Metsemakers J \& van Heugten C. A process evaluation of a stroke-specific follow-up care model for stroke patients and caregivers; a longitudinal study. Submitted.

\section{National publications}

Manon Fens. Nieuw instrument voor probleemsignalering na een CVA. Cordiaal, 2011, 5e editie, p.154-156.

Werkgroep Zorg in de Chronische Fase. Uitbehandeld, hoezo? Een leidraad in het doolhof aan van zorg in de chronische fase na een CVA. Maastricht, Kennisnetwerk CVA NL; 2011.

Manon Fens, George Beusmans, Caroline van Heugten, Job Metsemakers, Martien Limburg \& Liesbeth van Hoef, 2013 (uitgave Kennisnetwerk CVA NL). SIGEB, Signaleringsinstrument voor de lange termijn Gevolgen van een Beroerte. Universitaire Pers Maastricht, Maastricht.

Tom Vluggen, Manon Fens, Jolanda van Haastregt, Jeanine Verbunt, George Beusmans \& Caroline van Heugten. De effecten van multidisciplinaire nazorg voor thuiswonende CVA-patienten; een systematische review. Fysiotherapie \& Ouderenzorg, 2013, 37(3), p17-31. 


\section{International presentations}

Manon Fens, Caroline van Heugten, George Beusmans, Martien Limburg, Job Metsemakers. Do TIA or minor stroke patients experience problems after being discharged from the ER or TIA outpatient clinic? Poster presentation. European Stroke Conference '09, Stockholm SW, 26 May 2009.

Manon Fens, Caroline van Heugten, George Beusmans, Martien Limburg, Job Metsemakers. An assessment tool for detecting stroke-related problems. Poster presentation. European Stroke Conference '10, Barcelona ES, 25 May 2010.

M. Limburg, M. Fens, T. vd Laar, G. Beusmans, J. Courlander, M. Edelbroek, E. v Gorp, I. Middelkoop, D. Raymakers, R. Wimmers. National Stroke registry in The Netherlands. Set-up and first results. Poster presentation. European Stroke Conference '11, Hamburg DE, 25 May 2011.

\section{National presentations}

Joke de Meris, Elly van Gorp, Riet van Rooijen, Jos van Erp, Manon Fens, Tineke Krikke, Joze van Hoppe, Joke Driessen, Silvie Bollars, Marijn Luijpen en Thessa Veenis. Hoe ziet uw zorg in de chronische fase eruit? Poster presentatie. Symposium CVA Kennisnetwerk, Nijmegen NL, 26 november 2010.

Manon Fens. Een nieuwe kijk op 'nazorg' van mensen met NAH. Orale presentatie (uitgenodigd). Congres 'Venijn zit in de staart III', Ede NL, 31 maart 2011.

Manon Fens, Tom Vluggen, Jolanda van Haastregt, Jeanine Verbunt, George Beusmans \& Caroline van Heugten. Multidisciplinary care for stroke patients living in the community; a systematic review. Poster presentatie. CAPHRI Research Meeting, Maastricht NL, 19 mei 2011.

Manon Fens. SIGEB: gestructureerde assessment voor zorg op lange termijn. Orale presentatie (uitgenodigd). Symposium 'Proeftuin en Kruisbestuiving', Huizen NL, 25 mei 2011.

Manon Fens. Een signaleringsinstrument voor de gevolgen na een beroerte: een evaluatie. Orale presentatie. NHG Wetenschapsdag 2011, Nijmegen NL, 23 juni 2011. Manon Fens. Screening in de thuissituatie, ACAS. Orale presentatie (uitgenodigd). Symposium CVA Kennisnetwerk, Nijmegen NL, 11 november 2011.

Jos van Erp, Manon Fens (design), Elly van Gorp, Joze van Hoppe Tineke Krikke, Joke de Meris, Beat Notz, Silvie Bollars, Riet van Rooijen, Antoinette van de Ven, Tom Vluggen. Aanbevelingen zorg in de chronische fase. Poster presentatie. Symposium CVA Kennisnetwerk, Nijmegen NL, 11 november 2011. 
Manon Fens. Structureel screenen van CVA-problemen op de lange termijn; wat levert het op? Orale presentatie (uitgenodigd). Symposium Hersenletsel 2012, Ede NL, 12 november 2012.

Manon Fens. SIGEB, signaleringsinstrument voor de lange termijn gevolgen na een beroerte. Orale presentatie (uitgenodigd). Symposium CVA NL Kennisnetwerk, Zeist NL, 22 november 2013. 
